\title{
SIMULAÇÃO DE ESCOAMENTO E DE PRODUÇÃO DE SEDIMENTOS EM UMA MICROBACIA HIDROGRÁFICA UTILIZANDO TÉCNICAS DE MODELAGEM E GEOPROCESSAMENTO
}

\author{
RONALTON EVANDRO MACHADO
}

Tese apresentada à Escola Superior de Agricultura "Luiz de Queiroz", Universidade de São Paulo, para obtenção do título de Doutor em Agronomia, Área de Concentração: Irrigação e Drenagem.

PIRACICABA

Estado de São Paulo - Brasil

Janeiro - 2002 


\section{SIMULAÇÃO DE ESCOAMENTO E DE PRODUÇÃO DE SEDIMENTOS EM UMA MICROBACIA HIDROGRÁFICA UTILIZANDO TÉCNICAS DE MODELAGEM E GEOPROCESSAMENTO}

\section{RONALTON EVANDRO MACHADO}

Engenheiro Agrícola

Orientador: Prof. Dr. CARLOS ALBERTO VETTORAZZI

Tese apresentada à Escola Superior de Agricultura "Luiz de Queiroz", Universidade de São Paulo, para obtenção do título de Doutor em Agronomia, Área de Concentração: Irrigação e Drenagem.

PIRACICABA

Estado de São Paulo - Brasil

Janeiro - 2002 
Dados Internacionais de Catalogação na Publicação (CIP) DIVISÃO DE BIBLIOTECA E DOCUMENTAÇÃO - ESALQ/USP

Machado, Rona Iton Eva ndro

Simulação de escoamento e de produção de sedimentos em uma mic roba cia hidrográfic a utilizand o téc nic as de modelagem e geoprocessamento / Ronalton Evandro. - - Piracicaba, 2002.

154 p. : il.

Tese (doutorado) - - Escola Superior de Agricultura Luiz de Queiroz, 2002.

Bibliografia.

1. Erosão 2. Geoprocessamento 3. Microbacia hidrográfic a 4. Poluição difusa 5. Sedimentação 6. SIG (Sistema de computa dor) I. Título

CDD 631.45

\section{"Permitida a cópia total ou parcial deste documento, desde que citada a fonte - $\mathrm{O}$ autor"}


"Magoados, ao crepúsculo dormente,

Ora em rebojos galopantes, ora

Em desmaios de pena e de demora,

Rios, chorais amarguradamente.

Desejais regressar... Mas, leito em fora,

Correis... E misturais pela corrente

Um desejo e uma angústia, entre o nascente

De onde vindes, e a foz que vos devora.

Sofreis da pressa, e, a um tempo, da lembrança...

Pois no vosso clamor, que a sombra invade,

No vosso pranto, que no mar se lança,

Rio tristes! Agita-se a ansiedade

De todos os que vivem de esperança,

De todos os que morrem de saudade..."

Olavo Bilac - "Os Rios"

À memória do meu pai, meu grande incentivador, 
OFEREÇO

à minha filha Giovanna e minha esposa Laura, à minha mãe e irmãos,

DEDIC $\mathrm{O}$ 


\section{AGRADECIMENTOS}

À Escola Superior de Agricultura "Luiz de Queiroz", da Universidade de São Paulo, pela oportunidade de realização do curso.

À Coordenadoria de Aperfeiçoamento de Pessoal de Ensino Superior - CAPES pela concessão da bolsa de estudo.

Ao Prof. Dr. Carlos Alberto Vettorazzi, pela orientação, amizade e a confiança em mim depositada para a realização deste trabalho.

Ao DAEE/SP e ao CTH/USP, nas pessoas do Dr. Luiz Roberto Moretti e do Eng $^{\circ}$ Gré de Araújo Lobo pela cessão dos dados hidrossedimentométricos referentes à microbacia do Ribeirão dos Marins;

Ao Eng. Agrônomo Matheus de Oliveira Chaves e ao Instituto Agronômico de Campinas (IAC), pela cessão de parte dos dados climáticos da região de Piracicaba/SP.

À Dr $^{\text {a. }}$ Nancy Sammons e à toda equipe do SWAT, pela cooperação na soluções das dúvidas e bugs" na execução do SWAT, comuns a qualquer modelo computacional. 
Aos colegas Francisco Parise, Eder Pozzebon e Alexandre Xavier pela cooperação em algumas fases desse trabalho e pelo aprendizado em conjunto. Aos demais colegas da pós-graduação em Irrigação e Drenagem pelo agradável convívio durante o curso.

Aos funcionários do Departamento de Engenharia Rural e a todos aquele que, direta ou indiretamente contribuíram para a realização desse trabalho. 


\section{SUMÁRIO}

Página

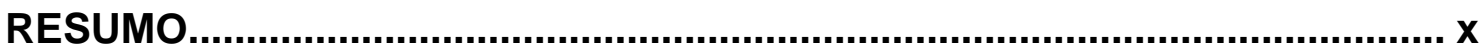

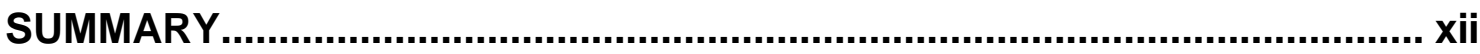

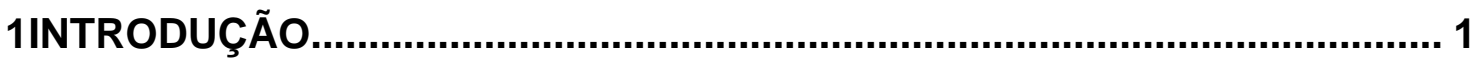

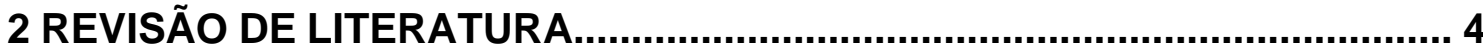

2.1 Microbacia hidrográfica como unidade de estudo................................... 4

2.2 Modelos hidrológicos e de qualidade de água ......................................... 6

2.3 Sistemas de Informações Geográficas (SIG's) e modelagem hidrológica e de qualidade de água.......................................... 14

2.4 Método da Curva Número (CN)........................................................... 21

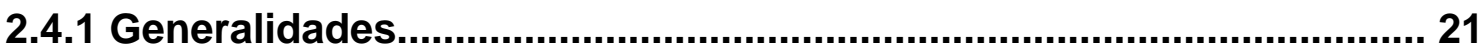

2.4.2 Determinação da Curva Número a partir de tabelas.......................... 27

2.4.3 Avaliação do Método da Curva Número............................................... 34

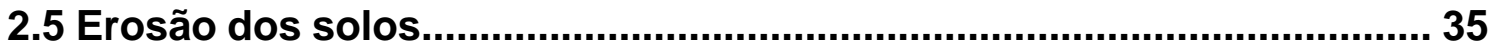

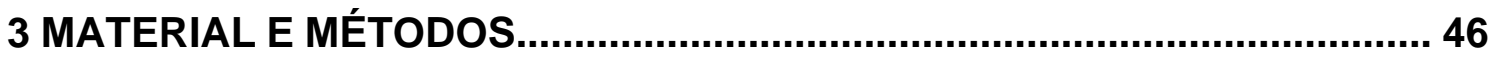

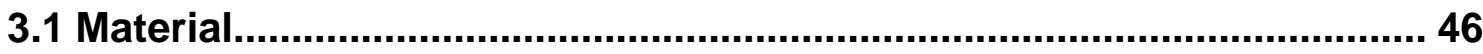

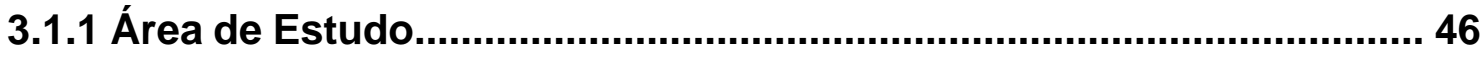

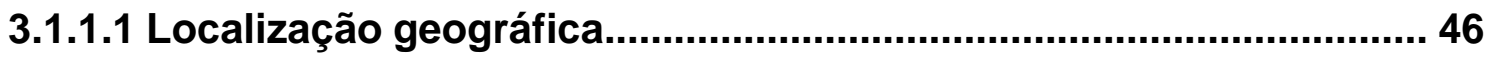

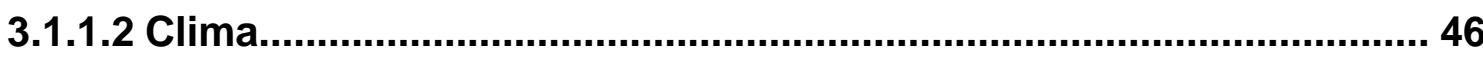

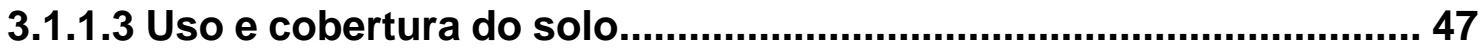

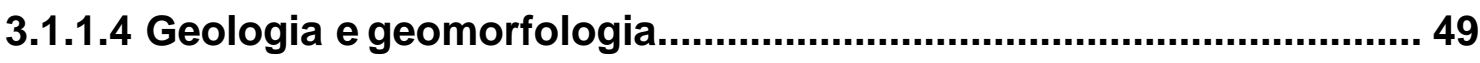

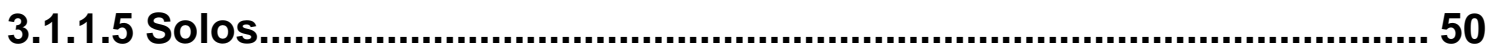

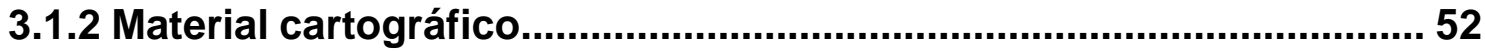




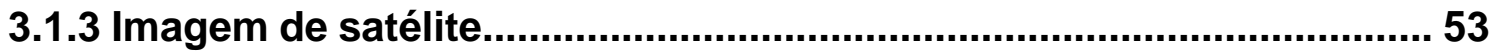

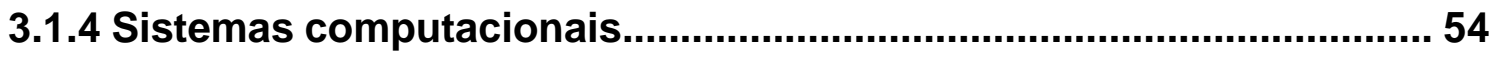

3.1. 5 Descrição do modelo SWAT ............................................................... 54

3.1.5.1 Componentes do modelo SWAT...................................................... 57

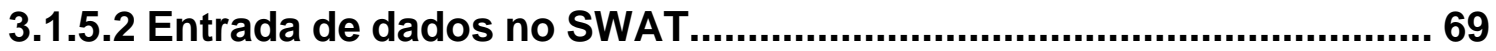

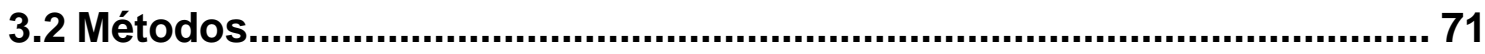

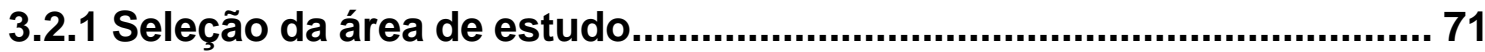

3.2.2. Geração dos Planos de Informação (Pl's) ......................................... 71

3.2.2.1 Geração do Modelo Numérico do Terreno (MNT) ............................ 71

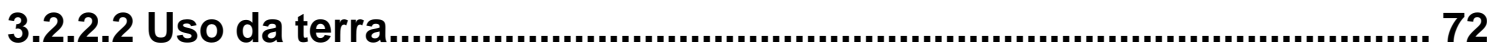

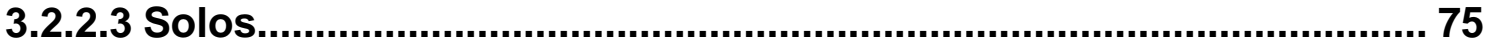

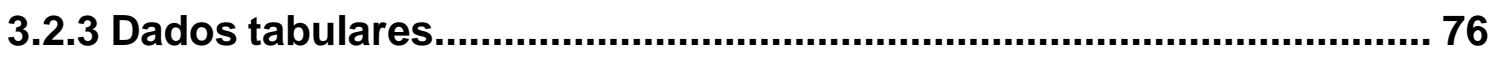

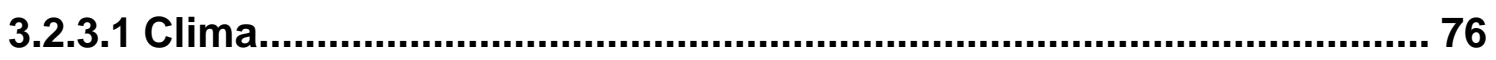

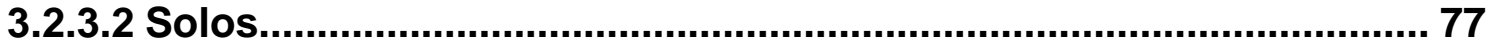

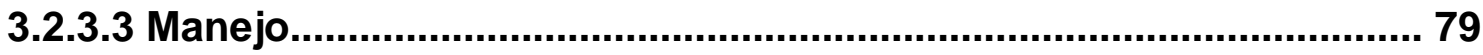

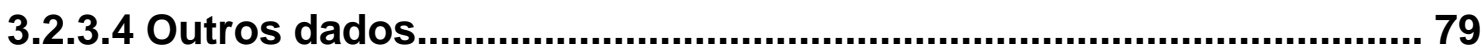

3.2.4 Definição do número de sub-bacias................................................. 80

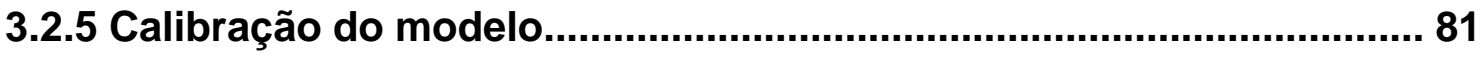

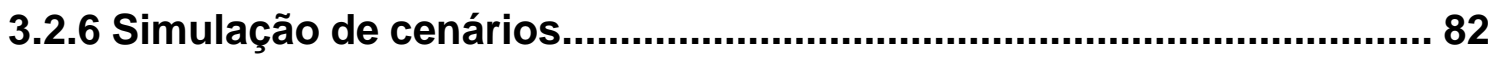

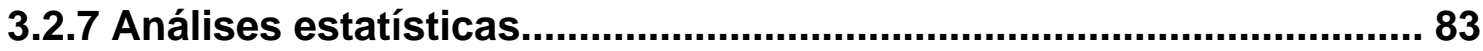

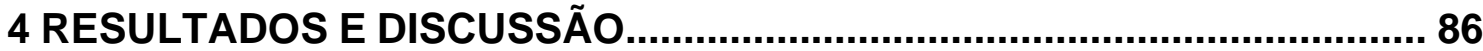

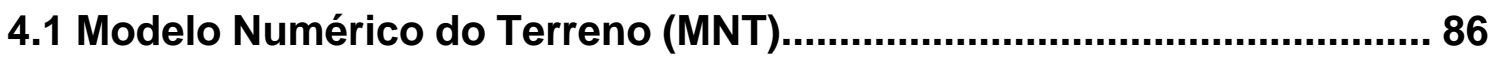

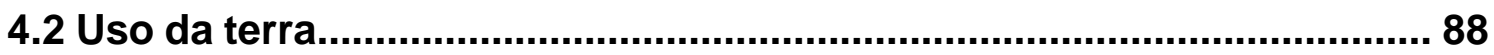

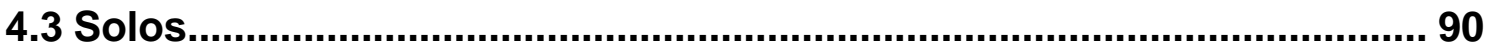

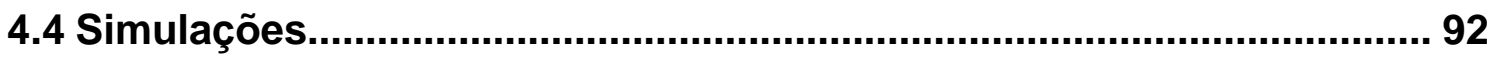

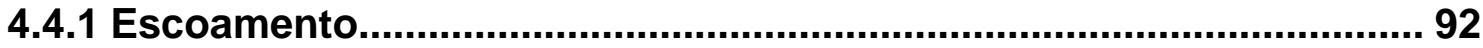

4.4.2 Produção de sedimentos................................................................... 100

4.4.3. Distribuição espacial da produção de sedimentos.......................... 107

4.4 Calibração do modelo ......................................................................... 112

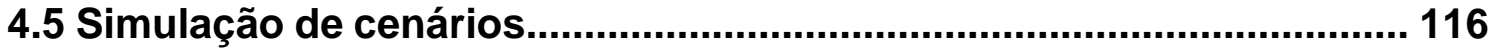




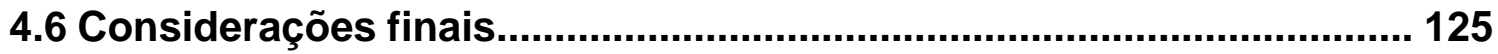

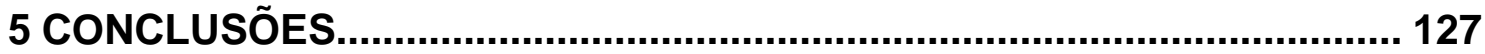

REFERÊNCIAS BIBLIOGRÁFICAS........................................................ 128 


\title{
SIMULAÇÃO DE ESCOAMENTO E DE PRODUÇÃO DE SEDIMENTOS EM UMA MICROBACIA HIDROGRÁFICA UTILIZANDO TÉCNICAS DE MODELAGEM E GEOPROCESSAMENTO
}

\author{
Autor: RONALTON EVANDRO MACHADO \\ Orientador: Prof. Dr. CARLOS ALBERTO VETTORAZZI
}

\section{RESUMO}

Modelos hidrológicos e de qualidade de água vêm sendo desenvolvidos para avaliar a poluição causada por fontes de origem difusa, em bacias hidrográficas agrícolas. Com esse objetivo, o modelo SWAT Soil and Water Assessment Tool) foi aplicado para simular o escoamento e a produção de sedimentos produzidos pela microbacia hidrográfica do Ribeirão dos Marins, afluente do rio Piracicaba, SP, no biênio 1999/2000. A aplicação do modelo requer a entrada dos dados na forma espacializada. A manipulação desses dados foi feita com o auxílio de um Sistema de Informações Geográficas (SIG) e uma interface entre o modelo e o SIG que, automaticamente, subdivide a bacia em sub-bacias a partir do Modelo Numérico do Terreno (MNT) e, então, extrai os dados de entrada relacionados para cada sub-bacia dos outros Planos de Informação (Pl's), uso da terra e solos, associados a um extenso banco de dados. Posteriormente, os resultados finais da simulação são apresentados no formato de mapas, gráficos e tabelas. Os resultados obtidos da simulação, médias mensais do escoamento e a produção de sedimentos, foram 
comparados aos dados observados em um posto hidrossedimentométrico localizado no terço superior da microbacia, utilizando o Coeficiente de Eficiência de Nash e Sutcliffe (COE) e o desvio dos dados simulados em relação aos observados $\left(D_{v}\right)$. Foi feita uma calibração de alguns parâmetros físico-hídricos do solo e físico das sub-bacias, para as duas variáveis simuladas. Dois cenários alternativos de uso da terra foram simulados. No primeiro, o uso atual foi mantido, mas considerou-se uma faixa de mata ciliar de $30 \mathrm{~m}$ em toda a extensão dos cursos d'água e de $50 \mathrm{~m}$ ao redor das nascentes, de acordo com o Código Florestal. No segundo cenário, como as pastagens ocupam as encostas mais íngremes, com alto potencial erosivo, as áreas ocupadas por pastagem foram substituídas por vegetação florestal. As simulações dos dois cenários foram comparadas com as condições do cenário atual em termos de redução da produção de sedimentos. Os resultados obtidos para o escoamento simulado foram de 0,92 e $-0,7 \%$ para o COE e o $D_{v}$, respectivamente, após a calibração. Na simulação da produção de sedimentos pelo modelo, após a calibração, o COE obtido foi de 0,83 e o $D_{v}$ de $-3,2 \%$. Os cenários produziram diferentes padrões espaciais da produção de sedimentos. Uma redução de $84,4 \%$ na produção de sedimentos foi obtida com a substituição da pastagem por vegetação nativa (cenário 2). No cenário 1, a redução foi de $10,8 \%$. Esses resultados evidenciam a necessidade de se tratar a paisagem em bacias hidrográficas de uma forma global, identificando as "áreas ambientalmente sensíveis", onde são necessárias práticas de controle dos processos erosivos e não somente com a proteção dispensada aos cursos d'água por meio da mata ciliar.

Palavras-chave: erosão, modelos hidrológicos, poluição difusa, runoff, SIG, SWAT 


\title{
STREAMFLOW AND SEDIMENT YIELD SIMULATION WITHIN A SMALL WATERSHED THROUGH GEOPROCESSING AND MODELING TECHNIQUES
}

\author{
Author: RONALTON EVANDRO MACHADO \\ Adviser: Prof. Dr. CARLOS ALBERTO VETTORAZZI
}

\section{SUMMARY}

Hydrological and water quality models have been developed to evaluate the nonpoint source pollution in agricultural watershed. With this objective, SWAT (Soil and Water Assessment Tool) model was applied to simulate the streamflow and sediment yield in Ribeirão dos Marins watershed, on the Piracicaba river basin, Brazil, for the period 1999/2000. The application of the model requires the input data in spatial format. The manipulation of these data was made with an interface between the model and the Geographic Information System (GIS) that, automatically, subdivides the basin in subbasins, from the Digital Terrain Model (DTM) and extracts the input data for each subbasin from the land use and soil layers. Later, the results of the simulation are presented in the format of maps, graphs and tables. The results of the simulation, monthly averages of the streamflow and the sediment yield, were compared to the observed data in a gauge station located in Ribeirão dos Marins watershed, using the Nash Sutcliffe Coefficient (COE) and the deviation of the simulated data in relation to the observed data (Dv). A calibration of some 
physical-hydrological parameters of soil and physical of the subbasins was made for the two variables simulated. Two alternative scenarios of land use have been simulated. In the first, the current land use was kept, with a riparian buffer of $30 \mathrm{~m}$ along of the drainage network and of $50 \mathrm{~m}$ around the springs, in accordance with the Forest Code. In the second scenario, as the pastures occupy the steepest hillsides, with high erosive potential, pastures were changed by native forest. The simulations of the two scenarios were compared to the current scenario, regarding the reduction of sediment yield. The results of the simulated streamflow were of 0,92 and $-0,7 \%$ for the COE and the Dv, respectively, after the calibration. In the simulation of the sediment yield, after the calibration, the COE was 0,83 and Dv was $-3,2 \%$. The scenarios produced different spatial patterns of the sediment yield. The reduction in sediment yield of $84,4 \%$ was obtained with the substitution of the pasture by native vegetation (scenario 2). In scenario 1, the reduction was of $10,8 \%$. These results show that is necessity to manage watershed considering the whole landscape aspects, identifying environmentally sensitive areas, mainly in relation to erosion, instead of protecting only riparian areas.

Key words: erosion, hydrological models, non point source pollution, runoff, GIS, SWAT 


\section{INTRODUÇÃO}

O uso inadequado dos solos agrícolas vem causando a perda gradual da sua capacidade produtiva e a contaminação dos recursos hídricos por sedimentos e poluentes de origem difusa.

A erosão dos solos constitui-se em um grande problema no Brasil, onde são perdidas, a cada ano, em torno de 600 milhões de toneladas de solo agrícola (Bahia et al., 1992). Para o melhor controle da erosão hídrica, deve ser estabelecido um plano de uso, manejo e conservação em nível de bacia hidrográfica, em que os diversos fatores que interferem na erosão sejam considerados.

Apesar dos esforços que podem ser feitos para mitigar os impactos adversos da agricultura, uma investigação no sistema real, envolvendo medições de todas as variáveis que influenciam um processo em uma escala mais ampla é, na maioria das vezes, impossível de ser conduzida, devido ao longo prazo em projetos pilotos e altos custos em medições e monitoramento (Pessoa, 1997). Por esse motivo, para identificar áreas com problemas de poluição difusa em bacias hidrográficas, modelos estão sendo cada vez mais freqüentemente utilizados.

Modelos hidrológicos e de qualidade da água vêm sendo desenvolvidos para predizer o impacto da agricultura na qualidade das águas superficiais e subterrâneas.

A maior limitação ao uso desses modelos é a dificuldade em trabalhar uma grande quantidade de dados que descrevem a heterogeneidade dos sistemas naturais. Pesquisadores têm reconhecido que a variabilidade espaço- 
temporal nas características da paisagem, incluindo solo, uso da terra, relevo e clima, afeta a resposta hidrológica do sistema físico, implicando em limitações na aplicação de modelos. A complexidade extrema da manipulação de grandes volumes de dados de natureza espacial e não espacial, por exemplo, limita e muito o uso dos modelos de parâmetros distribuídos.

Por essas razões, Sistemas de Informações Geográficas (SIG's) são empregados na criação do banco de dados para esses modelos. Os SIG's são destinados à aquisição e ao tratamento de dados georreferenciados (referenciados espacialmente), permitindo a manipulação de dados de diversas fontes, recuperando e combinando informações e efetuando vários tipos de análises (Alves, 1990).

No SIG, as sucessivas análises dos dados espaciais podem dividir grandes áreas heterogêneas em pequenas unidades hidrologicamente homogêneas, sobre as quais os modelos são aplicados (Tim,1994). Modelos têm sido interfaciados a SIG's desde a metade dos anos de 1980, mas a partir do inicio da década de 1990, muitos modelos de simulação de sedimentos e de poluição não pontual têm sido aplicados em combinação com SIG, permitindo a análise espacial e temporal e determinar a capacidade desses novos sistemas computacionais em melhorar e prover informações sobre erosão e poluição. A modelagem hidrológica e de qualidade da água e SIG's têm evoluído para um ponto em que as vantagens de cada sistema podem ser totalmente integradas dentro de uma poderosa ferramenta para análise em bacias hidrográficas.

Nos Estados Unidos e na Europa tem crescido o interesse na modelagem do movimento de poluentes de origem não pontual integrada a SIG's. No Brasil, essa poderosa combinação ainda é relativamente pouco conhecida. Nesse contexto, este trabalho apresenta-se com os seguintes objetivos: (i) avaliar espacialmente a produção de sedimentos na microbacia hidrográfica do Ribeirão dos Marins (Piracicaba, SP), por meio da integração SWAT-ArcView; (ii) analisar comparativamente os resultados gerados pelo modelo quanto à produção de sedimentos e ao escoamento, com os dados 
obtidos em campo; (iii) simular cenários alternativos de uso e ocupação da terra na microbacia hidrográfica em estudo e analisá-los quanto à produção de sedimentos. 


\section{REVISÃO DE LITERATURA}

\subsection{Microbacia hidrográfica como unidade de estudo}

A bacia hidrográfica pode ser definida como unidade física, caracterizada como uma área de terra drenada por um determinado curso d'água e limitada, perifericamente, pelo chamado divisor de águas. Segundo Moldan \& Cerny (1994), a microbacia, do ponto de vista hidrológico, pode ser considerada como a menor unidade da paisagem capaz de integrar todos os componentes relacionados com a qualidade e disponibilidade de água como: atmosfera, vegetação natural, plantas cultivadas, solos, rochas subjacentes, corpos d'água e paisagem circundante. Ambientalmente, pode-se dizer que a bacia hidrográfica é a unidade ecossistêmica e morfológica que melhor reflete os impactos das interferências antrópicas, tais como a ocupação das terras com as atividades agrícolas (Jenkins et al., 1994).

A microbacia hidrográfica deve ser utilizada como unidade básica para o planejamento conservacionista, entretanto os trabalhos de manejo e conservação do solo vêm sendo em grande parte, ainda hoje, realizados de maneira isolada, em nível de propriedade. O planejamento conservacionista, levando em conta as características da microbacia hidrográfica, visa a um controle integrado da erosão do solo em toda a área que converge para uma mesma seção de deságüe (Calijuri et al., 1998).

Em alguns programas, a escala de microbacia hidrográfica vem sendo adotada como preferencial para o planejamento conservacionista e para a efetiva execução de programas de controle de erosão e conservação de 
recursos hídricos. Exemplos desta consagração são os Programas de Microbacias Hidrográficas (Bertolini et al., 1993). Esses programas, principalmente aqueles implantados na região sul do Brasil, vêm servindo de referência e de exemplo internacional de sucesso de agricultura conservacionista (Busscher et al., 1996). Em regiões úmidas, principalmente se o enfoque está relacionado a projetos conservacionistas, a delimitação da microbacia hidrográfica engloba a área de drenagem dos primeiros canais fluviais de fluxo permanente, geralmente coincidindo com os afluentes de um rio principal em nível regional. No entanto, o conceito de bacia de drenagem como um sistema hidrogeomorfológico é mais amplo e define a bacia de drenagem como uma área da superfície terrestre que drena água, sedimentos e materiais dissolvidos para uma saída comum, num determinado ponto de um canal fluvial. Definida desta forma, a bacia de drenagem comporta diferentes escalas, desde uma bacia do porte daquela drenada pelo rio Amazonas, até bacias com poucos metros quadrados que drenam para a cabeceira de um pequeno canal erosivo (Coelho Netto, 1994). Assim, a delimitação adotada nos Programas Conservacionistas é uma convenção consagrada pelo uso e não um conceito hidrogeomorfológico fechado.

Em trabalhos de pesquisa, observa-se maior flexibilidade nos critérios de delimitação das bacias de drenagem, muito mais vinculados aos objetivos do trabalho do que a definições e conceitos pré-estabelecidos. Exemplos são os trabalhos de Hamlett et al. (1992), que utilizaram Sistemas de Informações Geográficas para definir áreas potencialmente poluidoras, devido à atividade agrícola na Pensilvânia, E.U.A., considerando áreas de drenagem de milhares de hectares; ou o de Moldan \& Cerny (1994), que consideram que a microbacia hidrográfica, visando a estudos biogeoquímicos, não deve ultrapassar 500 ha.

O importante é que, o conceito adotado para a delimitação da bacia de drenagem deve garantir que a área escolhida seja integradora de todos os processos envolvidos no objetivo da análise e que apresente um certo grau de homogeneidade, de forma que estratégias, ações e conclusões gerais possam 
ser estabelecidas para toda a área delimitada. No caso de programas conservacionistas, o principal objetivo é o controle da erosão, que consiste no processo mais diretamente relacionado com a perda de potencial produtivo das terras agrícolas e com a degradação dos recursos hídricos (Lal, 1990).

As ações governamentais relacionadas ao manejo e conservação dos solos e recursos hídricos são elaboradas nesta escala. Segundo Bertolini et. al. (1993), em São Paulo, "através do Programa Estadual de Microbacias Hidrográficas, os Governos Estadual e Municipal e as associações de agricultores estão iniciando um trabalho visando a adequar o aumento da produção de alimentos para atender ao consumo interno e gerar excedentes para o mercado externo, melhorando o padrão de vida do agricultor e, ao mesmo tempo, utilizando de modo racional e integrado os recursos naturais do solo, da água, flora e fauna". Da mesma forma, em outros Estados, como o Paraná, há programas de Microbacias Hidrográficas com resultados muito positivos, principalmente na adequação do uso e manejo das terras de maneira a proporcionar um padrão agrícola economicamente viável e ambientalmente sustentável (Mariano, 1996). Ainda segundo o autor, a bacia hidrográfica é considerada como área de influência a partir da resolução no 001/86 do CONAMA (Conselho Nacional do Meio Ambiente), de 1981, passando a ser considerada como a área a ser analisada no estudo de impacto ambiental.

\subsection{Modelos hidrológicos e de qualidade de água}

Modelos podem ser definidos como "uma proposição simplificada da natureza com o propósito de conhecer um fenômeno" (Batchelor, 1994). Modelos também podem ser descritos como uma simplificação da realidade. Eles são uma ferramenta extraordinária para conhecer os processos ambientais (Tim, 1996).

Basicamente, a modelagem matemática consiste em representar matematicamente o que acontece na natureza a partir de um modelo 
conceitual, idealizado com base nos dados de observação do sistema real. O objetivo desta modelagem é, então, compreender melhor o sistema e prever situações futuras, algumas vezes também reproduzir o passado, para direcionar as ações de decisão. Hassuda (2000), cita os procedimentos para a construção do modelo matemático que represente um sistema real: desenvolvimento do modelo conceitual, que envolve todo o levantamento e interpretação de dados e observações do sistema real; seleção do programa computacional a ser utilizado segundo as necessidades e os dados existentes; tradução do modelo conceitual para a linguagem matemática, construindo-se os diversos bancos de dados para a entrada das informações no programa selecionado; e calibração do modelo matemático construído de forma a diminuir as incertezas inerentes a uma representação simplificada (modelo matemático) de um sistema real, em geral, complexo.

Modelos matemáticos integram o conhecimento existente dentro de princípios lógicos de procedimentos e de relações (Moore \& Gallant, 1991), e podem ser usados para estabelecer mais conhecimentos sobre os sistemas ambientais, tanto como um meio de testar hipóteses, como de permitir um método para predizer o manejo desses ecossistemas (Beven, 1989; Grayson et al., 1992).

Os tipos gerais de modelos aplicados ao manejo do ambiente requerem que esses modelos sejam classificados de acordo com o critério de uso. De acordo com Woolhiser \& Brakensiek (1972), modelos podem ser classificados como materiais ou conceituais (Figura 1). O modelo material representa um sistema físico que é assumido para ser significativamente mais simples do que o sistema idealizado e é também assumido para ter propriedades similares ao sistema idealizado. Modelos conceituais são representações matemáticas do sistema físico idealizado que têm a propriedade estrutural importante do sistema físico real. Esses modelos são baseados em tratamento teórico ou empírico dos processos e mecanismos que influenciam o sistema físico real. Enquanto modelos empíricos omitem as leis 
da Física que estão relacionadas nos processos do sistema e usam dados observados para formular as relações do sistema, modelos teóricos usam leis físicas para desenvolver um grupo de algoritmos para o sistema físico idealizado.

Chow (1988) divide os modelos teóricos em determinísticos e não determinísticos (Figura 1). Modelos não determinísticos são expressos em termos probabilísticos ou estocásticos e definem o sistema físico com resultado incerto e aleatório. Modelos estocásticos, entretanto, têm alguns componentes que são aleatórios com a probabilidade direta do domínio do espaço e tempo, e suas saídas podem ser expressas em termos de média e variação de probabilidade. Modelos determinísticos, de outra maneira, ignoram o impacto das perturbações atribuídas à aleatoriedade nos parâmetros do sistema e definem o sistema físico como ele ocorre em um dado grupo de eventos governados por um resultado identificável. Sob a filosofia da modelagem determinística, somente um grupo de saídas pode ser obtido em um grupo equivalente de entradas.

Modelos determinísticos podem ainda ser divididos em concentrados (lumped) ou distribuídos (distributed), dependendo do tratamento do espaço. Um modelo é dito concentrado quando seus parâmetros e variáveis apresentam variação com o tempo, sendo a variabilidade espacial representada por um valor médio, o que é uma simplificação muito grande da realidade. Os modelos distribuídos subdividem a bacia em elementos que são considerados homogêneos quanto æ̀s propriedades avaliadas, representando, além da variação temporal, a variabilidade espacial do sistema físico.

Segundo Tucci (1998), na prática não existem modelos puramente distribuídos, já que são utilizadas discretizações numéricas que, de alguma forma, tornam o modelo distribuído concentrado numa pequena subdivisão. $\mathrm{O}$ que não deixa de ser uma grande vantagem, já que os modelos distribuídos permitem analisar com melhor embasamento a modificação das características do sistema, o que é quase impossível através dos modelos concentrados, 
devido ao excesso de empirismo e da característica concentrada da sua formulação.

Existem críticas (Beven, 1985) quanto à utilização de modelos concentrados como forma de representação dos processos hidrológicos. Os modelos distribuídos são uma tentativa de melhor adequar os problemas de escala a modelagem hidrológica. Entretanto, os modelos ditos distribuídos requerem grande investimento sob 0 ponto de vista da informática $e$ programação, preparação de dados e experimentação de campo.

Beven (1985), identifica quatro grandes áreas que oferecem grande potencial para a aplicação dos modelos distribuídos: previsão dos efeitos de usos da terra; previsão de efeitos da localização espacial das variáveis de entrada e saída; previsão do movimento de poluentes e sedimentos; e previsão de resposta hidrológica não monitoradas, onde os dados estão disponíveis para os modelos concentrados.

Muitos modelos ambientais requerem parâmetros de entrada espacialmente distribuídos, porque soluções para a erosão acelerada do solo, para a poluição difusa e para outros problemas ambientais, envolvem variações no uso da terra e no seu manejo, para uma inclinação de superfície e uma escala de captação (Moore et al., 1993). A escassez de dados de entrada, para uma resolução espacial preferencial, e a dificuldade de manejar múltiplas entradas, que variam de diferentes formas na paisagem, têm emergido como os maiores obstáculos àaplicação com sucesso de modelos.

Ambos os modelos, concentrado e distribuído, podem ainda ser classificados como contínuos ou baseados em eventos isolados, dependendo da escala de tempo. Por exemplo, um modelo concentrado baseado em eventos isolados, simula a resposta do sistema físico para uma simples entrada (precipitação) e assume que ambos os parâmetros, de entrada e de saída, não variam no espaço e no tempo. Modelos distribuídos contínuos, por outro lado, simulam os processos seqüencialmente dentro do sistema físico, no intervalo 
de tempo que pode variar de frações de hora a um dia (ou mesmo maior) e fornece séries temporais de saída do modelo (Tim, 1996).

Há uma diferença significativa entre os modelos distribuídos com base em eventos e contínuos, nos métodos de extração das entradas e métodos de análise e exibição dos resultados, devido ao componente tempo envolvido na modelagem em tempo contínuo (Srinivasan \& Arnold, 1994). Modelos de parâmetros distribuídos de tempo contínuo, consideram a bacia dividida em sub-bacias com base no relevo, solos e uso da terra e, dessa forma, preservam os parâmetros distribuídos espacialmente e características homogêneas dentro da bacia.

Alguns modelos são citados como modelos pontuais e modelos não pontuais, termos esses geralmente associados à fonte de poluição que está sendo modelada. O modelo de poluição pontual é aquele que tem sua fonte localizada: os lixos industriais, esgotos etc. Os modelos de poluição não pontuais apresentam fontes difusas, isto é, com caminhos dispersos. Substancial progresso tem sido feito no controle da poluição das águas de origem pontual. Por outro lado, o controle da poluição de origem não pontual não tem sido efetivo, em parte, por causa da sua natureza difusa. Segundo FitzHugh \& Mackay (2000), a poluição de origem não pontual é a causa de muitos problemas de qualidade de água nos E.U.A. e no mundo, mas devido à sua natureza distribuída, ela não pode ser monitorada diretamente da mesma maneira que a poluição pontual. Nesse contexto, modelos computacionais têm o potencial de ser usados como uma ferramenta de suporte a políticas de manejo de bacia hidrográficas, por poderem fazer estimativas de cargas de sedimentos, nutrientes e pesticidas em bacias hidrográficas agrícolas. 


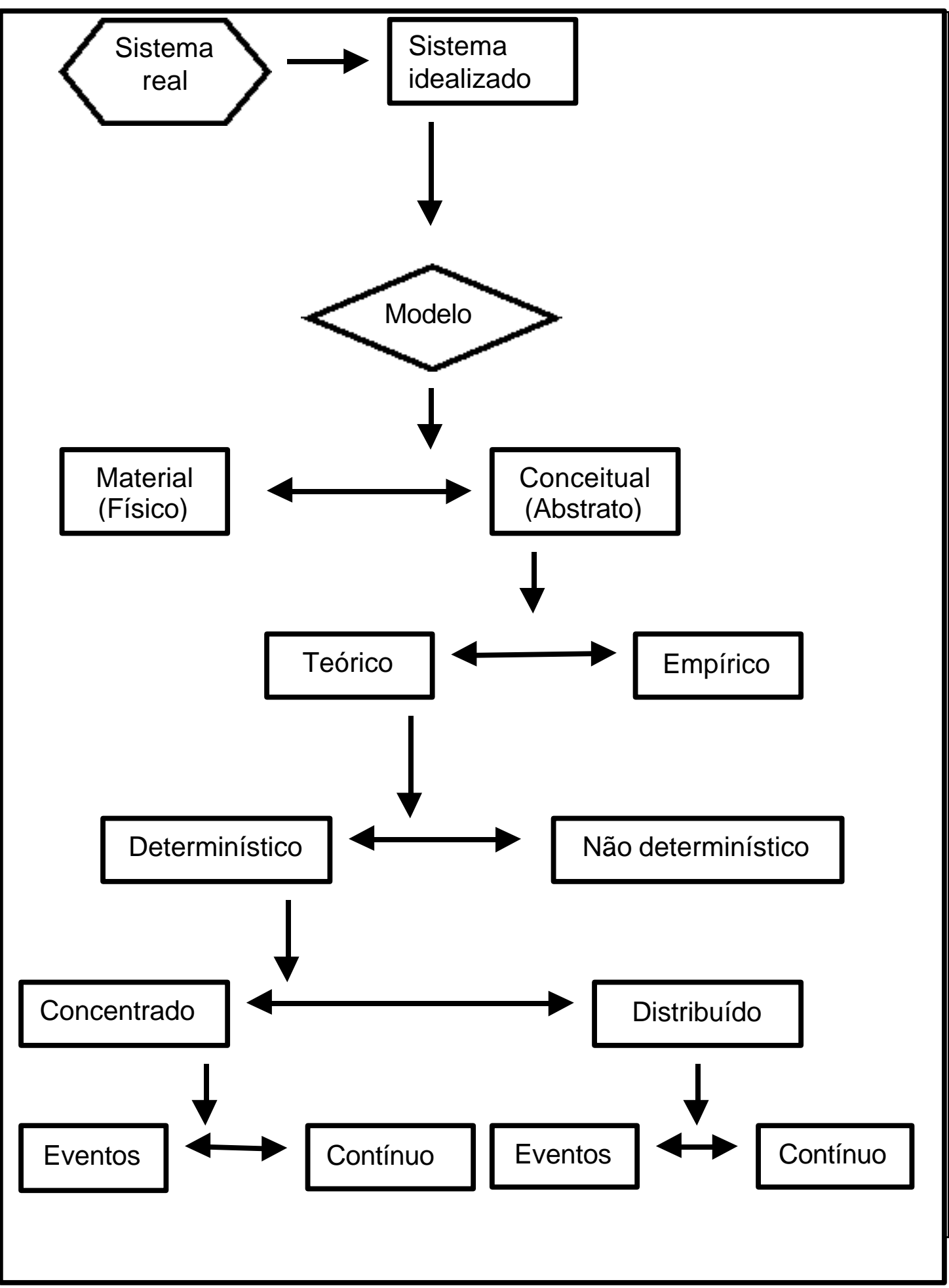

Figura 1 - Classificação simplificada dos modelos. Fonte: Tim (1996) (adaptado de Chow et al., 1988). 
É claro que a utilização de modelos não apresenta somente vantagens. Faz-se necessário o conhecimento de suas limitações e dos problemas relativos a essa ferramenta, para a realização de trabalhos sérios com base no seu uso.

Uma alternativa para contornar esse problema é partir da preposição de uma descrição do sistema real, que o represente na escala do objeto do estudo. Essa representação deve basear-se em conhecimento técnico de alto nível, adquirido em pesquisas básicas, que facilitem a descrição dos processos envolvidos. Mediante essa abordagem, torna-se possível a proposição de modelos matemáticos que representem o problema de forma mais eficiente e, posteriormente, sua transcrição para a linguagem computacional, viabilizando o acompanhamento da dinâmica desse sistema pela simulação de cenários alternativos, muitos deles ainda não testados em cenário real (Pessoa et al., 1997).

Uma importante vantagem da utilização de simulação está associada a seu baixo custo. Na maioria das aplicações, o custo de executar um programa computacional é muitas ordens de magnitude menor do que o correspondente custo relativo à investigação experimental. Esse fator adquire maior importância à medida que o problema real estudado apresenta maiores dimensões e complexidade (como uma bacia hidrográfica), além dos custos operacionais mais elevados relativos às pesquisas de campo. Segundo Pessoa et al. (1997), a vantagem de baixo custo, entretanto, não elimina a necessidade da pesquisa de campo, mas auxilia na realização de experimentos que, certamente, trarão maior quantidade de informações novas e relevantes àpesquisa básica.

A necessidade de validação dos modelos e simuladores já existentes pode ser considerada uma desvantagem desse processo. Às vezes é demorada e requer conhecimento amplo do problema, além da obtenção dos dados de campo. Entretanto, sem a execução dessa etapa, todo o resultado obtido por simulação poderá estar seriamente comprometido e repercutindo na obtenção de tendências equivocadas. 
A crescente demanda no uso, proposição e validação de modelos matemáticos e simuladores, cada vez mais próximos da realidade, reside nas vantagens obtidas com o emprego dessas técnicas, a saber: (a) baixo custo; (b) velocidade; (c) informação completa; (d) criação de cenários diversificados; e (e) proposição de cenários ideais (Pessoa et al., 1997). A possibilidade de criação de cenários, isto é, a simulação de condições diversas, já é bem conhecida. Através dela é possível investigar cenários alternativos, muitos deles ainda não explorados em experimentos reais.

O grande número de modelos de poluição de origem não pontual existente atualmente reflete $\mathrm{o}$ avanço dessa tecnologia. Existem muitos modelos de poluição de origem não pontual, cada um com certa força e deficiência, as quais devem ser consideradas na escolha de acordo com a necessidade do usuário e as características da área de estudo. O GLEAMS (Groundwater Loading Effects of Agricultural Management Systems, Leonard et al., 1987), é um modelo de simulação desenvolvido para áreas experimentais para avaliar o movimento de pesticidas agrícolas dentro e através da zona radicular das plantas. O ANSWERS (Area Non-point Source Watershed Environmental Response Simulation, Beasley \& Huggins, 1982), baseado em eventos, de parâmetros distribuídos, foi desenvolvido para simular a ação da agricultura como uso principal em bacias hidrográficas. O modelo AGNPS (AGricultural Non-Point Source, Young et al., 1989), é baseado em eventos, e simula runoff, sedimentos e nutrientes transportados em bacias hidrográficas agrícolas. Esses modelos foram desenvolvidos para predizer o impacto da agricultura na qualidade das águas superficiais e subterrâneas.

Um outro modelo, relativamente novo, é o Soil and Water Assessment Tool (SWAT), que permite uma grande flexibilidade na configuração de bacias hidrográficas (Peterson \& Hamlett, 1998). O modelo foi desenvolvido para predizer o efeito de diferentes cenários de manejo na qualidade da água, produção de sedimentos e cargas de poluentes em bacias hidrográficas agrícolas (Srinivasan \& Arnold, 1994). O SWAT considera a bacia dividida em 
sub-bacias com base no relevo, solos e uso do solo e, desse modo, preserva os parâmetros espacialmente distribuídos da bacia inteira e características homogêneas dentro da bacia. Várias aplicações do SWAT têm mostrado resultados promissores (Srinivasan \& Arnold, 1994; Rosenthal et. al., 1995; e Cho et al., 1995).

Segundo Magalhães (1989), o uso de modelos globais tem sido uma prática muito importante para os projetos na área de recursos hídricos. Enquanto os processos convencionais fazem análises hidrológicas com base em alguns eventos de precipitação isolados, os modelos que englobam todo, ou quase todo, o ciclo hidrológico, podem analisar uma longa série temporal, procurando interpretar melhor as não-linearidades contidas nos processos hidrológicos ligados àbacia hidrográfica, propriamente dita, e à calha fluvial de forma conjugada. Esses modelos constituem-se numa ferramenta mais confiável para a simulação hidrológica do comportamento de uma bacia hidrográfica, permitindo melhores interpolações e extrapolações.

Embora em outros países seja comum o uso de modelos matemáticos e simuladores na pesquisa ambiental e agropecuária, no Brasil essa prática ainda é tímida. Soma-se aos impedimentos do uso de modelos matemáticos e simuladores, a ausência de informações qualitativas e quantitativas, geralmente em decorrência da falta de publicação de dados que possibilitem a elaboração, manutenção e atualização de um banco de dados detalhados relativos æ̀̀ questões mais variadas relacionadas ao ambiente estudado (Pessoa et al., 1997).

\subsection{Sistemas de Informações Geográficas (SIG's) e modelagem hidrológica e de qualidade de água}

O Geoprocessamento pode ser definido como o conjunto de tecnologias de coleta e tratamento de informações espaciais e de desenvolvimento e uso de sistemas que as utilizam (Rodrigues, 1990). 
Segundo Mendes (1998), a utilização de técnicas de Geoprocessamento constitui-se em instrumento de grande potencial para o estabelecimento de planos integrados de conservação do solo e da água. Neste contexto, os Sistemas de Informações Geográficas (SIG's) se inserem como uma ferramenta que tem a capacidade de manipular as funções que representam os processos ambientais em diversas regiões, de uma forma simples e eficiente, permitindo uma economia de recursos e tempo. Estas manipulações permitem agregar dados de diferentes fontes (imagens de satélite, mapas topográficos, mapas de solos, hidrografia etc.) e em diferentes escalas. O resultado destas manipulações, geralmente é apresentado sob a forma de mapas temáticos com as informações desejadas.

As aplicações dos SIG's são incontáveis, podendo-se citar como exemplos: monitoramento e análise ambiental; planejamento de uso da terra; manejo de recursos naturais; projetos de engenharia (transportes, irrigação, mineração, etc); e manejo florestal (Vettorazzi, 1992).

Os Sistemas de Informações Geográficas são uma tecnologia que tem sido desenvolvida para lidar com informações espaciais e tem muitas aplicações ambientais, sociais e econômicas. Eles são idealmente adequados para combinar informações topográficas, de solos, uso da terra e meteorológicas para pequenas áreas dentro da bacia, onde é possível visualizar cenários passados, atuais e simular cenários futuros (Grigg, 1996). Desde que o uso de modelos é limitado pela necessidade de dados espaciais, e desde que os SIG's têm uma grande facilidade em manipular esses dados, a união dessas duas tecnologias representa um importante passo para o manejo de poluições não pontuais (Wilson \& Wang, 1998).

A integração de modelos ambientais e SIG é um vasto campo para a ciência ligada ao Geoprocessamento, meio ambiente e agricultura. Após a expansão de pesquisas baseadas em SIG no final da década de 1980, é evidente o desenvolvimento de uma nova onda de interesse em SIG pelas ciências do meio ambiente (ex: ecologia, biologia e hidrologia) agricultura 
(agricultura de precisão e planejamento do uso da terra), dado o número de pesquisadores envolvidos na integração de modelos ligados à agricultura e ao meio ambiente à tecnologia SIG (Bacellar, 1994; Carver et al., 1995; Shirmohammadi et al., 1994; e Hartkamp et al., 1999). Essa combinação permite uma análise espacial e temporal e determina a capacidade desses novos sistemas computacionais em melhorar e prover informações sobre erosão e poluição.

A integração do SIG com os modelos hidrológicos e a sua aplicação em bacias hidrográficas permite a realização de um grande número de operações, como o projeto, calibração, simulação e comparação entre os modelos. O uso do SIG permite, portanto, subdividir a bacia hidrográfica em subáreas homogêneas (Calijuri et al., 1998).

Numerosos estudos têm descrito o uso de SIG na modelagem hidrológica e de qualidade de água (Fedra, 1993; Tim et al., 1992; Zhang et al., 1990; Maidment, 1993; Goodchild et al., 1993; Kovar \& Nachtnebel, 1993; Harlin \& Lanfear, 1993). Os modelos CREAMS (Chemicals, Runoff, and Erosion from Agricultural Management Systems, Knisel, 1980), ANSWERS (Areal Nonpoint Source Watershed Environment Response Simulation, Beasley et al., 1982) e AGNPS (AGricultural NonPoint Source, Young et al., 1989) são exemplos de modelos distribuídos, capazes de simular a distribuição de sedimentos e a concentração de poluentes agrícolas em diferentes pontos da bacia, utilizando estrutura em grade, a fim de armazenar os dados que representam a variabilidade espacial das variáveis.

Quando os modelos anteriores foram criados, apenas alguns conceitos de SIG foram utilizados. No final da década de 80 , muitos modelos começaram a utilizar toda a funcionalidade do SIG, como armazenamento, apresentação e manipulação dos dados distribuídos (Mendes, 1998), entre eles o SWAT.

O desenvolvimento de interfaces entre SIG e modelos é uma área ativa de pesquisa, particularmente em questões de proteção da qualidade de 
água, planejamento de uso da terra e manejo de recursos naturais (Tim \& Jolly, 1994). Há, basicamente, três formas de interface; união, combinação e integração.

No primeiro nível de interface (união) (Figura 2a), o SIG e o modelo são desenvolvidos separadamente. Os dados de entrada do modelo são extraídos a partir do SIG. Uma simples transferência de arquivos no formato ASCII ou em arquivo binário é usualmente suficiente (Hartkamp et al., 1999). O modelo é rodado independente do SIG e as saídas podem ser analisadas como desejado pelo usuário (Tim \& Jolly, 1994). Comparada com as outras técnicas, essa interface é fácil de desenvolver, mas tem algumas limitações: (1) a dependência do sistema ao formato de saída do SIG ou do modelo; (2) falha para tirar total vantagem das capacidades funcionais dos SIG's (Hartkamp et al., 1999); a incompatibilidade do ambiente operacional e hardware. Tim (1996) e Fedra (1993) enfatizam que os usuários não podem aproveitar o potencial total do sistema através desse tipo de interface. Exemplos de união são GLEAMS para Arclnfo (Stallings et al., 1992) e USLE para MAP GIS (Hession \& Shanholz, 1988).

O segundo nível de interface, combinação (Figura 2b), também envolve o processamento dos dados via SIG e exibição dos resultados do modelo. Entretanto, o modelo é configurado com as ferramentas interativas do SIG e os dados são trocados automaticamente. Há um uso intensivo de mecanismos que são oferecidos pelos pacotes SIG: macro-linguagens, programas de interface escritos na linguagem de programação padrão e comandos de rotinas (Tim, 1996). Esse tipo de interface usualmente requer programação mais complexa e maior manuseio dos dados do que a simples união. Exemplos de combinação são: GLEAMS com Arclnfo (Fraisse et al., 1994), WEPP com ArcView (Cochrane et al., 1997), SWAT com GRASS (Srinivasan \& Arnold, 1994) eSWAT com ArcView (Di luzio et. al., 2001).

Integração é o terceiro nível de interface (Figura 2c), e implica na incorporação de um sistema ao outro. Ou o modelo é embutido no SIG, ou um 
SIG simples é incluído no sistema de modelagem, evitando, desse modo, transferir dados entre os softwares ou o uso de programas de interface (Tim \& Jolly, 1994). Um considerável esforço de programação entre os especialistas de SIG e os modeladores é necessário para desenvolver esse sistema (Hartkamp et al., 1999). Esse tipo de interface é mais usual em modelos simplificados (Tim, 1996). Exemplos de combinação são encontrados em Lam et al., (1996) e na interface descrita por Stuart \& Stocks (1993).

Mendes (1998) faz algumas considerações sobre a utilização de modelos hidrológicos e SIG. Segundo ele, modelos hidrológicos lidam com fenômenos contínuos e dinâmicos, enquanto os SIG's disponíveis atualmente no mercado tratam apenas com dados estáticos e discretos. Em termos de estrutura de dados que representam a "realidade", o SIG utiliza os conceitos de pontos, linhas, polígonos, grades, Redes de Triângulos Irregulares, Quadtrees etc. Na Hidrologia, os sistemas a serem representados espacialmente são bacias, aqüíferos, rios, canais, lagos etc. No campo conceitual, a análise de fenômenos é feita no SIG através da manipulação e interpretação de dados geográficos. Na Hidrologia esta análise é feita através da simulação do movimento da água e de seus constituintes, usando equações que representam leis físicas. É fundamental que os técnicos envolvidos na área de recursos hídricos reconheçam este problema fundamental e entendam as suposições e limitações da representação discreta da "realidade" (manipulada através do SIG) e o uso destes dados em modelos.

$\mathrm{Na}$ modelagem hidrológica, o desenvolvimento de técnicas automáticas nas últimas décadas para determinar as propriedades da drenagem em bacias hidrográficas, fez com que a representação cartográfica usual do relevo fosse substituída gradualmente por Modelos Numéricos do Terreno (MNT's), o que facilitou e muito a tarefa de preparação desses dados. 


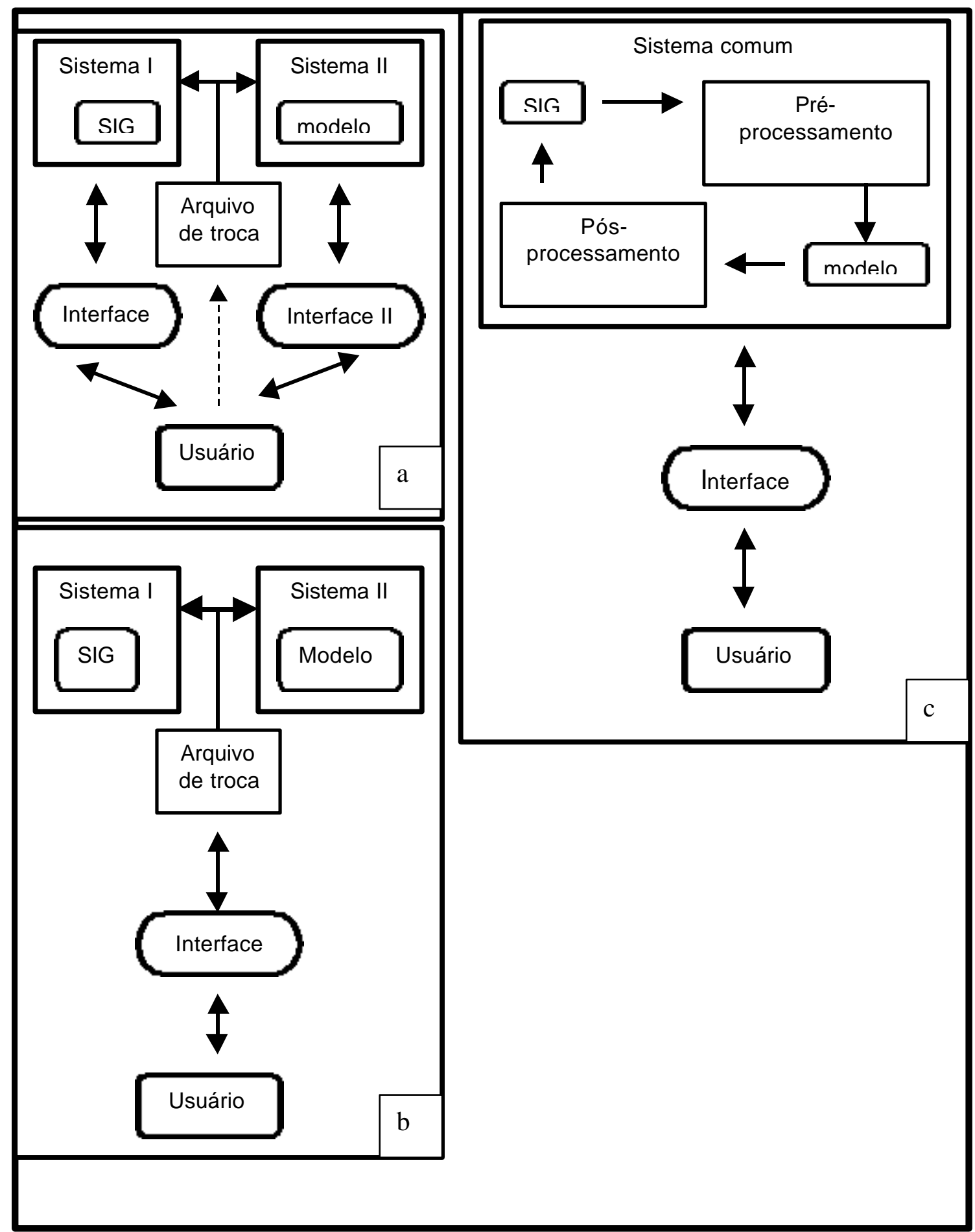

Figura 2 - Estrutura organizacional de modelos e SIG: União (a), Combinação (b) e Integração (c) (adaptado de Tim, 1996). 
O Modelo Numérico do Terreno (MNT) indica a distribuição espacial do relevo, sendo representado através de uma imagem digital, onde cada $f(x, y)$ fornece o valor da cota topográfica na posição x, y. Geralmente, a informação topográfica está disponível na forma de mapas topográficos.

Moore et al. (1991) mencionam três tipos de MNT usados em modelos hidrológicos: (1) rede regular triangular ou regularmente espaçada $R G N)$; (2) rede irregular triangular (TIN); e (3) rede de contorno (CBN).

O modelo TIN requer menor espaço de armazenamento que o RGN e, ao mesmo tempo, representa melhor as feições da paisagem (cristas, vales, picos e lombadas) e é capaz de adaptar-se às diferentes resoluções para a complexidade topográfica (Polarski, 1997). Mas, segundo Wise (2000), o modelo TIN produz áreas planas em cristas e vales.

Um importante aspecto na modelagem espacial distribuída é decidir o delineamento de sub-bacias e a extração da rede de drenagem a partir dos MNT's. O adequado conhecimento do sistema de drenagem de uma bacia hidrográfica e do seu grau de ramificação, permite caracterizar a maior ou menor velocidade com que a água e, conseqüentemente, os poluentes escoam ao longo desta (Calijuri et al., 1998). O uso comum consiste em especificar a área limite (threshold), a qual é a área mínima necessária para drenar para um ponto para formar um canal (Band, 1986; Jensen \& Domingue, 1988; Tarboton et al., 1991; Tribe, 1992; Chorowicz et al., 1992). A escolha da área limite (As) obviamente influencia o resultado final. Geralmente As é assumida como constante e seu valor é fixado por um julgamento arbitrário ou uma comparação visual da rede gerada com a rede digitalizada dos mapas topográficos (Band, 1986; Jensen \& Domingue, 1988 e Moussa \& Bocquillon, 1996). 


\subsection{Método da Curva Número (CN)}

\subsubsection{Generalidades}

A técnica mais utilizada para estimar o volume de runoff em bacias hidrográficas é a desenvolvida pelo Serviço de Conservação de Solos Soil Conservation Service - SCS) do Departamento de Agricultura dos Estados Unidos (United States Department of Agriculture - USDA), denominado de método da Curva Número ou CN. Sua primeira versão data de 1954 e, desde então, o CN tem sido objeto de numerosas contribuições de aperfeiçoamento, incluindo aplicações para bacias urbanas. Ao longo dos anos o método $\mathrm{CN}$ se tornou a mais popular ferramenta para cálculo do runoff, devido a sua relativa facilidade de uso, disponibilidade de dados confiáveis e ter sido desenvolvido por uma agência altamente credenciada.

A principal razão da grande popularidade do uso do método da CN é a sua simplicidade, requerendo somente quatro características da bacia hidrográfica. O CN é um método empiricamente baseado em dados da relação entre intensidade da chuva, condições da superfície da terra e volume de runoff, sendo pois o valor da Curva Número uma função do uso e cobertura da terra, condições hidrológicas, grupo hidrológico do solo e condições de umidade antecedente (AMC). Cada um destes fatores pode apresentar alta variabilidade espacial, dificultando a determinação precisa dos valores da CN para todas as áreas de uma bacia hidrográfica (Grove, 1998). As determinações precisas da $\mathrm{CN}$ são requeridas quando se aplica o método SCS para pequenos eventos de precipitação porque mesmo pequenas variações na $\mathrm{CN}$ podem gerar sérios erros.

Os procedimentos aqui descritos baseiam-se principalmente em USDA $(1972,1997)$ e Ponce (1989). O método da Curva Número é um procedimento para determinações da abstração hidrológica. Nesse método, a intensidade do runoff (intensidade da chuva efetiva) é uma função da 
intensidade da chuva total e de um parâmetro denominado de Curva Número de runoff, Curva Número ou CN. A Curva Número varia de 1 a 100, sendo uma função dos seguintes fatores: (1) padrão hidrológico do solo; (2) uso e manejo da terra; (3) condições da superfície do solo; e (4) umidade antecedente.

O método foi desenvolvido com base em dados da relação chuva/runoff para 24 horas. A limitação para o cálculo da intensidade do runoff não está, especificamente, relacionada à variação temporal da intensidade da chuva. A distribuição temporal é introduzida em um estágio posterior, durante a geração da hidrógrafa do runoff, através da convolução da hidrógrafa unitária (Ponce,1989). O SCS obteve curvas que relacionam a precipitação com o escoamento de muitas bacias. No sentido de padronizar essas curvas, foram definidos números adimensionais, as CN's.

No método, o runoff efetivo é denominado de $Q$ e o runoff potencial (chuva total) é representado por $P$, onde $P \geq Q$. A retenção atual após o início do runoff é $P-Q$. A retenção potencial ou potencial máximo de retenção é $S$, onde $S \geq P-Q$.

O método assume uma proporcionalidade entre retenção e runoff:

$$
\frac{P-Q}{S}=\frac{Q}{P}
$$

em que a relação entre a taxa de retenção atual e a retenção potencial é igual à relação runoff efetivo/runoff potencial. Esta condição é a base conceitual do método da Curva Número.

Para aplicações práticas a equação 1 é melhorada, reduzindo o runoff potencial para uma equação originada da abstração inicial. A abstração inicial consiste, essencialmente, na interceptação, infiltração e armazenamento superficial que ocorrem antes do início do runoff: 


$$
\frac{P-I a-Q}{S}=\frac{Q}{P-I a}
$$

sendo,

la = abstração inicial.

Calculando $Q$ pela equação (2), tem-se:

$$
Q=\frac{(P-I a)^{2}}{P-I a+S}
$$

que é fisicamente submetida à restrição $P \geq l a$, ou seja, o runoff potencial mínimo não pode ser negativo. Para simplificar a equação (3) a abstração inicial é relacionada com a retenção potencial máxima a seguir:

$$
\mathrm{la}=0,2 \mathrm{~S}
$$

Esta relação foi obtida com base em dados da relação chuva/runoff em pequenas bacias hidrográficas. O coeficiente 0,2 foi gerado de muitos dados e tem sido submetido a extensivos exames. Springer et al. (1980), citado por Ponce (1989), avaliaram dados de pequenas bacias em regiões úmidas e semiáridas e encontraram que o coeficiente da equação (4) variou de 0,0 a 0,26. Ainda assim, 0,2 é o padrão inicial recomendado pelo SCS. Para aplicações de pesquisa e particularmente quando se obtêm dados de campo é possível considerar o coeficiente da condição inicial como um parâmetro adicional no método da Curva Número. Em geral:

$$
\mathrm{la}=\mathrm{KS}
$$

Sendo: $\mathrm{K}$ = parâmetro da condição inicial. Assim com a equação (3), a equação (4) é reduzida para: 


$$
\mathrm{Q}=\frac{(\mathrm{P}-0,2 . \mathrm{S})^{2}}{\mathrm{P}+0,8 . \mathrm{S}}
$$

submetida à seguinte restrição $P>o u=0,2 S$. Sendo $Q, P$ e $S$ expressos em unidade de lâminas.

Considerando que o potencial de retenção máxima é muito variável, é mais apropriado expressá-lo em termos de uma Curva Número de runoff, uma integral variando na faixa de 1 a 100, da seguinte forma:

$$
S=\left\{\begin{array}{l}
\frac{25400}{\mathrm{CN}}-254(\mathrm{~mm}) \\
\left.\frac{1000}{\mathrm{CN}}-10 \text { (polegadas }\right)
\end{array}\right\}
$$

Para uma $\mathrm{CN}=100$ a abstração não é possível, com o runoff sendo igual àchuva total. De outro lado, para $\mathrm{CN}=1$ praticamente toda chuva poderá ser abstraída, com runoff sendo essencialmente igual a zero. O valor 1 é encontrado em áreas totalmente permeáveis, onde 0 potencial de armazenamento é elevado e não ocorre escoamento. Já, o valor 100 é aplicado a áreas totalmente impermeáveis, sem armazenamento ou outras perdas, como por exemplo os corpos de água ou as áreas saturadas.

Conforme Ponce (1989), a partir da equação (7), a equação (6) pode ser expressa em termos de CN:

$$
\mathrm{Q}=\frac{\mathrm{R} \cdot\left[\mathrm{CN}\left(\frac{\mathrm{P}}{\mathrm{R}}+2\right)-200\right]^{2}}{\mathrm{CN} \cdot\left[\mathrm{CN}\left(\frac{\mathrm{P}}{\mathrm{R}}-8\right)+800\right]}, \text { para } \mathrm{P} \geq \mathrm{R}\left[\left(\frac{200}{\mathrm{CN}}-2\right)\right]
$$

Nessa equação, P e Q são dados em cm, contanto que se considere o fator de transformação $R=2,54$. Para a inclusão da variável abstração inicial, a eq. (8) é rescrita da seguinte forma: 


$$
\mathrm{Q}=\frac{\mathrm{R}\left[C N\left(\frac{\mathrm{P}}{\mathrm{R}}+10 \mathrm{~K}\right)-1000 . \mathrm{K}\right]^{2}}{\mathrm{CN}\left\{\mathrm{CN}\left[\frac{\mathrm{P}}{\mathrm{R}}-10(1-\mathrm{K})\right]+1000(1-\mathrm{K})\right\}}, \text { para } \mathrm{P} \geq \mathrm{R}\left[\left(\frac{1000 \mathrm{~K}}{\mathrm{CN}}-10 \mathrm{~K}\right)\right]
$$

O método da $\mathrm{CN}$ foi desenvolvido com dados de pequenas bacias agrícolas no meio-oeste americano, de forma que sua aplicação em ambientes diferentes da que foi desenvolvida é incerta.

O método tem passado por várias revisões, como a de Ponce \& Hawking (1996) que fizeram uma análise crítica, esclarecendo sua base conceitual e empírica, delimitando sua capacidade, limitações e usos e identificando áreas de pesquisa empregando o método da CN.

Pesquisadores têm usado fatores como: padrão de chuvas; umidade inicial do solo; práticas agrícolas; propriedades físicas do solo; e influência da vegetação; bem como transformações matemáticas para modificar e melhorar o método da CN (Williams \& Lascur, 1976; Schroeder, 1987; Madramootoo \& Enright, 1987; Hauser \& Jones, 1987; Miller \& Lakotos, 1977; Aron, 1992; Hawkins, 1973, 1978b, Clopper, 1980; Wanielista \& Taylor, 1979, Dass, Tamke \& Stofel, 1977) todos citados por Mack, 1995.

Tradicionalmente, o método da $\mathrm{CN}$ tem sido aplicado usando um procedimento de composição em que a média ponderada da CN é calculada ou para a bacia inteira sob estudo, ou para sub-bacias relativamente homogêneas. Esta técnica do valor médio ponderado era necessária para reduzir o número de cálculos em análises feitas manualmente. O uso de computadores pessoais tem reduzido e facilitado os cálculos, apesar da composição dos valores da CN ser ainda muito utilizada. Isso se deve ainda à pouca familiaridade com as técnicas computacionais, como o uso de bancos de dados espaciais na forma digital e o uso de Sistemas de Informações Geográficas que têm melhorado a praticidade da estimativa do volume de runoff usando a $\mathrm{CN}$ distribuída.

No trabalho de Grove et al. (1998) foram feitas duas simulações em uma bacia idealizada para comparar o volume de runoff gerado com a técnica 
de $\mathrm{CN}$ composta com o volume gerado com o uso da técnica $\mathrm{CN}$ distribuída. Segundo os autores, os resultados mostraram que o volume de runoff estimado usando $\mathrm{CN}$ distribuída foi $100 \%$ maior do que o volume gerado usando $\mathrm{CN}$ composta. A subestimação do runoff pela técnica da $\mathrm{CN}$ composta é o resultado da relação curvilínea entre $\mathrm{CN}$ e volume de runoff e é mais severa para grandes variações de $\mathrm{CN}$, baixos valores de $\mathrm{CN}$ e baixas precipitações; para chuvas intensas, entretanto, a diferença no volume de runoff computado utilizando $\mathrm{CN}$ composta e distribuída é mínimo. Diante dos resultados, os autores recomendam que seja feito o uso de $\mathrm{CN}$ distribuída, especialmente quando forem estudados os efeitos de urbanização que apresentarem valores bem diferentes dentro de uma mesma área.

Schroeder (1994) conduziu um estudo para comparar a estimativa de abstração inicial (la), retenção potencial máxima (S) e valores de $\mathrm{CN}$ para regiões semi-áridas, em solos recuperados de regiões de minérios sob várias condições, usando a equação original do SCS e a equação mais comumente usada na qual la $=0,2 \mathrm{~S}$ é assumida. Chuvas simuladas foram aplicadas em 40 parcelas para este tipo de solo, com várias texturas, declividades e coberturas. Valores de la estimados a partir dos dados de campo foram somente $13 \%$ do $S$ quando comparados com o valor assumido de $20 \%$ no método do SCS. Geralmente, o método do SCS superestimou la e CN e subestimou S, quando la foi assumido como sendo $20 \%$ de S. Os resultados, segundo os autores, indicaram que essa metodologia pode ser usada em regiões semi-áridas, na recuperação de solos de mineração com razoável grau de confiança.

No Brasil, vários exemplos do uso e aplicação do método da $\mathrm{CN}$ podem ser encontrados na literatura, como a estimativa de runoff feita em áreas sob cultivo de trigo e soja (Souza et al., 1995); projeto da seção transversal de terraços feito por Chaves (1996); e uma descrição ambiental e agrícola de uma microbacia sob cultivo intenso usada principalmente para propósito de irrigação (Dolabella, 1996). Nesses três trabalhos a conclusão foi que o método da CN pode ser usado para estimar adequadamente o runoff. Nenhum estudo tem sido 
feito para bacias sob condições naturais nessas três referências. O trabalho de Silva et al. (1999) vem preencher essa carência. Os autores compararam valores medidos e simulados de volume de runoff usando o método da $\mathrm{CN}$ para cada evento de chuva. O trabalho foi desenvolvido na microbacia do Córrego Capetinga, localizada no Distrito Federal. A cobertura vegetal da bacia era predominantemente natural, constituída de cerrados, campo-cerrado, campo sujo e campo limpo. Os valores da $\mathrm{CN}$ foram selecionados em função das características edafogeológicas e vegetativas da microbacia. Verificou-se uma subestimativa nos valores simulados do runoff total de $15 \%$, quando comparados com os valores observados. Utilizando valores de $\mathrm{CN}$ calculados para a microbacia, o método superestimou os resultados em $39 \%$. Os autores recomendam cautela no uso desse método em área sob vegetação natural, em razão das discrepâncias.

Como se pode observar, o método da $\mathrm{CN}$ tem passado por modificações e revisões pela sua grande importância, devido a sua facilidade de aplicação, pois requer somente quatro parâmetros de entrada, sendo usado separadamente ou inserido em modelos hidrológicos mais complexos. Estudos ainda devem ser conduzidos com a finalidade de melhorar o método para regiões diferentes das quais ele foi desenvolvido, caso do Brasil.

\subsubsection{Determinação da Curva Número a partir de tabelas}

As CN's para as diversas condições hidrológicas e coberturas de solos para áreas rurais e urbanas estão disponíveis em tabelas do SCS. A relação condições hidrológicas/cobertura do solo, descreve uma combinação específica entre o grupo hidrológico do solo, o uso e manejo da terra e as condições da superfície. Todos esses fatores têm influência direta sobre 0 volume de runoff produzido pela bacia hidrográfica. O grupo hidrológico descreve o tipo de solo. O uso e manejo descrevem o tipo e as condições da cobertura vegetal. As condições hidrológicas referem-se à capacidade da 
superfície da bacia para aumentar ou reduzir diretamente o runoff. A umidade inicial antecedente informa o histórico recente da chuva e, conseqüentemente, é uma mensuração do valor da umidade armazenada pela retenção.

A) Grupos hidrológicos de solos. Pelo SCS (USDA, 1972 e 1986), os solos são classificados em quatro grupos hidrológicos ( $A, B, C$ e $D)$ em função de suas distintas produções de escoamento.

Segundo Ponce (1989), de acordo com o SCS os grupos hidrológicos de solos podem ser identificados usando-se três critérios: características do solo, levantamentos de solos ou a taxa mínima de infiltração.

Nos Estados Unidos existem mapas mostrando a distribuição geográfica dos grupos hidrológicos de solos. Também, os levantamentos de solo dos municípios, feitos pelo SCS, fornecem uma descrição detalhada do solo e sua localização. Este é, normalmente, o melhor meio para identificar o grupo hidrológico do solo naquele país.

No Brasil, a disponibilidade destas informações ainda é limitada. Neste contexto existe uma proposição de Setzer \& Porto (1979) para enquadramento dos solos de São Paulo em cinco grupos hidrológicos (Tabela 2). Complementando este trabalho, Lombardi Neto et al. (1989) fizeram uma associação entre as classes de solos com os grupos hidrológicos, com base no Levantamento e Reconhecimento de Solos do Estado de São Paulo (BRASIL, 1960), permitindo que se obtenham diretamente os grupos hidrológicos de solos e as correspondentes áreas que ocupam nas bacias hidrográficas (Tabela 3). Nos demais Estados as informações são escassas e pontuais. 
Tabela 1. Grupos hidrológicos de solos.

Grupos Caracterização

A Solos arenosos, profundos, com pouca argila e silte.

Bem drenados.

Apresentam altas taxas de infiltração, mesmo quando úmidos.

Apresentam altas taxas de transmissão da água.

Produzem baixo escoamento superficial.

Taxa de infiltração: 7,6 - 11,4 mm/hora*.

B Solos com textura fina a moderadamente grosseira.

Moderadamente profundos a profundos.

Bem drenados a moderadamente drenados.

Apresentam taxas de infiltração moderada quando úmidos.

Apresentam taxas moderadas de transmissão da água.

Taxa de infiltração: 3,8 - 7,6 mm/hora*.

C Solos com texturas moderadamente finas a finas.

Solos com baixa infiltração quando úmidos.

Solos com camada de impedimento ao movimento da água.

Apresentam baixas taxas de transmissão da água.

Taxa de infiltração: 1,3 - 3,8 mm/hora*.

D Solos com argilas expansivas e pouco profundos.

Solos com camadas de argila próximas à superfície ou na superfície.

Solos superficiais sobre materiais impermeáveis ou quase impermeáveis.

Apresentam taxas muito baixas de infiltração quando úmidos.

Apresentam taxas moderadas de transmissão da água.

Alto potencial de produção de escoamento superficial.

Taxa de infiltração: 0 - 1,3 mm/hora*.

${ }^{*}$ Segundo Skaggs \& Khaleel (1982) 
Tabela 2. Valores dos parâmetros $\mathrm{CN}$ para bacias rurais na condição antecedente de umidade do solo II (Setzer \& Porto, 1979).

\begin{tabular}{|c|c|c|c|c|c|c|c|}
\hline \multirow{2}{*}{$\begin{array}{l}\text { Cobertura vegetal ou } \\
\text { tipo de uso do solo }\end{array}$} & \multirow{2}{*}{$\begin{array}{l}\text { Condição da } \\
\text { superfície }\end{array}$} & \multirow{2}{*}{$\begin{array}{l}\text { Situação } \\
\text { hidrológica }\end{array}$} & \multicolumn{5}{|c|}{ Grupo hidrológico do solo } \\
\hline & & & A & B & C & D & E \\
\hline \multirow{2}{*}{$\begin{array}{l}\text { Solo arado ou quase, } \\
\text { sem cobertura }\end{array}$} & SR & Boa & 65 & 80 & 88 & 92 & 95 \\
\hline & SR & Boa & 65 & 78 & 86 & 90 & 92 \\
\hline \multirow{6}{*}{$\begin{array}{l}\text { Cultivos de ciclo curto } \\
\text { e arações freqüentes }\end{array}$} & SR & Má & 60 & 72 & 81 & 87 & 90 \\
\hline & SR & Boa & 52 & 66 & 75 & 82 & 86 \\
\hline & C & Má & 56 & 65 & 78 & 84 & 87 \\
\hline & C & Boa & 48 & 60 & 72 & 78 & 82 \\
\hline & C-T & Má & 52 & 62 & 74 & 80 & 84 \\
\hline & C-T & Boa & 45 & 55 & 67 & 75 & 80 \\
\hline \multirow{6}{*}{$\begin{array}{l}\text { Cultivos de ciclo médio e } \\
\text { arações anuais }\end{array}$} & SR & Má & 58 & 65 & 73 & 82 & 88 \\
\hline & SR & Boa & 54 & 62 & 70 & 79 & 85 \\
\hline & C & Má & 55 & 64 & 72 & 78 & 84 \\
\hline & C & Boa & 50 & 60 & 67 & 75 & 83 \\
\hline & $\mathrm{T}$ & Má & 52 & 62 & 70 & 77 & 82 \\
\hline & $\mathrm{T}$ & Boa & 48 & 55 & 65 & 73 & 80 \\
\hline \multirow{6}{*}{$\begin{array}{l}\text { Semeadura densa ou } \\
\text { a lanço; cobertura curta } \\
\text { mas densa, como } \\
\text { a das leguminosas e } \\
\text { dos pastos em rodízio }\end{array}$} & SR & Má & 56 & 64 & 72 & 80 & 86 \\
\hline & SR & Boa & 50 & 58 & 66 & 76 & 82 \\
\hline & C & Má & 54 & 60 & 69 & 76 & 83 \\
\hline & C & Boa & 48 & 56 & 64 & 72 & 80 \\
\hline & $\mathrm{T}$ & Má & 50 & 58 & 65 & 75 & 80 \\
\hline & $\mathrm{T}$ & Boa & 45 & 52 & 60 & 70 & 76 \\
\hline \multirow{6}{*}{$\begin{array}{l}\text { Pastagem velha com } \\
\text { arbustos }\end{array}$} & & Má & 65 & 70 & 78 & 85 & 90 \\
\hline & & Boa & 60 & 66 & 75 & 82 & 87 \\
\hline & & Má & 56 & 62 & 72 & 79 & 84 \\
\hline & C & Boa & 55 & 62 & 70 & 78 & 86 \\
\hline & C & Má & 42 & 59 & 67 & 75 & 82 \\
\hline & C & Boa & 50 & 56 & 64 & 72 & 79 \\
\hline \multirow[t]{4}{*}{ Reflorestamento } & SR & Má & 35 & 50 & 62 & 74 & 83 \\
\hline & SR & Boa & 30 & 42 & 55 & 68 & 78 \\
\hline & C & Má & 30 & 45 & 57 & 69 & 80 \\
\hline & C & Boa & 25 & 36 & 52 & 64 & 75 \\
\hline Mata & & Má & 32 & 40 & 55 & 67 & 76 \\
\hline Capoeira velha & & Boa & 18 & 25 & 42 & 58 & 70 \\
\hline Gramados & & Má & 65 & 72 & 78 & 84 & 88 \\
\hline tratados & & Boa & 59 & 67 & 74 & 81 & 86 \\
\hline Estradas de & & Má & 80 & 85 & 90 & 93 & 95 \\
\hline terra & & Boa & 74 & 80 & 86 & 90 & 92 \\
\hline
\end{tabular}

Notas: $\mathrm{SR}=$ sulcos retos; $\mathrm{T}$ =terraceamento; $\mathrm{C}=$ cultivo em contorno, paralelamente às curvas de nível.

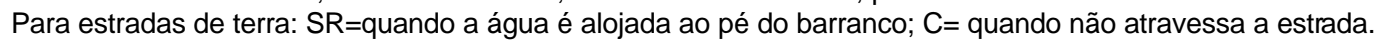

Fonte: Setzer \& Porto (1979). 
Os CN's apresentados na Tabela 2 foram tabulados pelo SCS em função do tipo de solo e uso da terra e foram definidos cinco grupos de solos conforme a divisão de Setzer \& Porto (1979). Segundo Genovez (1991), esses autores basearam-se em estudos pedológicos ocorrentes em todas as formações geológicas do Estado de São Paulo e em fotografias aéreas e, aproveitando as idéias do SCS, dividiram os solos em cinco grupos hidrológicos, conforme a descrição a seguir:

A-Solos arenosos com baixo teor de argila total, inferior a 8\%; não há rocha nem camadas argilosas e nem mesmo densificadas até a profundidade de $1,5 \mathrm{~m}$. O teor de húmus é muito baixo, não atingindo 1\%. Com potencial mínimo de escoamento superficial. Alta taxa de infiltração.

B-Solos arenosos, menos profundos que os do grupo A, e com maior teor de argila total, porém ainda inferior a $15 \%$. No caso de terras roxas, este limite pode subir a $20 \%$ graças à maior porosidade. Os dois teores de húmus podem subir, respectivamente, a 1,2\% e 15\%. Não pode haver pedras e nem camadas argilosas até $1,5 \mathrm{~m}$, mas é quase sempre presente camada mais densificada que a camada superficial. Taxa de infiltração superior àmédia.

C-Solos barrentos, com teor total de argila de $20 \%$ a $30 \%$, mas sem camadas argilosas impermeáveis ou contendo pedras até a profundidade de 1,2 m. No caso de terras roxas, estes dois limites máximos podem ser de $40 \%$ e 1,5m. Nota-se a cerca de $60 \mathrm{~cm}$ de profundidade camada mais densificada que no grupo $B$, mas ainda longe das condições de impermeabilidade.

D-Solos argilosos (30\%-40\% de argila total) e ainda com a camada densificada a uns $50 \mathrm{~cm}$ de profundidade. Ou solos arenosos como B, mas com camada argilosa quase impermeável ou horizonte de seixos rolados. Alto potencial de escoamento superficial. 
E-Solos barrentos como C, mas com camadas argilosa impermeável ou com pedras. Ou sem tal camada, mas o teor total de argila supera $40 \%$. No caso de terras roxas, este teor pode subir a $60 \%$ (no caso D, $45 \%$ ). O mais alto potencial de escoamento superficial (Genovez ,1991, p.53-54).

Tabela 3. Agrupamento de solos segundo suas qualidades, características e resistência àerosão (Lombardi Neto et al., 1989).

\begin{tabular}{|c|c|c|c|c|c|c|c|}
\hline \multirow[b]{2}{*}{ Grupo } & \multirow[b]{2}{*}{$\begin{array}{c}\text { Resistência } \\
\text { àerosão }\end{array}$} & \multicolumn{3}{|c|}{ Principais características } & \multirow[b]{2}{*}{$\begin{array}{c}\text { Razão }^{\text {Rextural }} \\
\text { t(2) }^{2}\end{array}$} & \multirow[b]{2}{*}{ Exemplos } & \multirow[b]{2}{*}{ Índice } \\
\hline & & Profundidade ${ }^{(1)}$ & Permeabilidade ${ }^{(1)}$ & Textura $^{(1)}$ & & & \\
\hline A & alta & $\begin{array}{l}\text { muito profundo } \\
(>2 \mathrm{~m}) \\
\text { profundo } \\
(1 \mathrm{a} 2 \mathrm{~m})\end{array}$ & $\begin{array}{c}\text { rápida/rápida } \\
\text { moderada/rápida }\end{array}$ & $\begin{array}{c}\text { média/média } \\
\text { m.argilosa/m.argilosa } \\
\text { argilosa/argilosa }\end{array}$ & $<1,2$ & $\begin{array}{l}\text { LR, LE, LV, } \\
\text { LVr, LVt, LH, } \\
\text { LEa e LVa }\end{array}$ & 1,25 \\
\hline B & moderada & $\begin{array}{l}\text { profundo } \\
\text { (1 a } 2 \mathrm{~m})\end{array}$ & $\begin{array}{c}\text { rápida/rápida } \\
\text { rápida/moderada } \\
\text { moderada/moderada }\end{array}$ & $\begin{array}{l}\text { arenosa/arenosa } \\
\text { arenosa/média } \\
\text { arenosa/argilosa } \\
\text { média/argilosa } \\
\text { argilosa/m.argilosa }\end{array}$ & 1,2 a 1,5 & $\begin{array}{l}\text { LJ, LVP, PV, } \\
\text { PVL, PIn, TE, } \\
\text { PVIs, R, RPV- } \\
\text { RLV, Lea } \\
\quad \text { LVa }\end{array}$ & 1,1 \\
\hline C & baixa & $\begin{array}{c}\text { profundo } \\
(1 \mathrm{a} 2 \mathrm{~m}) \\
\text { moderadamente prof. } \\
(0,5 \mathrm{a} 1 \mathrm{~m})\end{array}$ & $\begin{array}{c}\text { lenta/rápida } \\
\text { lenta/moderada } \\
\text { rápida/moderada }\end{array}$ & $\begin{array}{l}\text { arenosa/média } \\
\text { média/argilosa } \\
\text { arenosa/argilosa } \\
\text { arenosa/m.argilosa }\end{array}$ & $>1,5$ & $\begin{array}{c}\text { Pml, PVp, } \\
\text { PVls, Pc e } \\
\text { M }\end{array}$ & 0,9 \\
\hline $\mathrm{D}$ & muito baixa & $\begin{array}{c}\text { moderadam. prof. } \\
(0,5 \mathrm{a} 1 \mathrm{~m}) \\
\text { raso } \\
(0,25 \mathrm{a} 0,5 \mathrm{~m})\end{array}$ & $\begin{array}{l}\text { rápida, moderada } \\
\text { ou lenta sobre lenta }\end{array}$ & muito variável & $\begin{array}{c}\text { muito } \\
\text { variável }\end{array}$ & $\begin{array}{c}\text { Li-b, Li-ag, gr, } \\
\text { Li-fi, Li-ac e } \\
\text { PVp (rasos) }\end{array}$ & 0,75 \\
\hline \multicolumn{8}{|c|}{$\begin{array}{l}\text { (1) Segundo Lepsch et al., } 1983 . \\
\text { (2) Média da porcentagem de argila do horizonte B (excluindo B3) sobre a média de todo o horizonte A } \\
\text { (3) Abreviações segundo Brasil (1960). } \\
\text { (4) Somente com a mudança textural abrupta entre os horizontes A e B. } \\
\text { (5) Somente aqueles com horizonte A arenoso. }\end{array}$} \\
\hline
\end{tabular}

B) Condições de umidade antecedente (AMC). São também chamadas de condições de saturação do solo e no método da Curva Número existem três níveis de umidade antecedente. Estes níveis são dependentes da chuva total e são obtidos em um período mínimo de 5 dias antecedentes à determinação do armazenamento (Tabela 4). Períodos maiores podem ser utilizados (2 semanas), porém não acrescentam precisão ao método (Ponce, 1989). 
Tabela 4. Condições de umidade antecedente em função da precipitação total nos cinco dias antecedentes, considerando a estação do ano.

\begin{tabular}{ccc}
\hline \multirow{2}{*}{ AMC } & \multicolumn{2}{c}{ Precipitação nos 5 dias antecedentes $(\mathrm{mm})$} \\
\cline { 2 - 3 } & Estação seca & Estação úmida \\
\hline II & Menos que 12 & menos que 36 \\
III & 12 a 28 & 36 a 53 \\
& mais que 28 & mais que 53
\end{tabular}

Fonte: (USDA, 1972)

Condição AMC I: Baixo potencial de runoff. Esta é a condição na qual os solos da bacia estão secos, porém com umidade suficiente para serem satisfatoriamente arados e cultivados.

Condição AMC II: Médio potencial de runoff. Nesta situação os solos da bacia estão com umidade média, sendo este o caso em que as condições da bacia precederam a ocorrência de cheias em numerosos casos.

Condição AMC III: Alto potencial de runoff. Nesta condição a bacia está com seus solos praticamente saturados em conseqüência de chuvas nos cinco dias anteriores.

Os valores da $\mathrm{CN}$ apresentados na Tabela 2 são válidos para a condição de umidade antecedente AMC II. Para aplicação æ̀̀ outras duas condições, existem tabelas de correção. Hawkins et al. (1985) correlacionaram os valores do potencial máximo de retenção (S) para as condições de AMC I e III com o potencial para a condição AMC II e encontraram, com uma boa aproximação, a razão de 2,3 para SI/SII e SII/SIII. As seguintes relações foram então desenvolvidas para o cálculo dos CN's para as condições AMC I e AMCII.

$$
\begin{aligned}
& \mathrm{CN}(\mathrm{I})=\frac{4,2 \mathrm{CN}(\mathrm{II})}{10-0,058 \mathrm{CN}(\mathrm{II})} \\
& \mathrm{CN}(\mathrm{III})=\frac{23 \mathrm{CN}(\mathrm{II})}{10+0,13 \mathrm{CN}(\mathrm{II})}
\end{aligned}
$$


C) Uso e manejo da terra. $O$ efeito das condições da superfície da bacia hidrográfica é avaliado por meio das classes de uso e manejo. O uso da terra pertence à cobertura da bacia hidrográfica, incluindo toda a vegetação nova, restos culturais, mulch e também alqueive (solo nu), superfícies impermeáveis, como (estradas) e áreas urbanas. Manejo da terra aplica-se especificamente para uso agrícola e inclui práticas mecânicas como cordões de contorno e terraços, práticas de manejo como pastoreio controlado e rotação de cultura. Uma classe de uso e manejo resulta da combinação destes fatores.

O método da Curva Número separa as áreas em terra cultivada, pastagens e florestas. Para áreas cultivadas o método reconhece os seguintes usos e manejos: alqueive, cultivo em linha, grãos pequenos, leguminosas a lanço, rotações de culturas, cultivo direto em linhas, cultivos em contorno e terraços.

\subsubsection{Avaliação do Método da Curva Número}

A característica positiva do método da Curva Número é sua simplicidade e o fato de estar relacionado com as principais propriedades que produzem runoff em uma bacia hidrográfica, como o tipo de solo, tipo de vegetação, condições da superfície e umidade antecedente. O método é usado na prática para determinar o volume de runoff baseando-se na altura da chuva e na Curva Número sem explicitamente considerar a intensidade e a duração da chuva.

Consideráveis experiências têm sido acumuladas sobre o método da Curva Número. Trabalhos publicados sobre o método aumentam o já amplo conhecimento sobre o assunto ou para examinar criticamente a aplicabilidade do mesmo para situações distintas. Para melhores resultados o método deve ser usado de forma prudente, com particular atenção para suas possibilidades e limitações. 
Experiências têm mostrado que os resultados do método da Curva Número são sensíveis. Isto mostra a importância de uma precisa estimativa da $\mathrm{CN}$ para minimizar as variações das determinações de runoff. Tabelas padrões são guias úteis, mas experiências locais são recomendadas para obtenção de resultados mais precisos.

Segundo Ponce \& Hawking (1996), a popularidade do método CN é largamente creditada à sua simplicidade. $\mathrm{O} \mathrm{CN}$ é essencialmente um modelo conceitual para estimar o volume de runoff baseando-se em conceitos hidrológicos estabelecidos, onde o efeito da umidade antecedente representa uma importante variável. Na prática, a AMC II representa a condição típica de planejamento, embora outras condições de umidade antecedente, incluindo aquelas intermediárias entre I, II e III, possam ser consideradas.

Enquanto o procedimento de aplicação do método da Curva Número parece ser independente do tamanho da microbacia, seu uso indiscriminado em áreas com mais de $250 \mathrm{Km}^{2}$, sem subdividi-las não é recomendado Ponce, 1989). O método da CN foi originalmente desenvolvido pelo SCS para uso em bacias rurais. Posteriormente o método foi aplicado para pequenas bacias urbanas. Conseqüentemente, a aplicação em larga escala exige julgamento criterioso.

\subsection{Erosão dos solos}

A degradação dos recursos naturais, principalmente do solo e da água, vem crescendo de forma alarmante, atingindo níveis críticos que se refletem na deterioração do meio ambiente, no assoreamento dos cursos e corpos d'água, com prejuízos para a saúde humana e animal, na destruição de estradas, de pontes e bueiros, na geração de energia, na disponibilidade de água para irrigação e para abastecimento, na redução da produtividade agrícola, na diminuição da renda líquida e, conseqüentemente, no 
empobrecimento da sociedade local, com reflexos danosos para a economia (Bertoni \& Lombardi Neto, 1990).

A principal causa da degradação das terras agrícolas é a erosão dos solos, a qual consiste nos processos de desprendimento e arraste das partículas do solo, causados pela ação da água e do vento. Dentre as formas de erosão, a hídrica é, sobre grande parte do nosso planeta, a mais importante forma de erosão (Zachar, 1982). É causada pela chuva e pelo escoamento superficial, sendo afetada por um grande número de agentes naturais e antropogênicos. Souto \& Crestana (2000) descrevem que os problemas derivados da erosão hídrica podem ser de distintas grandezas. Nos locais onde ocorrem os processos erosivos, verifica-se a perda da capacidade produtiva, devido à remoção dos horizontes superficiais, por outro lado, os excedentes hídricos que chegam até a rede de drenagem da bacia hidrográfica transportam sedimentos, nutrientes e agroquímicos que contaminam as águas superficiais. Esta forma de poluição difusa, ou seja, oriunda do escoamento superficial, é denominada também de poluição de origem não pontual.

A erosão em uma bacia de drenagem, constitui um fator geográfico de estruturação de paisagens e morfogênese, e deve ser encarada àluz dos ciclos morfoclimáticos como um conjunto de fenômenos mecânicos e químicos sob influência direta do clima (Mortatti, 1995). Já a erosão mecânica, caracterizada como um fenômeno de abrasão, está relacionada com o transporte de material em suspensão na bacia de drenagem, principalmente pelo escoamento superficial rápido, estando intimamente ligada ao regime hídrico predominante no ecossistema (Tardy,1990).

Os processos hidrológicos, direta e indiretamente afetam a erosão do solo, o transporte de sedimentos erodidos, a deposição de sedimentos e as características físicas, químicas e biológicas que coletivamente determinam a qualidade das águas superficiais e subterrâneas. Práticas de manejo de bacias hidrográficas e uso da terra também diretamente afetam a erosão, 
sedimentação e qualidade de água, pelas variações nos processos hidrológicos (Brooks et al., 1991).

Embora o processo da erosão do solo ocorra mesmo em ecossistemas naturais, o seu considerável aumento que ocorre em muitos sistemas agrícolas, é sempre sintoma de declínio da fertilidade do solo e, assim como graves avarias ou destruição total de grandes áreas anteriormente férteis e aráveis é, geralmente, o resultado da incapacidade de conservar e restabelecer a fertilidade em declínio associada a práticas agrícolas impróprias, bem como incêndios florestais em regiões inclinadas e processo acelerado e desordenado de urbanização (Odum, 1988).

Apesar da importância que os solos têm para a sobrevivência da espécie humana, dos vegetais e dos animais na superfície da Terra, parece que o homem tem dado pouca atenção a esse recurso natural, pelo menos no que diz respeito à sua utilização e conservação (Guerra et al., 1995). Wild (1993) ressalta que o solo é um dos recursos que o homem utiliza sem se preocupar com o período necessário para a sua recuperação, acreditando que vá durar para sempre. Quando investe no solo é para obter maiores colheitas, raramente para conservá-lo (Guerra et al., 1995).

A erosão dos solos não causa problemas apenas nas áreas onde ocorre, podendo reduzir a fertilidade dos solos e criar ravinas e voçorocas, o que torna, às vezes, impossível sua utilização agrícola. A erosão causa, quase sempre, uma série de problemas ambientais, em nível local ou até mesmo em grandes áreas. Por exemplo, o material que é erodido em uma bacia hidrográfica pode causar o assoreamento de rios e reservatórios. Além disso, as partículas transportadas pela água, em uma área agrícola, podem estar impregnadas de agroquímicos e contaminar as águas dos rios. $\mathrm{O}$ desmatamento e a erosão dos solos podem provocar o desaparecimento de mananciais, bem como acentuar os efeitos das inundações. Enfim, a erosão dos solos causa uma grande gama de impactos ambientais, desde a sua 
própria degradação, passando por problemas ambientais de uma forma geral (Guerra et al., 1994).

A poluição das águas por fontes difusas tem sido apontada como conseqüência de práticas de uso do solo sem cuidado ou sem planejamento. Os problemas mais comuns são sedimentos e nutrientes levados pelo escoamento das áreas agrícolas, mineração, construção civil e outras atividades. A complexidade do manejo da poluição difusa em bacias hidrográficas está associada à natureza dos processos envolvidos e à dificuldade de se desenvolver procedimentos para a eliminação ou mitigação dos seus impactos. Por atingirem extensas áreas e agirem de forma intermitente, as fontes difusas são difíceis de serem identificadas e quantificadas (Brooks et al., 1991).

Tucci (1993) frisa que a qualidade de água dos mananciais que compõem uma bacia hidrográfica está relacionada com o uso do solo na bacia e com o grau de controle sobre as fontes de poluição. Tal afirmação é confirmada por Azevedo Netto (1991) que a água transporta substâncias e organismos, fruto de onde passou. Nesse contexto, Ward \& Elliot (1995) citam que o sedimento é, provavelmente, o mais significativo de todos os poluentes em termos de sua concentração na água, seus impactos no uso da água e seus efeitos no transporte de outros poluentes.

Dentro do ciclo completo do processo erosivo-sedimentológico, menciona-se que as conseqüências da erosão, sob o ponto de vista da perda de solo, é assunto bastante discutido e de suma importância em termos de degradação ambiental. Apesar do estudo da erosão do solo ser muito recente se comparado à grande maioria das ciências agrícolas (ane et al., 1992), a pesquisa sobre erosão vem sendo desenvolvida intensivamente sob vários pontos de vista em todas as partes do mundo, isto é, o tema erosão vem sendo pesquisado no sentido de produzir conhecimento técnico-científico dentro de áreas como hidrologia, geomorfologia, pedologia, agronomia, entre outras. 
Convém salientar que nenhum método de pesquisa em erosão possui abrangência o suficiente para ser utilizado exclusivamente e fornecer resultados sólidos e amplos para tomada de decisões em atividades conservacionistas e/ou de reabilitação de áreas degradadas pelo processo erosivo (Lane et al., 1992). Ou seja, são métodos de abrangência limitada e alguns deles quantificam apenas parte do processo erosivo, o qual é formado por uma complexa interação de vários fatores climáticos, pedológicos, antropológicos e de outras naturezas, sendo o ideal o uso de métodos que se complementam e, juntos, possibilitam uma compreensão global mais próxima da realidade. Segundo Tucci (1993), trata-se de uma metodologia muito complexa, da qual não se pode esperar resultados muito precisos.

Segundo James \& Burges (1982), modelos matemáticos são largamente empregados na predição do processo erosivo, tanto para o planejamento conservacionista (preventivo) como no seu controle. A principal vantagem da aplicação de modelos reside na possibilidade do estudo de vários cenários diferentes, tais como os piores cenários possíveis e diferentes tipos de manejo e práticas conservacionistas, com baixo custo e de forma rápida. Contudo, para que se tenha sucesso na aplicação de modelos de predição de erosão no planejamento de uso da terra ou controle do processo erosivo, devese levar em conta critérios importantes que dizem respeito à sua aplicabilidade (erosão em vertentes, em voçorocas, aporte de sedimentos em bacias, entre outros), a estrutura do modelo aos dados disponíveis e ao custo de sua obtenção, entre outros fatores.

Modelos de erosão do solo são descrições matemáticas usadas para representar os processos erosivos. Eles são utilizados para o dimensionamento de estruturas de controle de erosão, avaliação de práticas de manejo da terra e avaliação e planejamento ambiental. Segundo Cochrane \& Flanagan (1999), infelizmente é muito dispendioso e impraticável monitorar a erosão em toda bacia hidrográfica, por isso a necessidade de predizer a erosão com o uso de modelagem. De acordo com Lane et al. (1992), a estimativa da erosão é 
essencial para a conservação do solo e o controle de sua perda, e útil para prever impactos antes mesmo de uma determinada cultura ou prática agrícola ser adotada na área.

Dentre os muitos modelos que tentam exprimir a ação dos principais fatores que exercem influência nas perdas de solo pela erosão hídrica, o que trata o assunto de modo mais dinâmico, devido ao fato de superar parcialmente restrições climáticas e geográficas e ter uma aplicação generalizada, é a chamada "Equação Universal de Perda de Solo" (no inglês, Universal Soil Loss Equation-USLE) (Wischmeyer \& Smith, 1978). Para expressar a produção de sedimentos em uma bacia, a USLE é associada ao emprego de uma taxa de transferência (Sediment Delivery Ratio - SDR), que traduz a diminuição da produção bruta que pode ser estimada pela USLE, em decorrência dos depósitos ocorridos na bacia. Tanto a equação como a taxa de transferência (SDR) resultam de expressões empíricas, ainda limitadas no seu uso pelo fato de considerarem somente a produção anual de sedimentos (Tucci, 1993).

A USLE é a equação de estimativa de erosão mais conhecida e aplicada até hoje. Todos os modelos desenvolvidos após a USLE foram elaborados a partir dela, ou contêm parâmetros dessa equação (Renard \& Mausbach, 1990). O objetivo básico da USLE é de fazer previsão de médio e longo prazos de erosão do solo com base em séries de longos períodos de coleta de dados e daí então promover o planejamento de práticas conservacionistas para minimizar as perdas de solo em níveis aceitáveis (Larson et al., 1997).

A USLE foi inicialmente desenvolvida nos Estados Unidos em 1954 no "National Runoff and Soil Data Center", do Agricultural Research Service, na Universidade de Purdue. Após anos a equação evoluiu para ao modelo revisado por Wischmeier \& Smith (1978):

$$
A=\text { R.K.L.S.C.P }
$$


sendo:

$\boldsymbol{A}$ - perda de solo calculada por unidade de área, em t/ha.

$\boldsymbol{R}$ - fator erosividade da chuva (tm $\mathrm{mm} \mathrm{ha} \mathrm{h}^{-1} \mathrm{~h}^{-1}$ ): expressa numericamente a capacidade da chuva esperada em uma dada localidade de causar erosão em uma área sem cobertura (Bertoni \& Lombardi Neto, 1990).

Segundo Wischmeier \& Smith (1978), mantidos os outros fatores constantes, as perdas de solo pelas chuvas são diretamente proporcionais ao valor de um parâmetro de chuva identificado com "índice de erosão" (EI). Representa o efeito do impacto das gotas de chuva que golpeiam o solo, desprendendo as partículas pelo salpicamento e pela turbulência combinados com a enxurrada para transportar as partículas desprendidas. De acordo com Wischmeier \& Smith (1978), El é definido como o produto da energia cinética da chuva $(E)$ pela sua intesidade máxima em $30 \mathrm{~min}\left(\mathrm{l}_{30}\right)$, e é um termo que reflete como a energia total e o pico de intensidade são combinados em cada evento de chuva.

$$
K \text { - fator erodibilidade do solo (t ha ano } \mathrm{tm}^{-1} \mathrm{ha}^{-1} \mathrm{~mm}^{-1} \text { ): } \mathrm{O} \text { fator } K
$$
representa as diferenças na susceptibilidade natural dos solos à erosão (Tiwari et al., 2000). A erosão não é a mesma para todos os solos. Alguns solos são mais facilmente erodidos que outros, mesmo quando todos os outros fatores são os mesmos. Medidas diretas desse índice resultam em altos custos e demandam muito tempo para obter dados definitivos. Alguns métodos foram desenvolvidos para a determinação indireta da erodibilidade com base nas características físicas e químicas do solo, tais como o nomograma proposto por Wischmeier et al. (1971) ou métodos ainda mais simples, como o proposto por Williams (1995), citado por Neitsch et al. (2000). Para os solos brasileiros, porém, o método do nomograma apresenta algumas limitações, apontadas por diversos autores, entre eles Cogo (1978) e Henklain \& Freire (1983). 
LS - fator comprimento de rampa e grau de declive: a influência do relevo na erosão do solo é substancial, sendo que o fator declividade (S) e o fator comprimento de rampa $(\boldsymbol{L})$ são os que afetam a taxa de erosão hídrica. Moore \& Burch (1986) relatam que as formas de declive (côncava ou convexa), declividade e comprimento de rampa, em uma bacia hidrográfica, são importantes na determinação da perda de solo e relocação dentro da própria bacia. Uma área com a forma do declive côncava concentra o fluxo de escoamento aumentando a velocidade e, com isso, aumenta a capacidade de transporte de sedimentos. A forma do declive côncava pode ter um maior impacto na erosão. A forma do declive convexa produz taxas de erosão relativamente menores.

Como a USLE foi originalmente aplicada para rampas uniformes, uma de suas limitações é não considerar rampas não uniformes, não sendo aconselhável aplicá-la para áreas irregulares, por não considerar a deposição de sedimentos ao longo das encostas (tane et al., 1992). Esta é a grande limitação da utilização da USLE em bacias hidrográficas, pois ao analisar a declividade de uma encosta, verifica-se que geralmente ocorre desuniformidade no perfil longitudinal. A dinâmica das encostas, traduzida na forma de "complexo de rampa", atua diferentemente no tempo e no espaço. Os segmentos de rampa de forma côncava são zonas preferenciais àocorrência de processos erosivos, devido à convergência de segmentos, acarretando um maior número de descontinuidades entre colúvios e/ou colúvios e alúvios e dos fluxos de água, acelerando a ruptura entre materiais de diferentes características (Silva, 1988).

$\boldsymbol{C}$ - fator uso e manejo do solo: é a taxa de perda de solo durante um determinado estágio da cultura comparada àperda de solo na parcela padrão, durante o mesmo período (Tiwari et al., 2000). Para a determinação desse fator são considerados estágios definidos de desenvolvimento das culturas e suas influências na erosão do solo. O efeito das práticas cultural, como a rotação de 
culturas e o cultivo, é também descrito pelo fator $C$. Os efeitos das variações no uso e manejo da terra não podem ser avaliados independentemente, devido æ̀s diversas interações que ocorrem. Assim, uma cultura pode ser plantada continuamente em um mesmo local ou, então, em rotação com outras culturas. Seus restos podem ser removidos, deixados na superfície, incorporados próximos àsuperfície ou totalmente enterrados com o preparo do solo. Quando deixados na superfície, podem ser cortados ou mantidos como foram colhidos. Diferentes combinações dessas variáveis, provavelmente, apresentam diferentes efeitos nas perdas de solo (Bertoni \& Lombardi Neto, 1990).

Segundo Neitsch et al. (2000), a cobertura vegetal afeta a erosão por reduzir a energia efetiva das gotas de chuva. As gotas de chuva que foram interceptadas pela cobertura vegetal podem readquirir apreciável velocidade, mas irá ser muito menor do que a velocidade final se não tivessem sido interceptadas. A altura média de queda das gotas a partir da cobertura da vegetação e a densidade da vegetação irão determinar a redução na energia da chuva. Uma porcentagem de resíduos na superfície do solo é mais eficaz do que a mesma porcentagem de cobertura vegetal. Resíduos interceptam as gotas de chuva próxima à superfície, onde as gotas não têm possibilidade de readquirir velocidade de queda. Resíduos também obstruem o escoamento superficial, reduzindo sua velocidade e capacidade de transporte.

$\boldsymbol{P}$ - fator práticas conservacionistas: representa o efeito das práticas conservacionistas, tais como plantio em nível, terraceamento e plantio em faixas, na erosão do solo (Lane et al., 1992). O fator $P$ da USLE é a relação entre a intensidade esperada de tais perdas com determinada prática conservacionista e a intensidade quando a cultura está plantada no sentido do declive (morro abaixo) (Bertoni \& Lombardi Neto 1990). O fator $P$ está intimamente relacionado com os diferentes tipos de uso e manejo do solo. Segundo Neitsch et. al. (2000), plantios em contorno e terraceamento fornecem uma proteção quase completa contra a erosão de chuvas de baixa a moderada 
intensidade, mas pouca ou nenhuma proteção contra chuvas intensas e severas que causam "quebras" nas linhas contornadas. Plantios em contornos são mais eficientes em declividades variando entre 3\% e $8 \%$.

A USLE limita-se a dar estimativas somente de perdas de solo anuais médias e não estima nem o processo de deposição em vertentes côncavas e nem o transporte de sedimentos para fora de uma determinada área o que dificulta a sua aplicação na escala de bacias hidrográficas, pois estas com freqüência possuem relevo complexo, áreas de perda e deposição de sedimentos e erosão em sulcos (Renard et al., 1991; Kresnor et al., 1992).

Uma importante limitação da USLE como uma equação com base empírica $e^{\prime}$ não apresentar explicitamente os processos hidrológicos fundamentais na erosão. Por exemplo, o efeito do escoamento superficial, que é um componente importante de modelos hidrológicos, não é diretamente representado nessa equação. Por outro lado, se fosse incluída tal variável na equação, esta ganharia extrema complexidade (Renard et al., 1991).

Segundo Chaves (1991), a crescente preocupação com problemas de assoreamento e poluição de cursos d'água e de reservatórios contribuiu para o desenvolvimento de modelos matemáticos que prevêem 0 aporte de sedimentos em pontos específicos da bacia hidrográfica. Um desses modelos, a equação universal de perda de solo modificada (MUSLE) (Williams, 1975), é particularmente adequado às condições brasileiras, devido à simplicidade de sua estrutura e ao número relativamente pequeno de parâmetros, facilitando a sua calibração e aplicação (Chaves, 1991),. A MUSLE foi criada a partir da USLE, sendo os fatores do modelo os mesmos da USLE, com exceção do fator $R$ (erosividade das chuvas), o qual foi substituído por fatores que contemplam os processos hidrológicos na bacia. A MUSLE prevê o aporte de sedimentos oriundos de pequenas e médias bacias hidrográficas, em determinado exutório da bacia (Chaves, 1991). Este, pode ser um talvegue, um córrego, ou um reservatório (Williams, 1975). Ao contrário da USLE, a MUSLE dispensa a utilização de relações empíricas adicionais de aporte de sedimentos, e é 
aplicável a eventos isolados, tornando sua previsão mais precisa (Williams \& Berndt, 1977).

Entretanto, para se trabalhar com a MUSLE, os fatores hidrológicos necessários à estimativa do aporte de sedimentos nem sempre são de simples obtenção, uma vez que para se chegar aos valores finais de cada um destes fatores, é necessário ter-se em mãos informações de outros fatores necessários para aplicação no cálculo do volume de runoff $(Q)$ e da vazão de pico $\left(q_{p}\right)$, tais como informações sobre o manejo, permeabilidade e umidade do solo, tempo de pico do hidrograma, entre outros, além daquelas necessárias que são de uso comum na USLE e na MUSLE (Chaves, 1995). A descrição da MUSLE é feita no item 3.1.5.1.

Modelos conceituais distribuídos que simulam os diversos processos em jogo no ciclo hidrossedimentológico foram, ou estão sendo, desenvolvidos para expressar os sedimentos produzidos por chuvas isoladas sobre uma bacia (Tucci,1993). O ANSWERS, o AGNPS e o SWAT são alguns deles. Esses modelos utilização a USLE como sub-modelo associada a uma propagação dos sedimentos, no escoamento superficial até a saída da bacia. A exceção é o SWAT, que utiliza a MUSLE para simular a produção de sedimentos.

No Brasil, vários modelos vêm sendo aplicados com o intuito de estimar as perdas de solo e o planejamento para fins conservacionistas, alguns adequando equações desenvolvidas no exterior para as características do local de uso da equação. Progressos importantes têm sido registrados com a união dos modelos de simulação com o geoprocessamento. 


\section{MATERIAL E MÉTODOS}

\subsection{Material}

\subsection{1 Área de Estudo}

\subsubsection{Localização geográfica}

A área selecionada escolhida para esse estudo foi a bacia hidrográfica do ribeirão dos Marins (BHRM), afluente do rio Piracicaba, localizada no município de Piracicaba, Estado de São Paulo, entre as latitudes $22^{\circ} 41^{\prime}$ e $22^{\circ}$ $51^{\prime}$ sul e longitudes $47^{\circ} 40^{\prime}$ e $47^{\circ} 45^{\prime}$ oeste, com uma área aproximada de 5973 ha ou $59,73 \mathrm{~km}^{2}$ (Figura 3).

\subsubsection{Clima}

O clima da região, segundo a classificação de Köppen, é do tipo mesotérmico, Cwa, isto é, subtropical úmido com estiagem no inverno, cujas chuvas do mês mais seco não atingem $30 \mathrm{~mm}$ e a temperatura do mês mais quente é superior a $22^{\circ} \mathrm{C}$, enquanto a do mês mais frio é inferior a $18^{\circ} \mathrm{C}$. $\mathrm{Na}$ Tabela 5 são apresentadas as médias mensais para as temperaturas máxima e mínima e o total mensal de precipitação de uma série histórica de 30 anos nas condições climáticas de Piracicaba, SP. 
Tabela 5. Temperaturas (média mensal) máxima e mínima e o total mensal de precipitação nas condições climáticas de Piracicaba, SP.

\begin{tabular}{lccc}
\hline Período & $\mathrm{T} \max .\left({ }^{\circ} \mathrm{C}\right)$ & $\mathrm{T} \min .\left({ }^{\circ} \mathrm{C}\right)$ & Precipitação $(\mathrm{mm})$ \\
\hline Janeiro & 30,4 & 19,0 & 224,5 \\
Fevereiro & 30,9 & 19,0 & 104,1 \\
Março & 30,4 & 18,0 & 143,2 \\
Abril & 28,3 & 15,5 & 63,6 \\
Maio & 25,9 & 12,3 & 52,2 \\
Junho & 25,0 & 10,2 & 44,0 \\
Julho & 25,5 & 9,8 & 27,2 \\
Agosto & 27,2 & 11,3 & 29,7 \\
Setembro & 27,8 & 13,6 & 63,9 \\
Outubro & 29,3 & 15,9 & 110,3 \\
Novembro & 29,8 & 17,2 & 130,4 \\
Dezembro & 29,8 & 18,5 & 201,0 \\
\hline
\end{tabular}

\subsubsection{Uso e cobertura do solo}

Atualmente, o uso do solo é representado em grande parte por canade-açúcar (Saccharum spp.) e pastagens (Brachiaria spp.). No alto Marins, ocorrem extensas áreas de canaviais com ausência quase total de mata ciliar. Teramoto (1995), em estudo realizado na bacia do Ribeirão dos Marins, comenta que a cana-de-açúcar é cultivada nas áreas de menor declividade, enquanto que as encostas mais íngremes são ocupadas com pastagem. Pequenas áreas de eucalipto (Eucalyptus spp.) são encontradas nas partes mais elevadas e em alguns fundos de vales, ao passo que a vegetação original quase inexistente, encontrando-se apenas alguns remanescentes em algumas grotas e nas margens do ribeirão dos Marins. 


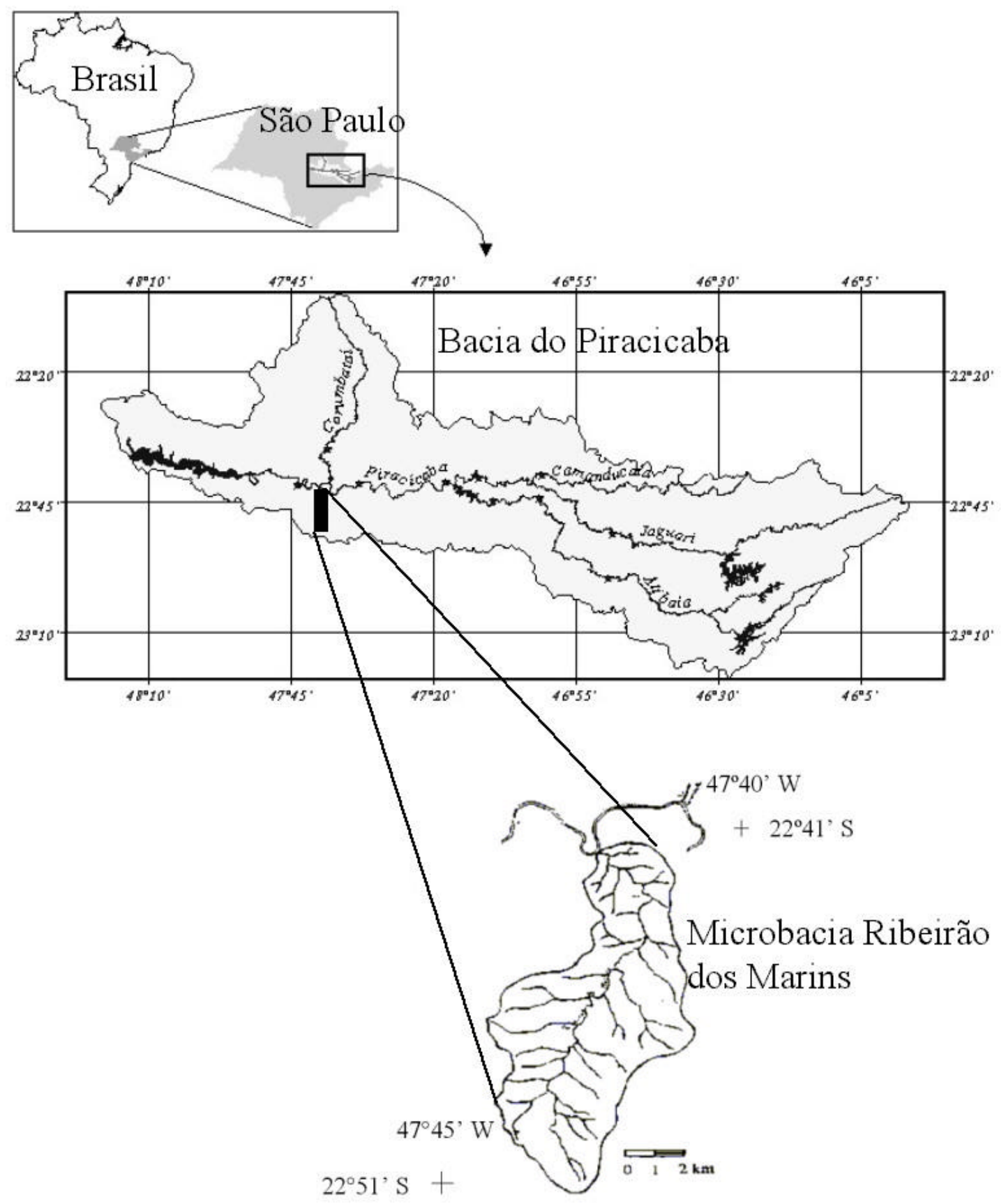

Figura 3 - Localização geográfica da área de estudo. 


\subsubsection{Geologia e geomorfologia}

A MHRM está inserida na bacia sedimentar do Paraná. Segundo IPT (1981), a maior parte do Estado de São Paulo está incluída nessa bacia, que é uma unidade geotectônica sobre a plataforma Sul-Americana. A persistente subsidência desta bacia permitiu a acumulação de grande quantidade de sedimentos (Teramoto, 1995).

As unidades predominantes na área são as Formações Pirambóia e Corumbataí. É sobre essas duas formações que está assentada a MHRM quase que em sua totalidade. Uma pequena porção de formação geológica do Holoceno aparece na região de confluência do Ribeirão dos Marins com o Rio Piracicaba.

A formação Pirambóia é caracterizada por depósitos aluviais, incluindo arenitos finos e esbranquiçados a médios avermelhados, sílticoargilosos, grãos polidos, subangulares e subarredondados com seixos de argila. Ocorre uma camada de $1 \mathrm{~m}$ a $2 \mathrm{~m}$ de espessura na porção mais inferior, de cor vermelha, areno-argilosa, com seixos de sílex (IPT, 1981).

A formação Corumbataí (IPT, 1981) é caracterizada por depósitos marinhos com estratificação plano paralela, predominando siltitos, folhelhos, arenitos finos em parte concrecionados por calcários, sílex, de coloração vermelha arroxeada na parte inferior e esverdeada na base, indicando ambiente deposicional oxidante. Sua espessura, em superfície, pode atingir valores da ordem de $250 \mathrm{~m}$.

A área apresenta relevo suavemente ondulado no topo. A partir daí, em direção ao ribeirão dos Marins, o relevo torna-se ondulado a fortemente ondulado. As colinas são estreitas formando esporões com lançantes longos, quase paralelos entre si, orientados no sentido do topo para o ribeirão. A declividade nessas colinas está em torno de 5\% a 10\% e o comprimento de rampa variando entre $500 \mathrm{~m}$ a $1000 \mathrm{~m}$. Estes lançantes são separados por 
vales escarpados em forma de "V", onde a declividade é superior a $30 \%$ (Teramoto, 1995).

\subsubsection{Solos}

De acordo com o mapa do levantamento pedológico semidetalhado do Estado de São Paulo, quadrícula de Piracicaba (Oliveira, 1999) e com o novo Sistema Brasileiro de Classificação de Solos (EMBRAPA, 1999), os solos ocorrentes na microbacia do ribeirão dos Marins são apresentados na Tabela 6.

Tabela 6. Solos ocorrentes na microbacia do ribeirão dos Marins.

Símbolo no mapa Classificação atual

(EMBRAPA)

Podzólicos Vermelho-Amarelos $\quad$ Alissolos

PV-7 Grupamento indiscriminado de Podzólicos Vermelho-Amarelos abruptos, A moderado e espesso, textura arenosa/média. Unidade Serrinha (Arenic Abruptic Paleudalt, Arenic Abruptic Paleudult).

PV-8 Grupamento indiscriminado de Podzólicos Vermelho-Amarelos abruptos, A moderado e espesso, textura arenosa/média, pouco profundos. Unidade Serrinha fase pouco profunda (Arenic Abruptic Paleudalf, Arenic Abruptic Paleudult).

PV-10 Grupamento indiscriminado de Podzólicos Vermelho-Amarelos eutróficos, A moderado, textura média/argilosa, pouco profundos. Unidade Manduca (Abruptic Paleudalf, Typic Paleudalf).

Latossolos Vermelho-Amarelos

Latossolos

LV-2 Latossolo Vermelho-Amarelo Álico, A moderado, textura média. Unidade Laranja Azeda (Typic Haplorthox). 
Tabela 6. Solos ocorrentes na microbacia do ribeirão dos Marins.

Litólicos

Neossolos

LI-3 Solo Litólico Eutrófico ou Distrófico, A moderado, proeminente ou chernozêmico, substrato sedimentos indiscriminados, do grupo Passa Dois (Typic Udorthent).

LI-5 Solo Litólico Eutrófico, A moderado ou chernozêmico, substrato arenitos das Formações Botucatu ou Pirambóia (Typic Udorthent e Lithic Hapludoll).

A seguir há uma breve descrição dos solos predominantes na microbacia dos Marins.

Latossolos - segundo Macedo (1994), os latossolos são solos com boas condições de drenagem, profundos, com teores de argila entre $15 \%$ e $90 \%$ e, segundo Vieira (1988), o teor de argila se dilui lentamente com a profundidade.

Vieira (1988) aponta ainda como características importantes destes solos: a transição gradual entre horizontes; ausência ou quase ausência de desenvolvimento estrutural, sendo que quando aparece, a estrutura é pouco desenvolvida, em geral maciça e apresenta-se com baixa capacidade de troca catiônica entre as argilas. Conforme a composição granulométrica (proporções de argila, silte e areia) são também classificados como: latossolo vermelhoescuro, textura média, por exemplo. Os latossolos são solos que, devido às suas características de estrutura, porosidade, permeabilidade e consistência, decorrentes da constituição de seus minerais e do relevo geralmente pouco acidentado, possuem elevada resistência à erosão. No entanto, tem-se observado que um manejo inadequado pode acarretar na formação de camadas compactadas, que diminuem significativamente a infiltração de água, aumentando os riscos de erosão (Macedo, 1994). 
Litólicos - ocorrem normalmente em regiões de relevo movimentado. Caracterizam-se como solos rasos, pedregosos, com horizonte $A$ assentado diretamente sobre o horizonte $\mathrm{C}$ ou sobre a rocha. Possuiem textura bastante variada (Macedo, 1994; Vieira, 1988). Esses solos possuem, segundo Bellinazzi Jr. et al. (1991), limitada capacidade de uso por possuirem alto risco à erosão, além das características anteriormente mencionadas.

Podzólicos - são solos de horizonte B textural, que apresentam um incremento de argila com a profundidade e distinta individualização de horizontes. Podem ser subdivididos em Podzólico Vermelho-Amarelo e Podzólico VermelhoEscuro, de fertilidade variada, dependendo da natureza do material de origem. Os perfis são bem drenados, moderadamente porosos, de textura média ou argilosa, com estrutura em blocos subangulares. No horizonte $\mathrm{Bt}$, podem apresentar cerosidade revestindo os agregados. Em geral, apresentam erosão moderada a forte, dependendo do relevo e da posição na paisagem. Cuidados especiais têm que ser tomados para o manejo destes solos, especialmente com aqueles que ocorrem em relevo acidentado, o que restringe sua utilização intensa (Macedo, 1994).

\subsubsection{Material cartográfico}

$\mathrm{Na}$ execução deste trabalho, foi utilizado o seguinte material cartográfico:

- cartas planialtimétricas do Plano Cartográfico do Estado de São Paulo, Secretaria de Economia e Planejamento, Coordenadoria de Ação Regional, Divisão de Geografia, 1 a edição, na escala 1:10.000: 
Folha

Santa Terezinha do Piracicaba

Bairro dos Marins

Bairro Volta Grande

Sete Barrocas

Mato Alto

Piracicaba V

Piracicaba III

Piracicaba II

Fazenda Pinheirinho

Saltinho
Nomenclatura

(SF-23-Y-A-IV-2-SO-C)

(SF-23-Y-A-IV-2-SO-E)

(SF-23-Y-A-IV-4-NO-A)

(SF-23-Y-A-IV-4-NO-D)

(SF-23-Y-A-IV-4-NO-E)

(SF-23-Y-A-IV-2-SO-D)

(SF-23-Y-A-IV-2-SO-F)

(SF-23-Y-A-IV-2-NO-B)

(SF-23-Y-A-IV-4-NO-D)

(SF-23-Y-A-IV-4-NO-F)
Ano

1979

1979

1978

1978

1977

1979

1979

1978

1978

1977

- Carta Pedológica Semidetalhada do Estado de São Paulo: Quadrícula de Piracicaba (SF-23-Y-A-IV) Governo do Estado de São Paulo, Secretaria de Economia e Planejamento, $1^{\text {a }}$ edição, 1989.

\subsubsection{Imagem de satélite}

Imagem do satélite SPOT-4, resolução espacial de 20 m, tomada em julho de 1998, com quatro bandas espectrais :

B1 (verde)

$(0,50-0,59 \mu \mathrm{m})$;

B2 (vermelho)

$(0,61-0,68 \mu \mathrm{m})$;

B3 (infravermelho próximo)

(0,79-0,89 $\mu \mathrm{m})$;

B4 (infravermelho médio)

$(1,58-1,75 \mu \mathrm{m})$. 


\subsubsection{Sistemas computacionais}

- Software ArcView v. 3.2; extensões, ArcView Spatial Analyst v. 1.1 e ArcView 3D Analyst v. 1.0 desenvolvidos pela Environmental Systems Research Institute (ESRI), Redlands, CA, EUA;

- interface ArcView-SWAT versão 2000, desenvolvida pelo Blackland Research Center da Texas Agricultural Experiment Station e USDA Agricultural Research Service;

- Software Idrisi v. 2.0 for windows.

- Software de digitalizacão TOSCA for DOS.

\subsection{Descrição do modelo SWAT}

O SWAT (Soil and Water Assessment Tool) é um modelo matemático que permite que diferentes processos físicos sejam simulados na bacia hidrográfica, com o objetivo de analisar os impactos das alterações no uso do solo sobre o escoamento superficial e subterrâneo, produção de sedimentos e qualidade da água, em bacias hidrográficas agrícolas não instrumentadas. Para satisfazer a estes objetivos o modelo: (i) é baseado em características físicas da bacia; (ii) usa dados de entrada normalmente disponíveis; (iii) é computacionalmente eficiente para operar sobre médias a grandes bacias $\left(>1.000 \mathrm{~km}^{2}\right)$; e (iv) é contínuo no tempo, sendo capaz de simular longos períodos (>100 anos) de forma a computar os efeitos das alterações no uso do solo.

É de domínio público, tendo suporte técnico do US Department of Agriculture, Agricultural Research Service no Grassland, Soil and Water Research Laboratory, em Temple, Texas, EUA. Embora o modelo opere em intervalos de tempo diários, ele é eficiente o bastante para simulações por muitos anos e seu objetivo não é simular eventos isolados. 
O SWAT incorpora as características de vários modelos do Agricultural Research Service (ARS), sendo um resultado direto do modelo SWRRB (Simulator for Water Resources in Rural Basins) (Williams et al., 1985; Arnold et al., 1990). Modelos específicos que contribuíram de forma significativa para o desenvolvimento do SWAT foram o CREAMS (Chemicals, Runoff, and Erosion from Agricultural Management Systems) (Knisel, 1980); GLEAMS (Groundwater Loading Effects on Agricultural Management Systems) (Leonard et al., 1987); e o EPIC (Erosion-Productivity Impact Calculator) (Williams et al., 1984).

Para o propósito da modelagem, a bacia pode ser dividida em subbacias. Cada sub-bacia pode ser parametrizada pelo SWAT usando uma série de Unidades de Resposta Hidrológica (Hydrologic Response Units - HRU's), as quais correspondem a uma única combinação de uso da terra e solos dentro da sub-bacia.

As HRU's são partes da sub-bacia que possuem uma única combinação de uso da terra/solo/manejo. Uma ou mais combinações de uso da terra/solo podem ser criadas para cada sub-bacia. Subdividir a bacia em áreas contendo combinações únicas, possibilita ao modelo refletir diferenças na evapotranspiração e outras condições hidrológicas para diferentes usos e solos. O escoamento é calculado para cada HRU e propagado para obter o escoamento total para a sub-bacia. Isso pode aumentar precisão das predições e fornecer uma melhor descrição física do balanço de água na bacia (Arnold et al., 1998).

Para gerar as HRU's em cada sub-bacia, um nível de sensibilidade é adotado eliminando as classes de uso da terra com área menor do que o valor arbitrado. O segundo passo controla a criação das HRU's com base na distribuição dos diferentes tipos de solo sobre os usos da terra selecionados. $O$ solo com área menor do que o nível de sensibilidade adotado (para solo), também é eliminado. Os processos representativos do modelo são apresentados na Figura 4. 


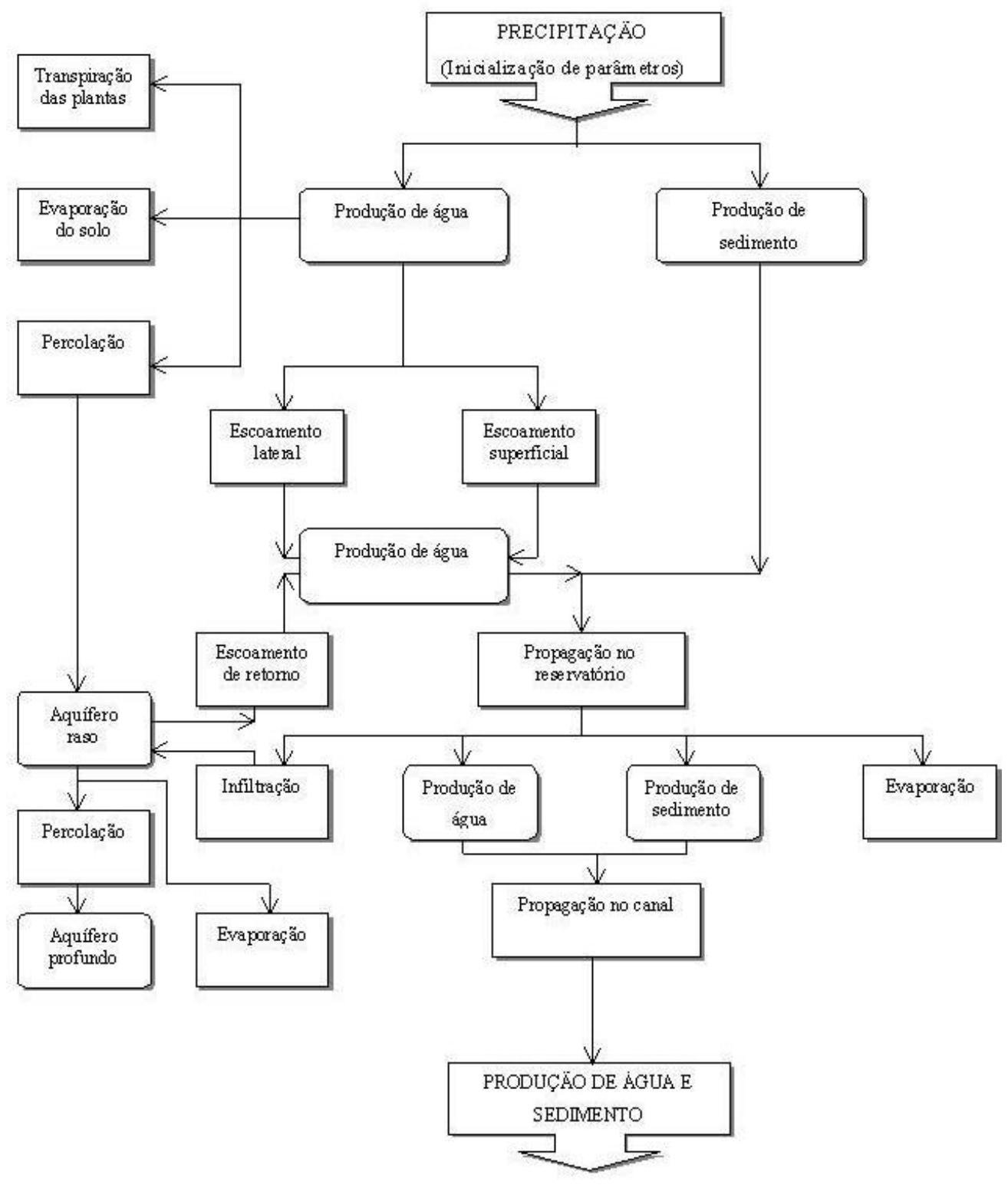

Figura 4 - Fluxograma de processamento do SWAT (modificado de King et al., 1996). 


\subsubsection{Componentes do modelo SWAT}

A estrutura do modelo hidrológico SWAT foi dividida em sete componentes: (i) hidrologia; (ii) clima; (iii) sedimentos; (iv) crescimento vegetal; (v) manejo agrícola; (vi) nutrientes; e (vii) pesticidas. A simulação hidrológica na bacia é separada em duas divisões. A primeira divisão é a fase terrestre do ciclo hidrológico. Essa fase controla a quantidade de água, sedimentos, nutrientes e pesticidas para o canal principal em cada sub-bacia. Nos itens subseqüentes são descritos apenas os componentes de interesse deste trabalho. Assim foi suprimido o módulo de produção de nutrientes e pesticidas. A segunda divisão é a fase de propagação (routing) da água no ciclo hidrológico, a qual pode ser definida como o movimento de água, sedimentos etc, através da rede de canais da bacia hidrográfica para a sua saída.

\section{A) Hidrologia}

O sistema hidrológico simulado pelo SWAT é composto de quatro volumes de controle: (i) reservatório superficial; (ii) reservatório subsuperficial; (iii) reservatório subterrâneo - aqüífero raso; e (iv) reservatório subterrâneo aqüífero profundo. A contribuição destes reservatórios para o escoamento superficial provém do escoamento lateral a partir do perfil de solo e do escoamento de retorno do aqüífero raso. O volume que percola do reservatório subsuperficial, através do perfil de solo, representa a recarga do aqüífero raso. A água que percola para o aqüífero profundo não retorna para o sistema.

A determinação do balanço hídrico é fundamental para a estimativa da infiltração, do escoamento superficial e da força de desprendimento pelo fluxo da água. Esse componente utiliza-se das informações dos componentes clima, crescimento vegetal e infiltração para a estimativa da evapotranspiração potencial e evaporação do solo e transpiração das plantas. A partir dessas informações o componente balanço hídrico determina a quantidade e o estado 
da água no solo diariamente para cada camada e calcula a percolação no perfil do solo.

No modelo SWAT a determinação da produção de água da bacia hidrográfica tem como base a equação do balanço hídrico:

$$
S W_{t}=S W+\sum_{t=1}^{t}\left(R_{i}-Q_{i}-E T_{i}-P_{i}-Q R_{i}\right)
$$

sendo:

$S W_{t}=$ conteúdo final de água no solo $(\mathrm{mm})$;

$S W=$ conteúdo de água no solo disponível para as plantas, definido como o conteúdo de água inicial menos o conteúdo de água no ponto de murcha permanente $(\mathrm{mm})$;

$t=$ tempo (dias);

$R_{i}=$ precipitação $(\mathrm{mm})$;

$Q_{\mathrm{i}}=$ escoamento superficial $(\mathrm{mm})$;

$E T_{i}=$ evapotranspiração $(\mathrm{mm})$;

$P_{i}=$ percolação $(\mathrm{mm}) ; \mathrm{e}$

$Q R_{i=}$-fluxo de retorno (ascensão capilar) (mm).

\section{B) Escoamento superficial}

É o fluxo que ocorre ao longo da inclinação da superfície. Usando chuvas diárias, o SWAT simula o volume do escoamento superficial para cada sub-bacia utilizando o Método da Curva Número, do Soil Conservation ServiceSCS (USDA-SCS, 1972):

$$
\begin{array}{ll}
Q=\frac{(R-0,2 S)^{2}}{R+0,8 S}, & \mathrm{R}>0,2 S \\
\mathrm{Q}=0,0, & \mathrm{R} \quad 0,2 S
\end{array}
$$


Sendo que,

Q é o runoff diário $(\mathrm{mm})$; $R$ é a chuva diária $(\mathrm{mm})$; e $S$ é o parâmetro de retenção. O parâmetro de retenção, $S$, varia: (a) na bacia, por causa do tipo de solo, uso da terra, manejo e declividade; e (b) com o tempo, por causa da variação do conteúdo de água no solo. $S$ é relacionado à $C N$ pela equação:

$$
S=254\left(\frac{100}{C N}-1\right)
$$

A escala da CN não é linear, variando entre 1 e 100. Estes valores extremos correspondem, respectivamente, a uma cobertura permeável até uma cobertura impermeável. Assim, para os valores de Curva Número são consideradas três condições:

$\mathrm{CN}_{1}$ : corresponde à Curva Número para a condição I de umidade, situação em que os solos estão secos;

$\mathrm{CN}_{2}$ : corresponde à Curva Número para a condição II de umidade, ou seja a situação média em que os solos apresentam a umidade da capacidade de campo;

$\mathrm{CN}_{3}$ : corresponde à Curva Número para a condição III de umidade, situação em que os solos estão saturados.

Para computar os valores corrigidos de $\mathrm{CN}_{1}$ e $\mathrm{CN}_{3}$, estes foram relacionados com o $\mathrm{CN}_{2}$ por meio das seguintes equações:

$$
\begin{aligned}
& C N_{1}=C N_{2}-\frac{20\left(100-C N_{2}\right)}{100-C N_{2}+\exp \left[2,533-0,0636\left(100-C N_{2}\right)\right]} \\
& C N_{3}=C N_{2} \exp \left[0,00673\left(100-C N_{2}\right)\right]
\end{aligned}
$$




\section{C) Percolação (P)}

A componente de percolação do SWAT usa uma técnica de propagação do armazenamento, combinado com um modelo de fluxo em fendas no solo para simular o escoamento através de cada camada de solo. Uma vez que a água percolou abaixo da zona das raízes (root zone), este volume é armazenado como água subterrânea ou surge como escoamento de retorno àjusante do ponto considerado. A quantidade de água que percola para a próxima camada é calculada pela equação:

$$
W_{\text {perc }, l y}=S W_{l y, \text { excess }} *\left(1-\exp \left[\frac{-\Delta t}{T T_{\text {perc }}}\right]\right)
$$

sendo,

$\mathrm{W}_{\text {perc,ly }}$ quantidade de água que percola para a próxima camada $(\mathrm{mm})$;

$\mathrm{SW}_{\mathrm{ly} \text {,excess }}=$ volume drenável de água na camada de solo $(\mathrm{mm})$;

$\Delta \mathrm{t}=$ duração do passo de tempo (h);

$\mathrm{TT}_{\text {perc }}=$ tempo de propagação através da camada i em $\mathrm{h}$.

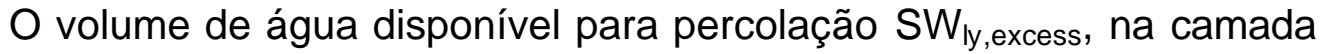
de solo é calculado:

$$
\begin{array}{lll}
S W_{l y, \text { excess }}=S W_{l y}-F C_{l y} & \text { se } & S W_{l y}>F C_{l y} \\
S W_{l y, \text { excess }}=0 & \text { se } & S W_{l y} \leq F C_{l y}
\end{array}
$$

sendo,

$\mathrm{SW}_{\mathrm{ly}}=$ conteúdo de água na camada do solo $(\mathrm{mm})$;

$\mathrm{FC}_{\mathrm{ly}}=$ conteúdo de água na camada de solo na capacidade de campo $(\mathrm{mm})$.

O tempo de propagação em cada camada de solo ( $\Pi_{\text {perc }}$ ) é calculado pela equação: 


$$
T T_{\text {perc }}=\frac{S A T_{l y}-F C_{l y}}{K_{s a t}}
$$

sendo,

$\mathrm{SAT}_{\mathrm{ly}}=$ quantidade de água na camada de solo quando completamente saturado $(\mathrm{mm})$;

$\mathrm{K}_{\text {sat }}=$ condutividade hidráulica saturada $(\mathrm{mm} / \mathrm{h})$.

\section{D) Clima}

O modelo requer dados diários de precipitação, temperaturas máxima e mínima do ar, radiação solar, velocidade do vento e umidade relativa. Os valores para esses parâmetros podem ser lidos a partir de registros de dados observados ou podem ser gerados pelo modelo.

No SWAT está incluindo o modelo gerador climático WXGEN (Sharpley \& Williams, 1990). O arquivo de entrada do gerador climático deve conter dados mensais necessários para gerar dados climáticos diários representativos para simular o clima da região. Esses dados climáticos diários são gerados pelo modelo em duas situações: quando é especificado que os dados irão ser gerados, ou quando algum dado está faltando.

\section{E) Sedimentos}

A erosão causada pela chuva é estimada com a Equação Universal de Perda de Solos Modificada (Modified Universal Soil Loss Equation - MUSLE) (Williams \& Berndt, 1977). A MUSLE é a versão modificada da USLE desenvolvida por Wischmeier \& Smith (1978). Enquanto a USLE prediz a erosão anual média em função da energia da chuva, a MUSLE eq. (23) utiliza a quantidade de escoamento para simular a erosão e a produção de sedimentos, representando a energia usada no destacamento e transporte de sedimentos. A substituição resulta em um número de benefícios (Neitsch, 2000): a precisão do 
modelo é aumentada; a necessidade de razão de transporte (delivery ratio) é eliminada e permite a equação ser aplicada para eventos de chuva individuais.

$$
\text { sed }=11,8 *\left(Q_{\text {surf }} * q_{\text {peak }} * \text { área } a_{\text {hru }}\right)^{0,56} * K_{\text {USLE }} * C_{\text {USLE }} * P_{U S L E} * L S_{U S L E}
$$

sendo que:

sed é a produção de sedimentos em um dado dia (ton); $Q_{\text {surf }}$ é o volume de escoamento superficial $(\mathrm{mm}) ; q_{\text {peak }}$ é a vazão de pico do escoamento $\left(\mathrm{m}^{3} / \mathrm{s}\right)$; área $_{h r u}$ é a área da HRU (ha); $K_{U S L E}$ é o fator erodibilidade do solo; $C_{U S L E}$ é fator de manejo e cobertura do solo; $P_{U S L E}$ é o fator práticas conservacionistas; e $L S_{U S L E}$ é o fator topográfico. O procedimento para o cálculo do escoamento superficial foi descrito no item 2.4 da Revisão Bibliográfica.

Os fatores da USLE foram discutidos no item 2.5 da Revisão Bibliográfica. Como a cobertura vegetal varia durante o ciclo de crescimento da cultura, o SWAT atualiza o fator $C$ diariamente, usando a eq. (24):

$$
C_{U S L E}=\exp \left\{\left[\ln (0,8) \operatorname{In}\left(C_{U S L E, m m}\right)\right] * \exp \left(-0,00115 * r s d_{\text {surf }}\right)+\ln \left(C_{U S L E, m m}\right)\right\}
$$

Sendo, $C_{U S L E}$ o valor mínimo para o fator uso-manejo do solo para a cobertura e $\mathrm{rsd}_{\text {surf }}$ a quantidade de resíduo na superfície do solo $(\mathrm{kg} / \mathrm{ha})$. O fator $C$ mínimo pode ser estimado a partir de um fator $C$ anual médio pela eq. (25) (Neitsch et. al., 2000).

$$
C_{U S L E}=1,463 \ln \left(C_{U S L E, a a}\right)+0,1034
$$

Sendo que:

$C_{\text {USLE }}$ é o fator $C$ mínimo para a cobertura e $C_{U S L E, a a}$ é o fator $C$ anual médio da cobertura. 


\section{F) Vazão de pico}

É a vazão máxima que ocorre com um dado evento de chuva. A vazão de pico é um indicador da força erosiva das chuvas intensas e é usada no cálculo da perda de sedimentos. O SWAT calcula a vazão de pico com o Método Racional Modificado:

$$
Q_{\text {peak }}=\frac{\alpha_{t c} \cdot Q_{\text {surf }} \cdot A}{3,6 . t_{\text {conc }}}
$$

sendo,

$Q_{\text {peak }}=$ vazão de pico do escoamento $\left(\mathrm{m}^{3} / \mathrm{s}\right)$;

$\alpha_{t c}=$ parâmetro adimensional que expressa a fração da chuva total que ocorre durante o tempo de concentração da bacia;

$Q_{\text {surf }} .=$ escoamento superficial $(\mathrm{mm})$;

$A=$ área da sub-bacia $\left(\mathrm{km}^{2}\right)$;

$t_{\text {conc }}=$ tempo de concentração da sub-bacia (h); e

$3,6=$ fator de conversão de unidade.

O Método Racional é fundamentado na suposição de que, se uma chuva de intensidade $i$ inicia instantaneamente e continua indefinidamente, a vazão de pico do escoamento irá aumentar até o tempo de concentração, $t_{\text {conc }}$, quando toda a sub-bacia estará contribuindo para o fluxo na saída. No Método Racional modificado, a vazão de pico do escoamento é função da proporção diária da precipitação que cai durante $0 t_{c o n c}$ da sub-bacia, do volume de escoamento superficial diário e do tempo de concentração da sub-bacia (Neitsch, 2000). 


\section{G) Tempo de concentração $\left(t_{\text {conc }}\right)$}

O $t_{\text {conc }}$ é calculado pela soma do tempo que a água flui na superfície a partir do ponto mais distante na sub-bacia até atingir um canal, mais o tempo de percurso no canal até atingir a saída da sub-bacia:

$$
t_{\text {conc }}=t_{c s}+t_{c c}
$$

sendo,

$t_{\text {conc }}=$ tempo de concentração na sub-bacia $(h)$;

$\mathrm{t}_{\mathrm{cs}}=$ tempo de concentração na superfície $(\mathrm{h})$;

$\mathrm{t}_{\mathrm{cc}}=$ tempo de concentração no canal $(\mathrm{h})$.

O tempo de concentração na superfície, $t_{c s}$, é calculado usando a seguinte equação:

$$
t_{c s}=\frac{L_{s l p}^{0,6} * n^{0,6}}{18 * s l p^{0,3}}
$$

sendo,

$$
\begin{aligned}
& L=\text { comprimento de rampa }(\mathrm{m}) ; \\
& n=\text { coeficiente de rugosidade de Manning (adimensional); } \\
& s l p=\text { declividade média na sub-bacia }(\mathrm{m} / \mathrm{m}) .
\end{aligned}
$$

Para o cálculo do tempo de concentração no canal, $t_{c c}$, o SWAT utiliza a seguinte equação:

$$
t_{c c}=\frac{0,62 * L * n^{0,75}}{A^{0,125} * s p_{c h}^{0,375}}
$$

sendo,

$L=$ comprimento do canal a partir do ponto mais distante da sub-bacia até a saída $(\mathrm{km})$;

$n$ = coeficiente de rugosidade de Manning para o canal (adimensional); 


$$
\begin{aligned}
& A=\text { área da sub-bacia }\left(\mathrm{km}^{2}\right) \\
& s l p=\text { declividade do canal }(\mathrm{m} / \mathrm{m}) .
\end{aligned}
$$

O SWAT estima a fração da chuva, $\alpha_{t c}$ que ocorre durante $t_{\text {conc }}$, como uma função da fração da chuva intensa de 30 min.

$$
\boldsymbol{\alpha}_{t c}=1-\exp \left[2 * t_{c o n c} * \ln \left(1-\boldsymbol{\alpha}_{0,5}\right)\right]
$$

sendo,

$$
\begin{aligned}
& t_{\text {conc }}=\text { tempo de concentração da sub-bacia }(\mathrm{h}) ; \mathrm{e} \\
& \alpha_{0,5}=\text { fração da chuva intensa de } 30 \mathrm{~min} .
\end{aligned}
$$

A chuva intensa de 30 min é calculada a partir da distribuição triangular, usando dados de precipitação diária e a maior chuva intensa de 30 min ocorrida em um dado mês. A chuva intensa de 30 min é calculada somente para os dias em que o escoamento superficial tenha sido gerado. A distribuição triangular usa um dos dois grupos de equações para gerar a fração da chuva intensa de 30 min:

$$
\begin{aligned}
& \text { se } r n d_{1} \leq\left(\frac{\alpha_{0,5 m o n}-\alpha_{0,5 L}}{\alpha_{0,5 U}-\alpha_{0,5 L}}\right) \text {, então, } \\
& \alpha_{0,5}=\alpha_{0,5 l}+\left[r n d_{1} *\left(\alpha_{0,5 U}-\alpha_{0,5 L}\right) *\left(\alpha_{0,5 m o n}-\alpha_{0,5 L}\right)\right]^{0,5} \\
& \text { se } r n d_{1}>\left(\frac{\alpha_{0,5 m o n}-\alpha_{0,5 L}}{\alpha_{0,5 U}-\alpha_{0,5 L}}\right) \text {, então, } \\
& \alpha_{0,5}=\alpha_{0,5 U}-\left(\alpha_{0,5 U}-\alpha_{0,5 m o n}\right) *\left[\frac{\alpha_{0,5 U}\left(1-r n d_{1}\right)-\alpha_{0,5 L}\left(1-r n d_{1}\right)}{\alpha_{0,5 U}-\alpha_{0,5 m o n}}\right]^{0,5}
\end{aligned}
$$

sendo,

$\alpha_{0,5 \text { mon }}=$ é a fração de chuva de 30 min máxima média para o mês; $r n d_{1}=$ um número aleatório gerado pelo modelo a cada dia; 
$\alpha_{0,5 L}=$ limite inferior da distribuição triangular $(=0,02083) ;$

$\alpha_{0,5 U}=$ limite superior da distribuição triangular.

$$
\alpha_{0,5 U}=1-\exp \left(\frac{-125}{R_{d a y}+5}\right)
$$

sendo,

$$
R_{d a y}=\text { precipitação em um dado dia. }
$$

A fração de chuva de 30 min máxima média para o mês, $\alpha_{0,5 \text { mon }}$, é calculada pela equação:

$$
\alpha_{0,5 m o n}=a d j_{0,5 \alpha}\left[1-\exp \left(\frac{R_{0,5 s m(m o n)}}{\mu_{m o n} * \ln \left(\frac{0,5}{y r s * d a y s_{\text {wet }}}\right)}\right)\right]
$$

sendo:

$a d j_{0,5 \alpha}=$ fator de ajuste;

$R_{0,5 \mathrm{sm}(\mathrm{mon})}=$ chuva máxima de 30 min para um dado mês;

$\mu_{m o n}=$ chuva diária média para o mês $(\mathrm{mm})$;

yrs = número de anos de dados de chuva usado para obter valores de chuvas intensas de 30 min máximas mensais;

days $_{\text {wet }}=$ número de dias de chuva no mês.

$$
R_{0,5 \text { sm(mon })}=\frac{R_{0,5 x(m o n-1)}+R_{0,5 x(m o n)}+R_{0,5 x(m o n+1)}}{3}
$$

sendo,

$\mathrm{R}_{0,5 \mathrm{x}}=$ chuva extrema de 30 min para o mês especificado. 


\section{H) Crescimento vegetal}

As condições de cobertura vegetal e de resíduos culturais são vitais para a estimativa do desprendimento e transporte de partículas do solo. O SWAT estima diariamente o crescimento de plantas usando uma versão simplificada do modelo de crescimento de planta, o EPIC (Williams et al., 1984). Como no EPIC, o SWAT utiliza-se dos conceitos de desenvolvimento fenológico da planta com base na unidade de calor acumulada diariamente (graus dias), índice de colheita e biomassa potencial. O crescimento da planta pode ser inibido pelo estresse devido a temperatura, água e nutrientes. O SWAT simula crescimento de culturas anuais e perenes.

\section{I) Manejo agrícola}

O principal objetivo da modelagem ambiental é avaliar o impacto das atividades antrópicas sobre um sistema. O centro para essa avaliação é especificar as práticas de manejo do solo e da água na bacia hidrográfica. $O$ componente manejo agrícola fornece submodelos que simulam os sistemas de cultivo, plantio, irrigação, aplicação de fertilizantes e pesticidas, colheita e pastoreio.

\section{J) Propagação no canal}

A propagação no canal consiste de: (i) propagação da vazão líquida e (ii) propagação da vazão sólida. Uma descrição detalhada dos componentes do método de propagação pode ser vista em Arnold et al. (1995). 


\section{K) Propagação da vazão líquida no canal}

A propagação da água através da rede de canais é feita pelo método do armazenamento variável, desenvolvido por Williams (1969) e usado nos modelos HYMO (Williams, 1975) e ROTO (Arnold et al., 1995). O método é uma variação do modelo da onda cinemática (Neitsch et al., 2000).

A propagação é realizada em passo de tempo diário e não requer cálculos interativos, fazendo com que o modelo seja eficiente para simular tempos longos (50-100 anos) sobre médias a grandes bacias (1.000 à 10.000 $\mathrm{km}^{2}$ ). Os dados requeridos pelo modelo incluem o comprimento, declividade, profundidade, declividade lateral e " $n$ " do canal, e declividade e " $n$ " da margem de inundação. A taxa de escoamento e a velocidade média são calculados usando a equação de Manning e o tempo de propagação é computado pela divisão do comprimento do canal pela velocidade. O fluxo a partir do canal é também ajustado para a perda por transmissão, evaporação e fluxo de retorno (Arnold et al., 1998).

\section{L) Propagação da vazão sólida no canal}

O transporte de sedimentos na rede de canais é uma função de dois processos, deposição e degradação, operando simultâneamente. O componente de deposição é baseado na velocidade de queda e o componente de degradação tem como base o conceito de força do escoamento definido por Bagnold (1977).

O conceito de força do escoamento é usado para predizer a degradação na propagação no canal. Bagnold (1977) definiu a força do escoamento como um produto da densidade da água, taxa de escoamento e a declividade da superfície da água. Williams (1980) usou a definição de Bagnold (1977) da força do escoamento para desenvolver um método para determinar a degradação, como uma função da declividade do canal e a velocidade. $\mathrm{Na}$ 
versão atual do SWAT (2000), as equações têm sido simplificadas e a máxima quantidade de sedimentos que pode ser transportada a partir de um segmento do canal é uma função da velocidade da vazão de pico no canal (Neitsch et al., 2000).

A descrição completa do modelo pode ser encontrada em Arnold et al. (1998) e Neitsch et al. (2000).

\subsubsection{Entrada de dados no SWAT}

A entrada de dados no SWAT (planos de informação cartográficos Pl's e dados alfanuméricos) é realizada via uma interface apropriada. Os Pl's necessários são: o Modelo Numérico do Terreno (MNT); solos; e uso da terra. Uma interface (Di Luzio et al., 2001) foi desenvolvida entre o SWAT e o SIG ArcView ${ }^{\circledR}$. A interface automaticamente subdivide a bacia em sub-bacias a partir do MNT, e então extrai os dados de entrada a partir dos Pl's e do banco de dados relacionais para cada sub-bacia. A interface permite que as saídas do modelo sejam exibidas utilizando-se dos mapas, gráficos e tabelas do ArcView®. Uma apresentação do método e dos procedimentos pode ser vista na Figura 5. 


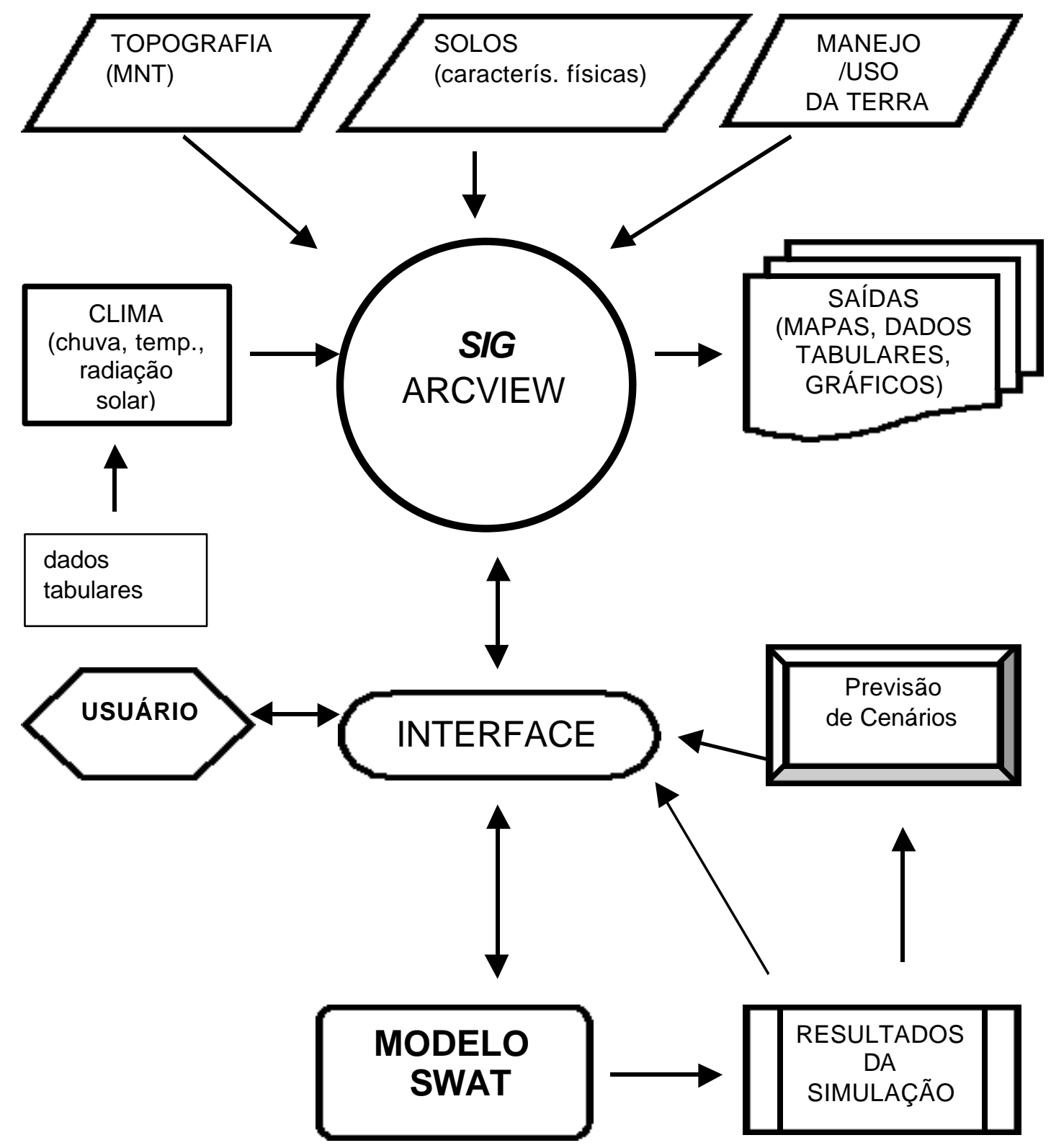

Figura 5 - Procedimentos para geração da base de dados e simulações do modelo SWAT via SIG. 


\subsection{Métodos}

\subsubsection{Seleção da área de estudo}

O primeiro motivo para a seleção dessa microbacia, é que ela faz parte do projeto: "Implantação de Posto Hidrossedimentométrico para Pequenas Bacias Hidrográficas" que tem como objetivo testar tecnologia para a implantação de estações hidrossedimentométricas fixas, em pequenas bacias hidrográficas, o que possibilitou a realização do trabalho, devido à disponibilidade dos dados. Outras estações estão sendo implantadas no Estado de São Paulo e fazem parte da Rede Hidrológica Básica do Estado de São Paulo, operada pelo Departamento de Águas e Energia Elétrica (DAEE) e o Centro Tecnológico de Hidráulica e Recursos Hídricos (CTH)/USP. O segundo motivo é que a BHRM é um exemplo de área problema quanto àocorrência de usos competitivos (agrícola $\mathrm{x}$ urbano) e degradação ambiental decorrente do uso agrícola intensivo (erosão acelerada devido à sobreutilização) (Weill et al. 1997). Além de ser historicamente considerada o "cinturão verde" do município de Piracicaba, o que ressalta a importância da disponibilidade dos recursos hídricos em qualidade e quantidade.

\subsubsection{Geração dos Planos de Informação (PI's)}

\subsubsection{Geração do Modelo Numérico do Terreno (MNT)}

As curvas de nível foram digitalizadas das cartas topográficas na escala de 1:10.000; espaçadas de $5 \mathrm{~m}$ em $5 \mathrm{~m}$, no software de digitalização TOSCA (extensão vec). No Idrisi, o arquivo com extensão vec foi exportado para o formato dxf. As curvas de nível no formato dxf foram interpoladas no ArcView utilizando a extensão 3D Analyst e o modelo de interpolação TIN (Triangular irregular Network). O resultado da interpolação foi convertido para o 
formato raster com resolução de $20 \mathrm{~m}$. Tal resolução do pixel foi definida em função da resolução da imagem de satélite. A digitalização foi feita utilizando como base o sistema de coordenadas "Universal Transversa de Mercador" (UTM).

\subsubsection{Uso da terra}

O plano usa da terra foi obtido a partir da retificação e da classificação da imagem do satélite SPOT. A retificação de uma imagem consiste em reorganizar os seu pixels em relação a um determinado sistema de projeção cartográfica. Essa correção foi realizada por meio da técnica de reamostragem dos pixels da imagem. A reamostragem implica na reformatação da cena em uma base cartográfica. As imagens foram retificadas utilizando cartas-base no sistema UTM, na escala de 1:10.000. Estabeleceram-se pontos de controle terrestre facilmente localizados nas cartas e na cena a ser retificada. Desse modo, criou-se um arquivo de correspondência no sistema Idrisi. Em continuação, foi feito um ajuste linear da superfície pelo método do vizinho mais próximo no Idrisi e assim se obteve, finalmente, a imagem georreferenciada, convertida no sistema UTM. Com a imagem georreferenciada criou-se uma composição falsa cor RGB; R (Red - B2), G (Green - B3) e B (Blue - B4).

Após ter sido georreferenciada, a imagem foi classificada no Idrisi utilizando-se a classificação supervisionada. A classificação supervisionada é o procedimento mais usado para análise quantitativa e nela o usuário seleciona áreas de treinamento pertencentes à classes desejadas. $O$ usuário treina $O$ analisador de imagens, deixando a ele a tarefa de localizar todos os demais pixels pertencentes às classes anteriormente definidas, baseado em algumas regras estatísticas pré-estabelecidas (Valério Filho, 1994).

$\mathrm{Na}$ fase de classificação, quando os atributos do padrão a ser classificado são mostrados ao classificador, este é associado àmesma classe apresentada na fase de treinamento. A classificação dos pontos só ocorre se os 
atributos daquela classe estiverem entre os limites encontrados na fase anterior, para um dos atributos (Crósta, 1993).

Entre os algoritmos de classificação supervisionada, e empregado nesse trabalho, o método de Máxima Verossimilhança (MaxVer) é o mais utilizado nas análises que envolvem o mapeamento de uso e cobertura do solo, devido àqualidade de seus produtos (Valério Filho, 1995).

As amostras de treinamento foram coletadas para 6 classes de cobertura do solo. As áreas urbanas, apesar de estarem localizadas na parte inferior da MHRM, foram excluídas da classificação com o objetivo de aumentar o desempenho do classificador, pois apresentaram respostas espectrais similares aos alvos de interesse da área agrícola. O limite da área urbana foi digitalizado por meio de interpretação visual da imagem na tela do computador; posteriormente, os polígonos resultantes foram rasterizados e utilizados como máscara.

A última etapa da classificação foi a avaliação da exatidão do mapeamento. Tal avaliação foi feita por meio da geração de pontos aleatórios no mapa para serem verificados no campo e comparados com a imagem classificada. Pontos de amostragem aleatoriamente estratificados foram gerados através do módulo SAMPLE do Idrisi e verificados no campo com o auxílio de fotografias aéreas e receptor Global Positioning System (GPS). Eastman (1995) recomenda a amostragem aleatória estratificada, cujo cálculo do tamanho amostral segue a eq. (36):

$$
\begin{aligned}
& N=\frac{Z^{2} * p * q}{e^{2}} ; \mathrm{e} \\
& A=\frac{N}{a}
\end{aligned}
$$

sendo:

$\mathrm{N}=$ número de amostras; 
$Z$ = valor da função de distribuição acumulada da normal padrão relativo a uma área igual a $1-\alpha / 2$;

$\mathrm{p}=$ exatidão de classificação mínima desejada;

$q=100-p$

e = erro máximo permissível;

$\mathrm{A}=$ número de amostras para a área de estudo; e

$\mathrm{a}=$ área de estudo (proporção).

A definição da exatidão mínima desejada para o mapeamento seguiu as recomendações de Anderson et al. (1979). Assim, adotou-se a exatidão mínima desejada de $85 \%$ e um erro máximo de estimativa de 0,05 , resultando num tamanho de 49 pontos amostrais para a imagem total e 27 pontos dentro dos limites da microbacia.

Posteriormente, a classificação supervisionada foi confrontada com os pontos de campo por meio do índice Kappa, que consiste de uma análise multivariada discreta tendo por base uma matriz de erro, também chamada de matriz de confusão ou de contingência (Ponzoni \& Almeida, 1996). O Índice Kappa é uma forma de testar se as diferenças em duas imagens são devido ao acaso ou se realmente discordam. O índice Kappa é calculado de acordo com Hudson \& Hamm (1987):

$$
K=\frac{\theta_{1}-\theta_{2}}{1-\theta_{2}}
$$

sendo:

$$
\begin{aligned}
\boldsymbol{\Theta}_{1} & =\frac{\sum_{i=1}^{r} \mathrm{X}_{i i}}{N} \\
\boldsymbol{\Theta}_{2} & =\frac{\sum_{i=1}^{r} \mathrm{X}_{i+} * \mathrm{X}_{+i}}{N^{2}}
\end{aligned}
$$


$r$ = dimensão da matriz quadrada;

$\mathrm{X}_{i i}=$ número de observações na linha i e coluna i que se refere à diagonal principal;

$\mathrm{X}_{i+}$ e $\mathrm{X}_{+i}=$ os totais marginais da linha i e coluna $\mathrm{i}$, respectivamente; $\mathrm{e}$ $\mathrm{N}=$ número total de observações da matriz de erros.

Landis \& Koch (1977) propuseram uma tabela para avaliação dos valores obtidos de Kappa. Assim o valor de Kappa encontrado foi analisado de acordo com a Tabela 7.

Tabela 7. Classes de qualidade do índice Kappa.

\begin{tabular}{cc}
\hline Valores de Kappa & Qualidade \\
\hline$<0,00$ & Péssima \\
$0,00-0,20$ & Ruim \\
$0,20-0,40$ & Razoável \\
$0,40-0,60$ & Boa \\
$0,60-0,80$ & Muito boa \\
$0,80-1,00$ & Exelente \\
\hline Fon
\end{tabular}

Fonte: Landis \& Koch (1977).

\subsubsection{Solos}

O mapa de solos foi digitalizado via software Tosca, gerando um arquivo no formato vetorial e importado para o software Idrisi para ser transformado para o formato "raster" com resolução de $20 \mathrm{~m}$. 


\subsubsection{Dados tabulares}

\subsubsection{Clima}

O modelo requer dados diários de precipitação, temperaturas máxima e mínima do ar, radiação solar, velocidade do vento e umidade relativa. Os dados diários de radiação solar, velocidade do vento e umidade relativa foram gerados pelo SWAT, utilizando o gerador climático WXGEN (Sharpley \& Williams, 1990), com base nos dados mensais da estação meteorológica da ESALQ/USP, localizada nas coordenadas geográficas 22 42'30" sul e 47 38'00" oeste. Dados diários de temperaturas máxima e mínima foram obtidos da mesma estação meteorológica e lidos pelo modelo no formato de tabela.

Os dados de precipitação, vazão e sedimentos são provenientes dos pluviógrafos e do posto hidrossedimentométrico, instalados na microbacia do ribeirão dos Marins, sob responsabilidade do Departamento de Águas e Energia Elétrica (DAEE) e do Centro Tecnológico de Hidráulica e Recursos Hídricos (CTH)/USP. Um dos pluviógrafos (D4118r) está instalado na porção superior da microbacia, nas coordenadas (UTM) 221379 m e 7473744 m. O outro pluviógrafo (D4116r) está instalado próximo ao posto hidrossedimentométrico, nas coordenadas (UTM) 221497 m e 7478241 m. A bacia de contribuição tem aproximadamente $22 \mathrm{~km}^{2}$ (2200 ha) (Figura 6).

O modelo oferece três opções para estimativa da evapotranspiração potencial: Hargreaves, Priestley-Taylor e Penman-Monteith. O método PenmanMonteith foi o utilizado nesse estudo. 


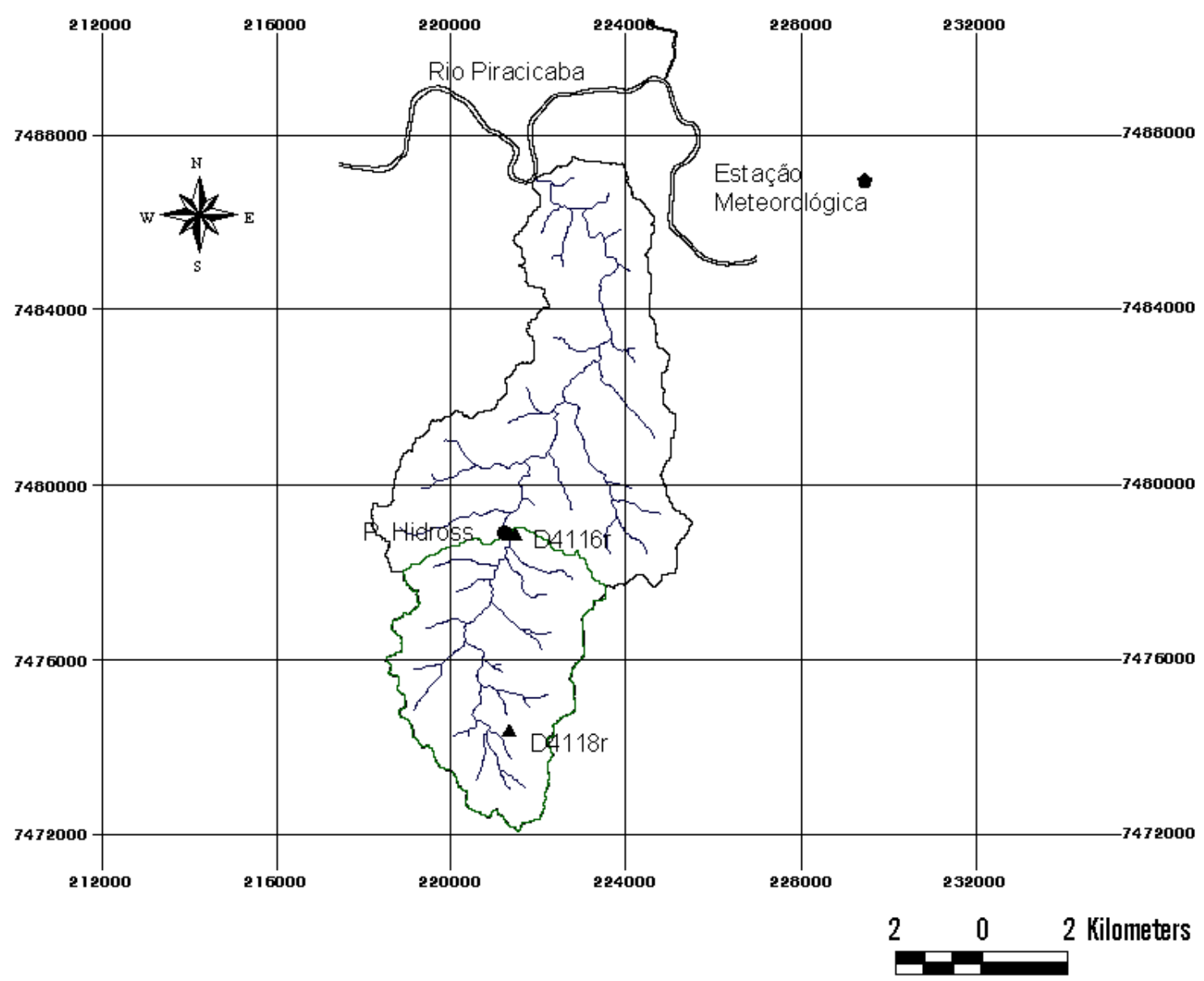

Figura 6 - Localização do posto hidrossedimentométrico e pluviógrafos na microbacia do ribeirão dos Marins

\subsubsection{Solos}

Os dados dos solos predominantes na MBHM foram retirados do Boletim Científico no 48 do Instituto Agronômico de Campinas (IAC) (Oliveira, 1999) e do banco de dados do Projeto PIRACENA (PIRACENA, 2001). Os dados foram digitados diretamente no banco de dados do modelo. $O$ banco de dados contém informações das características físico-hídricas (número de camadas, profundidade do limite inferior de cada camada à superfície, densidade do solo, capacidade de água disponível, condutividade hidráulica saturada e porcentagem das partículas do solo). O modelo associa os dados à 
categoria de solos especificada no plano de informação solos e cria o arquivo de entrada. Os solos da MBHM foram classificados como pertencentes aos grupos hidrológicos A, B e D, com base no trabalho de Lombardi Neto et al. (1989).

A condutividade hidráulica saturada (Ko) foi estimada com base nas relações das propriedades do solo desenvolvidas por Rawls \& Brakensiek (1985):

$$
K=10 \exp \left[\begin{array}{l}
19,52348 P O R-8,96847-0,028212 P C+0,00018107 P S^{2}- \\
0,0094125 P C^{2}-8,395215 P O R^{2}+0,077718 P S P O R- \\
0,00298 P S^{2} P O R^{2}-0,09492 P C^{2} P O R^{2}+0,0000173 P S^{2} P C+ \\
0,02733 P C^{2} P O R+0,001434 P S^{2} P O R-0,0000035 P C^{2} P S
\end{array}\right]
$$

sendo,

$$
\begin{aligned}
& \text { POR = porosidade do solo (\%); } \\
& \text { PS = porcentagem de areia; e } \\
& \text { PC = porcentagem de argila. }
\end{aligned}
$$

Esse utiliza a regressão polinomial dos componentes da textura do solo em porcentagem e da porosidade. A Ko é altamente variável, além de ser fortemente afetada pelas condições do solo como a compactação, a presença de macroporos e raízes das plantas. Isso introduz grande incerteza nas estimativas. Entretanto, ela é também fortemente dependente da escala, isto é, os valores medidos podem variar grandemente quando o tamanho da área varia, como em bacias hidrográficas (Timlin et al., 1996).

A capacidade de água disponível foi calculada de acordo com o método proposto por van den Berg et al. (2000):

$$
A W C=0,064+0,19 *(\arg \text { ila }+ \text { silte })^{2}-2,7 * 10^{2} * C_{\text {org }}^{2}
$$
sendo:

AWC = capacidade de água disponível em cada camada; 
$($ argila + silte $)=0$ conteúdo de argila e silte na camada do solo, em \%;

$C_{\text {org }}^{2}=$ conteúdo de carbono orgânico em cada camada $\left(\mathrm{kg} \mathrm{kg}^{-1}\right)$.

\subsubsection{Manejo}

O arquivo de manejo é utilizado para especificar as práticas de manejo do solo e da água dentro da bacia no período da simulação. Esse arquivo contém dados de plantio, colheita, aplicação de irrigação, aplicações de nutrientes e pesticidas e operações de cultivo. Para cada ano de operação de manejo, elas devem ser listadas em ordem cronológica iniciando em janeiro. Juntamente com os dados de clima e de solo, o modelo automaticamente simula a proteção oferecida ao solo pelas partes aéreas das plantas (cobertura vegetal) ao longo do ano e, depois de colhida a cultura, a deposição sobre o solo dos restos da cultura após a colheita.

Nesse arquivo foram incluídas as práticas de manejo para as culturas de cana-de-açúcar e pastagem. Cada arquivo incluiu operações como plantio, crescimento de plantas, colheita, resíduos após colheita, seqüências de preparo do solo e cultivo, aplicações de pesticidas e fertilizantes. Além dessas operações, foram incluídos a data, tipo de operação e quantidade aplicada (pesticidas e fertilizantes). Esses parâmetros de entrada das práticas em uso foram obtidos via comunicação pessoal na Cooperativa dos Plantadores de Cana-de-açúcar do Estado de São Paulo e no Departamento de Produção Animal da ESALQ/USP. Nenhuma irrigação foi considerada na microbacia para esses tipos de culturas.

\subsubsection{Outros dados}

Para cada sub-bacia o SWAT requer informações de áreas inundáveis (wetlands) e barragens; informações específicas da área superficial, fração da bacia que contribui para as áreas inundáveis ou barragens, o volume de 
escoamento necessário para enchimento até o vertedor principal ou emergencial, área superficial até o vertedor emergencial e volume inicial do reservatório e das áreas inundáveis.

Nenhum arquivo de entrada de barragens, áreas inundáveis e também de qualidade de água foi considerado para esse estudo devido a BHRM não ter áreas significativas ocupadas por uma dessas situações e também a grande quantidade de dados e dificuldade de obtenção.

\subsubsection{Definição do número de sub-bacias}

Um método adequado para determinar o número de sub-bacias pode auxiliar na definição do valor da área limite (thereshold) em modelos distribuídos como o SWAT. Na falta desse método, foram feitas simulações para vários níveis de discretização da MHRM, considerando as áreas limites de: 10 ha, 20 ha, 30 ha, 40 ha, 60 ha, 80 ha, 100 ha, 120 ha, 150 ha, e 200 ha.

As simulações foram feitas para duas situações. Na primeira, o uso da terra e o tipo de solo dentro da sub-bacia foram considerados como dominantes (uso da terra e solo de maior área na sub-bacia), gerando somente uma unidade de resposta hidrológica (HRU). Isso corresponde à área total da subbacia, já que os outros tipos de uso da terra e solo são eliminados. Na segunda situação, múltiplas HRU's foram determinadas, com o nível de sensibilidade variando de $10 \%$ para uso da terra e $20 \%$ para solo. Por exemplo, um nível de sensibilidade de $10 \%$ para uso da terra e $20 \%$ para solo, indica que as classes de uso da terra com área igual ou superior a $10 \%$ da área da sub-bacia é selecionada, e solos com área igual ou superior a $20 \%$ dentro de cada categoria de uso da terra selecionada irão formar uma HRU.

Caso se deseja incorporar uma maior complexidade de uso da terra e solo ocorrendo na bacia, deve-se definir o maior número de sub-bacias na bacia do que muitas HRU's dentro de poucas sub-bacias (Neitsch, 2000). Naturalmente, há uma exceção nessa regra. Um exemplo de exceção é em 
delimitação de sub-bacias que não conseguem capturar a diversidade de uso da terra sem a incorporação de muitas HRU's.

Posteriormente, os resultados das simulações dos níveis de discretização foram comparados com os dados de escoamento e de produção de sedimentos observados.

\subsubsection{Calibração do modelo}

O primeiro passo na calibração tradicional de modelos é separar a série temporal de dados medidos em dois períodos, um para calibração e o outro para validação do modelo. No período de calibração, as entradas do modelo são variadas até que um ajuste aceitável é obtido. O modelo é então rodado com os mesmos parâmetros de entrada para o período de validação e um ajuste é determinado (Arnold et al., 2000). Uma vez calibrados os parâmetros do modelo, este deve ser validado para situações semelhantes æ̀s que se quer aplicá-lo. Os resultados da verificação indicam se o modelo foi capaz de reproduzir a série de dados não usados em sua calibração.

A calibração total do modelo SWAT pode ser feita para: balanço de água e escoamento; sedimentos; nutrientes; e pesticidas. Como o objetivo do trabalho foi simular escoamento e sedimentos, somente essas duas variáveis foram calibradas.

Como todo teste de calibração depende da disponibilidade de dados observados, uma tentativa foi feita para uma calibração "grosseira" e não uma calibração detalhada do modelo e também não foi feito o teste de validação. Uma série histórica de dados é particularmente importante por causa da variabilidade natural de ano para ano nos fatores que afetam o transporte de água e sedimentos (Hill, 1986) e a imprecisão do modelo pode ser compensada com um maior período de tempo.

Durante o processo de calibração, quando o $\mathrm{D}$ atingisse um valor igual ou abaixo $\pm 5 \%$ entre os valores simulados e observados, o processo de 
calibração seria finalizado. Quatro variáveis foram selecionadas para calibração: (1) ALPHA_BF - Baseflow alpha factor ou constante de recessão do fluxo de base e definido como a taxa na qual a água subterrânea retorna para o rio; (2) AWC - Capacidade de água no solo disponível para as plantas; (3) CN Curva Número; e (4) SLSLOPE - comprimento de rampa. A calibração foi feita somente para o escoamento total. Nenhuma tentativa foi feita para calibrar especificamente o fluxo de base ou a recarga.

Para avaliar os dados simulados pelo modelo durante o período de calibração utilizou-se de métodos estatísticos e gráficos.

\subsubsection{Simulação de cenários}

Devido às inúmeras possibilidades de simulação de cenários e para não se tornar um trabalho repetitivo, somente duas simulações foram realizadas para avaliar a perda de solos na microbacia do ribeirão dos Marins.

É importante enfatizar que nesse estudo não há a intenção de caracterizar, de maneira completa, a efetividade das estratégias de manejo na microbacia em estudo. O objetivo foi exemplificar a aplicação e as vantagens da integração de modelos hidrológicos e de qualidade de água com SIG para avaliar alternativas de manejo e uso da terra em microbacias hidrográficas. As simulações para os cenários foram comparadas com as condições do cenário atual em termos de redução da produção de sedimentos.

- cenário 1 - considerando o uso da terra atual, mas atendendo a duas determinações do Código Florestal. O Código Florestal vigente, Lei ํㅜ 4771, de 15 de setembro de 1965, modificada pelas Leis no 7803/89 e 7875/89, estabelece legalmente uma faixa de área que deve ser protegida ao redor dos corpos d'água e nascentes. Essa faixa de área varia de acordo com a largura dos rios e engloba as matas ciliares, ou pelo menos a maior parte delas. A largura mínima de proteção a florestas e demais formas de vegetação natural, 
situadas ao longo dos cursos d'água, consideradas como Áreas de Preservação Permanente (APP's) é de 30 metros (para cursos d'água com largura de até $10 \mathrm{~m}$ ), e nas nascentes, ainda que intermitentes e nos "olhos d'água", em um raio de 50 metros. Assim, criou-se uma imagem (buffer) na rede de drenagem com esses valores para sobrepô-la àimagem de uso atual (Figura 7).

- cenário 2 - outra determinação do Código Florestal vigente considera de preservação permanente as florestas e demais formas de vegetação natural situadas nas encostas ou partes destas com declividade superior a $45^{\circ}(100 \%)$ na linha de maior declive. Como a cana-de-açúcar é cultivada nas áreas de menor declividade, enquanto as pastagens ocupam as encostas mais íngremes, nesse cenário, as áreas ocupadas por pastagem foram substituídas por vegetação nativa (Figura 8 ).

\subsubsection{Análises estatísticas}

A precisão da simulação do escoamento diário é importante porque eventos de chuvas intensas contribuem para a geração de cargas de sedimentos. Entretanto, a precisão das estimativas depende da habilidade do modelo em trabalhar com respostas hidrológicas de eventos isolados. O modelo SWAT foi desenvolvido como um modelo de respostas de longos períodos e não é capaz de detalhar respostas para eventos isolados (Arnold et al., 1998).

Para avaliar o desempenho do modelo, os dados mensais de escoamento e da produção de sedimentos simulados pelo SWAT foram comparados com os dados observados na microbacia do Ribeirão dos Marins no período de 1999 a 2000.

O desempenho de modelos é usualmente avaliado por meio do uso de medidas estatísticas. Um dos mais importantes critérios estatísticos para avaliar o ajuste de modelos H/QA é o Coeficiente Eficiência de Nash e Sutcliffe, COE, dado pela eq. (43) (ASCE, 1993): 
sendo que,

$$
C O E=1-\frac{\sum_{i=1}^{n}(E m-E s)^{2}}{\sum_{i=1}^{n}(E m-\bar{E})^{2}}
$$

Em é o evento observado; Es é o evento simulado pelo modelo; $\bar{E}$ é a média do evento observado no período de simulação; e n, o número de eventos. $\mathrm{O}$ coeficiente de Nash-Sutcliffe (COE), pode variar a partir de negativo infinito a 1 , sendo 1 , indicativo de um perfeito ajuste.

Um outro bom critério de ajuste é o desvio do evento analisado, o qual é a medida da habilidade do modelo para simular valores observados. Com esse método, quanto menor o valor de Dv, eq. (44), melhor é o ajuste, com 0,0 representando uma simulação perfeita do evento observado (ASCE, 1993).

$$
D_{v}[\%]=\frac{E-E^{*}}{E} * 100
$$

sendo que,

$E$ é o evento observado no período analisado e $E^{*}$ é o evento simulado no período. O cálculo do desvio do evento analisado $\left(D_{e}\right)$ é importante por considerar o erro potencial nos dados observados.

Esses dois parâmetros foram usados em conjunto com os métodos gráficos, como comparação de hidrógrafas e gráficos de dispersão, para avaliar o desempenho do modelo. 


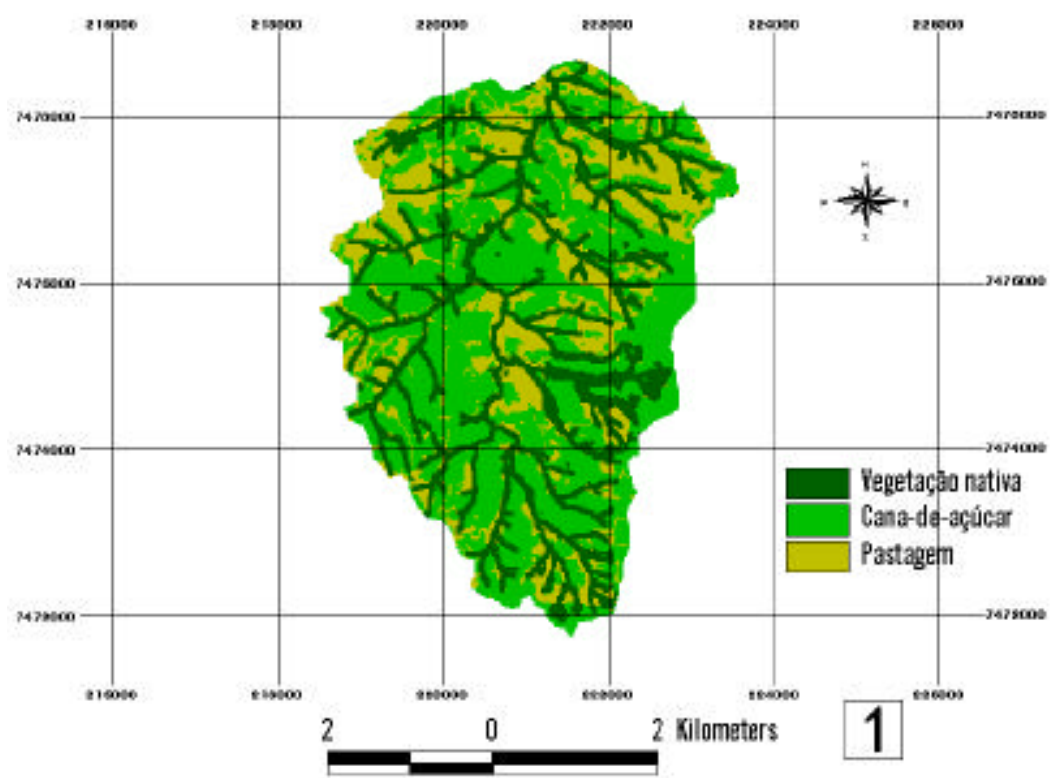

Figura 7 - Ocupação do uso da terra na microbacia do ribeirão dos Marins para o cenário 1.

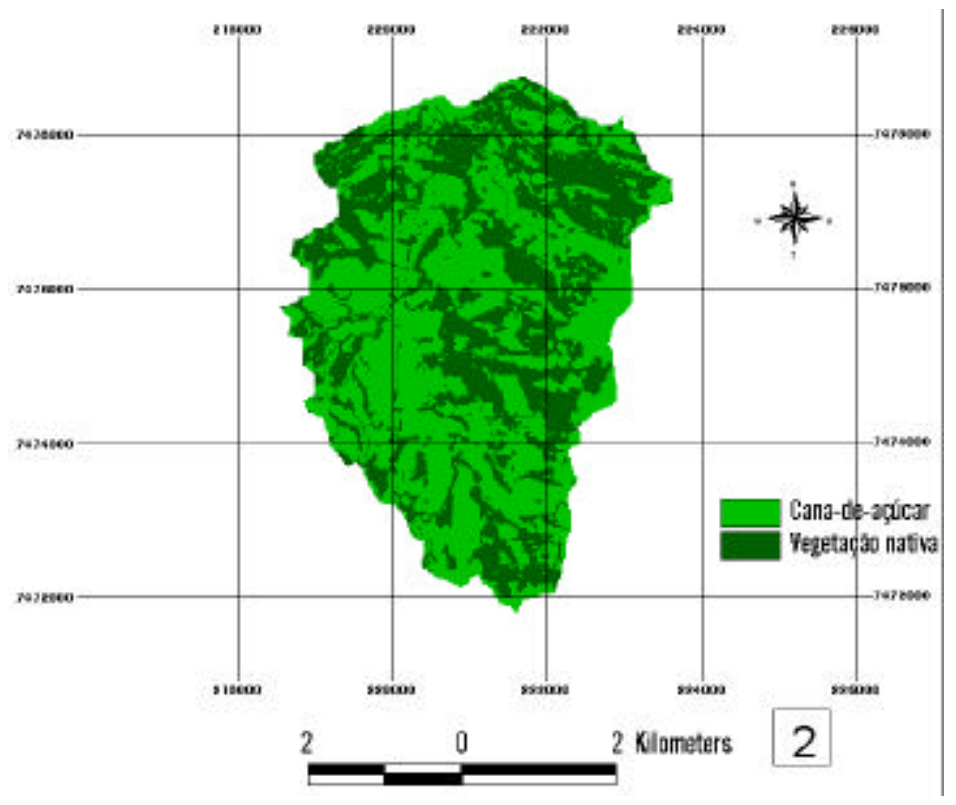

Figura 8 - Ocupação do uso da terra na microbacia do ribeirão dos Marins para o cenário 2. 


\section{RESULTADOS E DISCUSSÃO}

\subsection{Modelo Numérico do Terreno (MNT)}

O MNT gerado é apresentado na Figura 9. A altitude variou de $465 \mathrm{~m}$, na foz do ribeirão do Marins, a $620 \mathrm{~m}$, com uma média de $530 \mathrm{~m}$. A área apresentada $\left(154 \mathrm{~km}^{2}\right)$ é maior do que a área da bacia. Isso é necessário para se evitar problemas de interpolação pelo modelo ao definir as sub-bacias e a rede de drenagem.

A resolução do MNT é de $20 \mathrm{~m}$, compatível com a resolução da imagem de satélite. Essa resolução fornece detalhes suficientes para que as características do terreno e os padrões de drenagem sejam bem representados. Quanto maiores as resoluções do MNT, melhor representadas são as feições topográficas do terreno. Quinn et al (1991) apontaram que uma resolução acima de $50 \mathrm{~m}$ do MNT pode levar a resultados errôneos quando usado o algoritmo de direcionamento único do fluxo (D8). A literatura recomenda, para estudos de pequenas bacias, uma resolução do MNT entre $10 \mathrm{~m}$ e $30 \mathrm{~m}$. Entretanto, em relação æ̀s áreas planas, o nível de detalhamento pouco altera os valores de altitude. Ao contrário, um MNT muito detalhado, em aplicações hidrológicas, pode resultar em problemas na definição da rede de drenagem, gerando canais paralelos, não existentes na situação real. O uso de MNT para geração automática da rede de drenagem mostra-se muito promissor (Helmlinger et al., 1993; Montgomery \& Foufoula-Georgiou, 1993), mas deve ser feito com considerável cuidado, desde que a resolução do MNT seja adequada. 


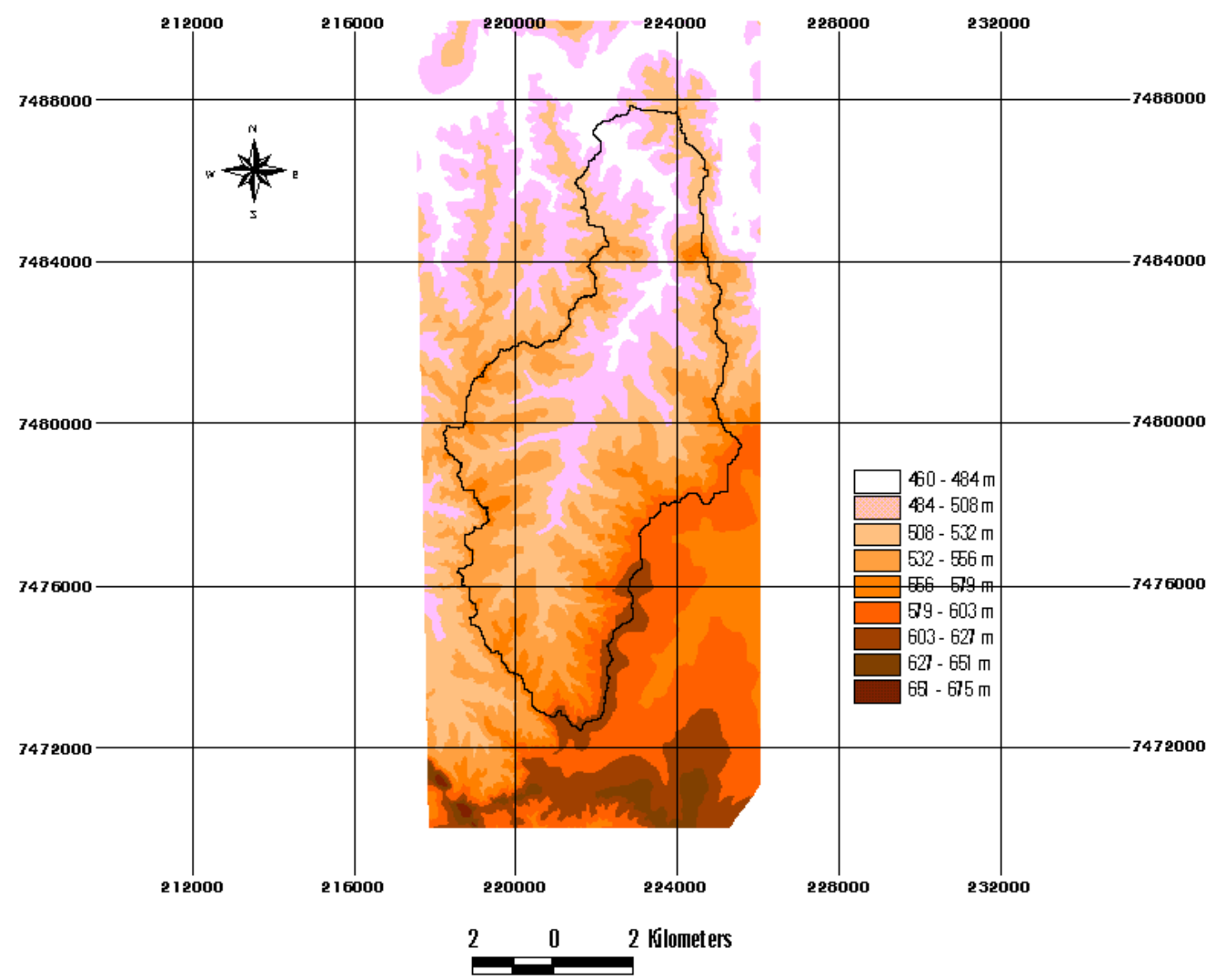

Figura 9 - Modelo Numérico do Terreno da Microbacia Hidrográfica do Ribeirão dos Marins e entorno. 


\subsection{Uso da terra}

O numero de classes de uso da terra (6) na imagem originalmente classificada foi reduzido pela combinação de classes que podem ser irrelevantes para a modelagem hidrológica e sedimentológica e por estar situadas na parte inferior da bacia, ocupando pequenas áreas (água, culturas anuais e culturas perenes). A imagem final, consistindo de um número de 4 classes de uso e ocupação (cana-de-açúcar, pastagem, vegetação nativa e área urbana), é apresentada na Figura 10. A Tabela 8 apresenta a porcentagem da área de cada classe na MHRM. A cultura da cana-de-açúcar ocupa a maior parte da área na microbacia $(56,2 \%)$, em terrenos de menor declividade, enquanto que as encostas mais íngremes são ocupadas com pastagem $(30,9 \%)$. A vegetação original, quase inexistente devido à evolução do uso e ocupação do solo na área de estudo, encontra-se apenas em algumas grotas e às margens do Ribeirão dos Marins (11,6\%). A área urbana ocupa 2,02\% e está localizada na porção inferior.

Desde que os tipos de cultura foram determinados, o banco de dados foi desenvolvido incluindo dados de índice de área foliar máximo, profundidade máxima das raízes, altura máxima da cultura, energia para conversão em biomassa e temperaturas base e ótima para o crescimento da planta.

A partir da concordância entre pontos aleatórios de verificação dentro da classificação digital e as observações terrestres, a avaliação da exatidão indicou, para o mapa de uso e ocupação da terra, um valor de 0,89 para o índice Kappa global. A classificação da imagem, de acordo com os intervalos do índice na Tabela 7, pode ser considerada como excelente. A representação real da cobertura vegetal e do uso da terra na área de estudo, é um fator importante na determinação da produção de sedimentos. 


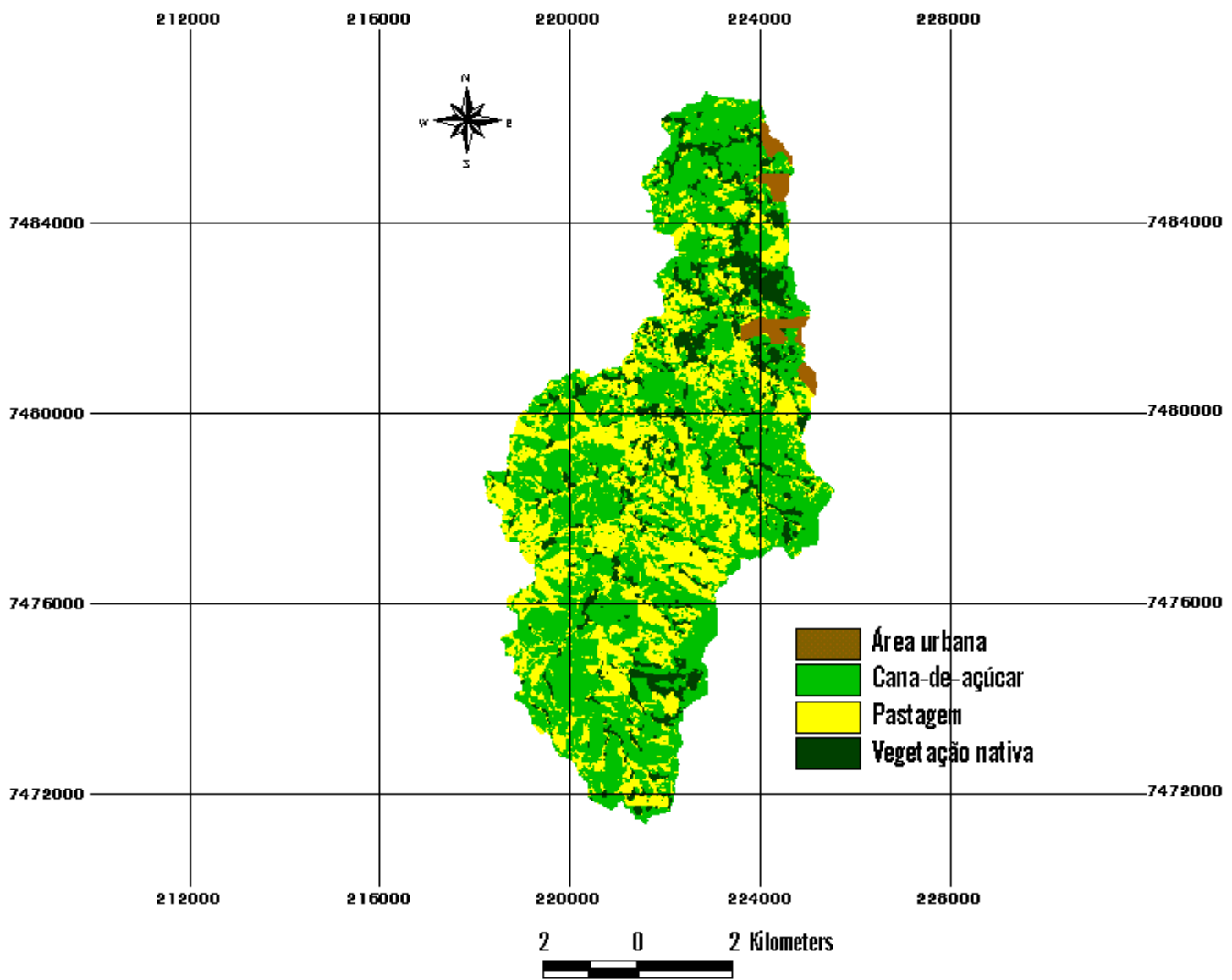

Figura 10 - Classificação do uso da terra derivada da imagem do satélite SPOT.

Tabela 8. Uso e ocupação da terra na área de estudo.

\begin{tabular}{lcc}
\hline Uso da terra & Área (ha) & Área (\%) \\
\hline Cana-de-açúcar & 3356,8 & 56,20 \\
Pastagem & 1802,7 & 30,19 \\
Vegetação nativa & 692,8 & 11,60 \\
Área urbana & 120,7 & 2,02 \\
\hline Total & 5973,0 & 100,00 \\
\hline
\end{tabular}




\subsection{Solos}

De acordo com o mapa de solos (Figura 11), existem 6 unidades de mapeamento distribuídas na microbacia do ribeirão dos Marins, com predominância de solos podzólicos e litólicos. Da área total da microbacia (5973 ha), em $41 \%$ ocorrem solos litólicos (Tabela 9). Esses solos estão sendo intensamente cultivados com cana-de-açúcar e com pastagens. No restante da área ocorrem os solos pozólicos (58,24\%).

Os solos litólicos são representados pelas unidades Li3 e Li5, ambos originados dos siltitos e folhelhos da formação Corumbataí, ocupando os locais de maior declividade na microbacia. É a classe de maior ocorrência, com $40,98 \%$ da área total da microbacia. A posição que ocupam na paisagem, geomorfologicamente instável, faz com que a erosão não permita o desenvolvimento maior desses solos, porque eles são constantemente rejuvenescidos pela retirada do material superficial pela erosão (Teramoto, 1995).

O material geológico mais homogêneo em termos de solo é a cobertura neo-cenozóica, representada principalmente pelo Latossolo Vermelho-Amarelo. A formação Pirambóia é a segunda em termos de homogeneidade de solos e mostrou predomínio dos Podzólicos VermelhoAmarelos, que perfazem em conjunto $58,24 \%$, ou agrupados a outros tipos de solos. A formação Corumbataí é constituída basicamente pelos solos pouco desenvolvidos, como os litólicos e cambissolos, sendo que os primeiros predominam, havendo também áreas de solos podzólicos (Teramoto, 1995). 


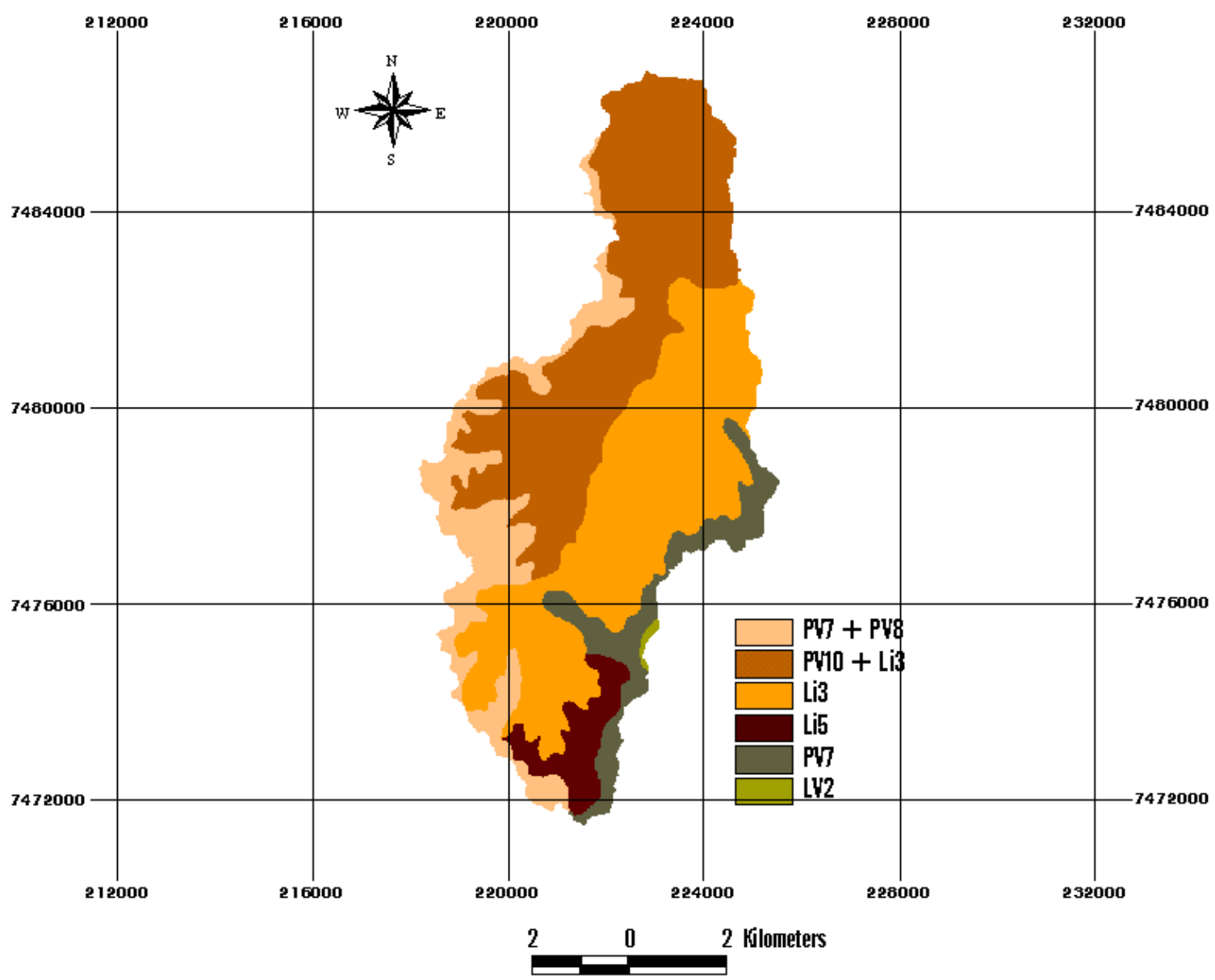

Figura 11 - Mapa de solos da microbacia do Ribeirão dos Marins.

Tabela 9. Ocorrência dos tipos de solo na microbacia do Ribeirão dos Marins.

\begin{tabular}{|c|c|c|}
\hline Tipos de solos & Área (ha) & Área (\%) \\
\hline PV10 + Li3 & 2194,5 & 36,74 \\
\hline Li3 & 2160,4 & 36,17 \\
\hline PV7 + PV8 & 842,2 & 14,10 \\
\hline PV7 & 474,3 & 9,97 \\
\hline Li5 & 287,3 & 4,81 \\
\hline LV2 & 14,3 & 0,24 \\
\hline Total & 5973,0 & 100,00 \\
\hline
\end{tabular}




\subsection{Simulações}

Os resultados da simulação, escoamento e produção de sedimentos, foram comparados com os dados do posto hidrossedimentométrico localizado na microbacia do Ribeirão dos Marins por um período de dois anos (1999 e 2000). Dados estatísticos, incluídos o coeficiente de eficiência (COE) e o desvio dos dados simulados em relação aos dados medidos (Dv), foram computados para as simulações descritas previamente para determinar a eficiência do modelo.

\subsubsection{Escoamento}

A comparação entre o escoamento observado e simulado pelo modelo foi feita, primeiramente analisando-se as diferenças entre os valores obtidos por ambos os procedimentos de discretização, considerando a combinação de uso da terra/solo dominante, nesse caso uma única $\mathrm{HRU}$, e posteriormente considerando várias HRU's.

A Tabela 10 mostra a comparação entre os níveis de discretização utilizando uma única combinação de cobertura/solo dominante e a opção de múltiplas combinações para o nível de sensibilidade de 10\% para uso da terra e $20 \%$ para solos. O COE variou entre 0,80 a 0,90 (dominante). Bons resultados foram obtidos usando a opção cobertura e solo dominante em qualquer nível de discretização e o COE não melhorou utilizando múltiplas HRU's. Por exemplo, utilizando-se a cobertura e solo dominante, para a área suporte de 10 ha, o COE foi 0,90 , enquanto utilizando a área suporte 100 ha, o COE foi 0,80 (Figura 12). Dentro dessa mesma configuração, a precisão na simulação não aumentou quando mais combinações de cobertura e solo foram simuladas. Portanto, o aumento na precisão foi mínimo quando mais sub-bacias foram geradas nas simulações, isto é, quanto mais detalhada foi a discretização. 
Tabela 10. Coeficiente de eficiência (COE) e desvio $\left(D_{v}\right)$ resultantes dos níveis de discretização para a simulação do escoamento.

\begin{tabular}{ccccccc}
\hline \multicolumn{3}{c}{ Discretizações } & \multicolumn{2}{c}{ COE } & \multicolumn{2}{c}{ Dv } \\
\hline $\begin{array}{c}\text { Área } \\
\text { (ha) }\end{array}$ & $\begin{array}{c}\text { № sub- } \\
\text { bacias }\end{array}$ & № HRU & Dominante & $10 \%$ e & Dominante & $10 \%$ e \\
\hline 10 & 107 & 371 & 0,90 & 0,90 & $-13,3$ & $-12,8$ \\
20 & 57 & 225 & 0,90 & 0,91 & $-10,2$ & $-10,0$ \\
30 & 43 & 202 & 0,82 & 0,84 & $-7,7$ & $-6,6$ \\
40 & 39 & 167 & 0,90 & 0,90 & $-12,7$ & $-10,7$ \\
60 & 33 & 144 & 0,90 & 0,89 & $-13,1$ & $-12,5$ \\
80 & 25 & 112 & 0,89 & 0,91 & $-14,8$ & $-11,8$ \\
100 & 17 & 79 & 0,89 & 0,89 & $-14,7$ & $-13,4$ \\
120 & 15 & 74 & 0,80 & 0,79 & $-23,2$ & $-22,2$ \\
200 & 7 & 30 & 0,90 & 0,91 & $-16,3$ & $-14,5$ \\
\hline
\end{tabular}

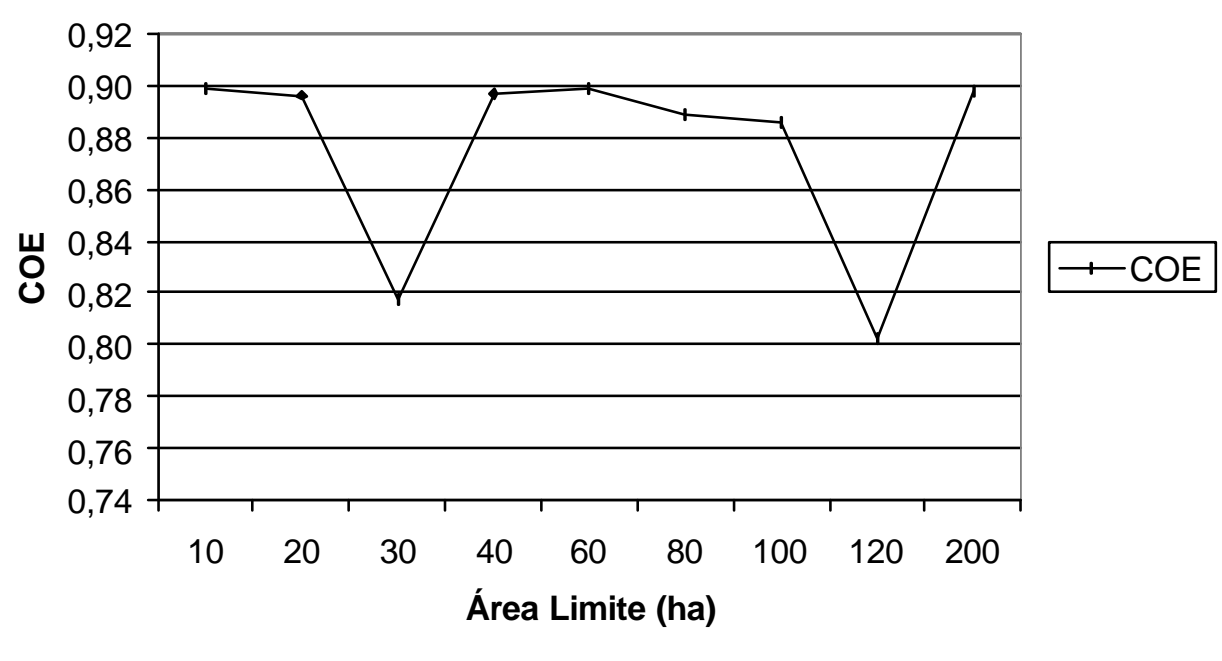

Figura 12 - Variação do coeficiente de eficiência (COE) entre os níveis de discretização. 
O $D_{v}$ teve uma maior variação entre as discretizações (Figura 13), variando de $-23,2 \%$ a $-7,7 \%$ (dominante), entre os valores observados e simulados pelo modelo, indicando o valor negativo os testes nos quais o valor do escoamento simulado superou o valor total observado nos dois anos de registro.

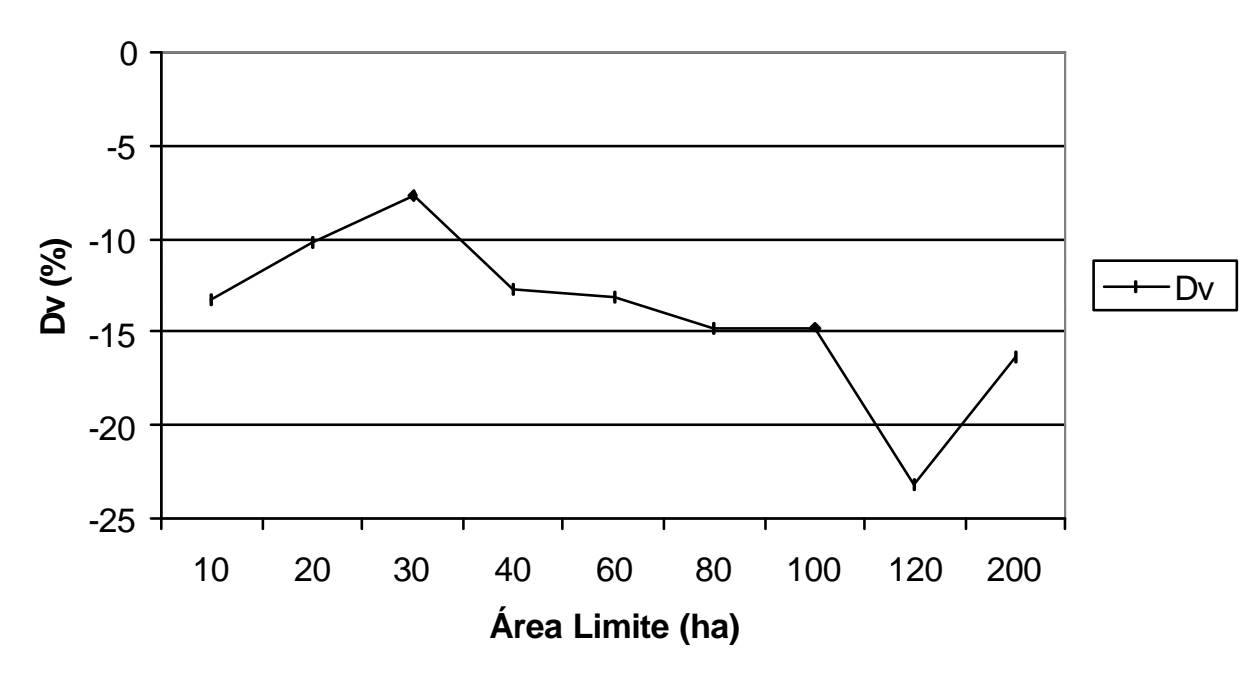

Figura 13 - Variação do desvio $\left(D_{\vee}\right)$ entre os níveis de discretização.

Como visto anteriormente, o aumento na discretização da microbacia nas simulações, considerando tanto múltiplas HRU's quanto uma única combinação de uso da terra/solo, não melhorou os resultados, mas de outro modo, aumentou o tempo de simulação e o tamanho dos arquivos gerados. Por exemplo, usando 20 ha como área limite, o número de combinações simuladas no caso dominante foi 57 , enquanto utilizando a mesma área suporte com área de 10\% para uso da terra e 20\% para solos, o número de combinações foi 225. Entretanto, não está claro a partir de outros estudos qual o efeito do nível de discretização na melhora da precisão dos resultados simulados. Para o uso efetivo da integração modelo-SIG, é necessário ter conhecimento do nível de discretização da bacia para um adequado nível de detalhamento. Uma discretização "grosseira", pode levar a resultados ruins, enquanto discretizações 
muito "detalhadas" podem requerer mais dados de entrada e aumentar significativamente o tempo e espaço computacionais (principalmente para grandes bacias), com pouco ou nenhum aumento na precisão.

A Figura 14 mostra as hidrógrafas mensais simuladas pelo SWAT para todos os níveis de discretização (dominante). O escoamento teve pouca variação para as diferentes delimitações da bacia, devido ao fato de ser estreitamente relacionado à $\mathrm{CN}$. $\mathrm{O}$ valor médio da $\mathrm{CN}$ é quase o mesmo para todas as delimitações, variando entre 59 a 83. Outro fator é a variabilidade espacial na microbacia (uso da terra e solos), que não é grande o suficiente e, assim, pouco sensível aos níveis de decomposição adotados. A hipótese de que o grau da variabilidade espacial não foi grande o suficiente para produzir diferenças significativas nos resultados simulados, em relação às discretizações adotadas, deve ser testada em outras bacias com maior grau de variabilidade espacial.

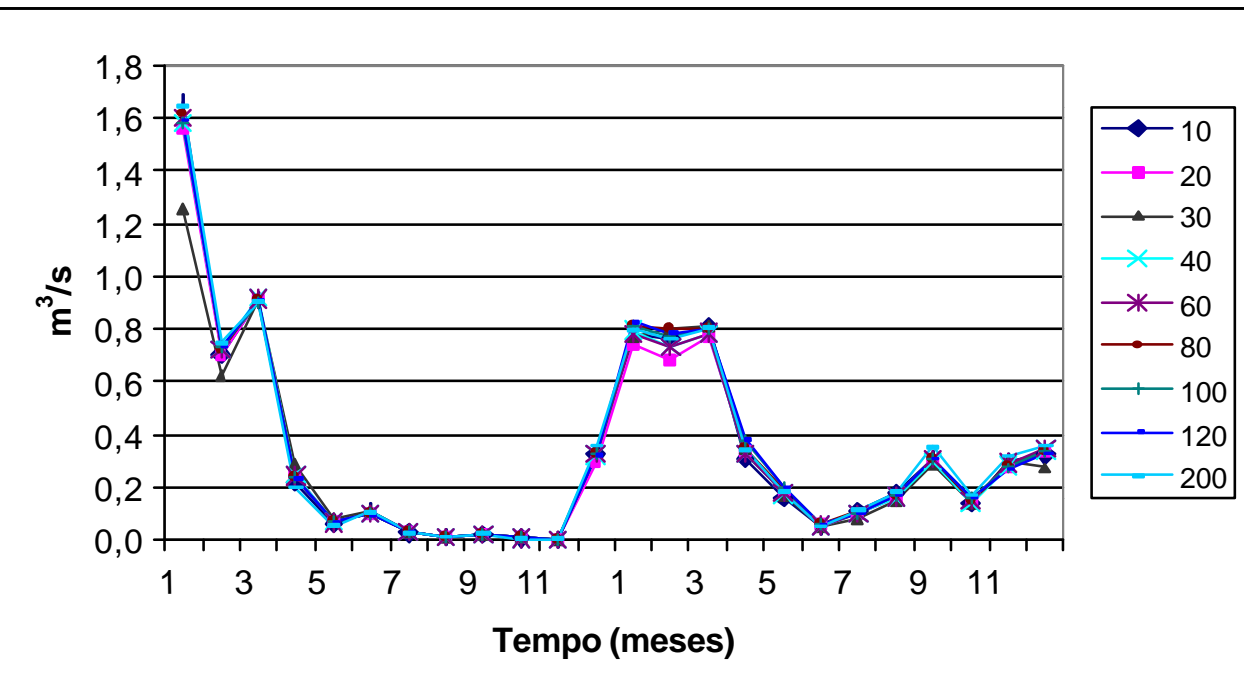

Figura 14 - Hidrógrafas resultantes dos níveis de discretização (dominante).

O emprego das propriedades do solo e uso da terra para determinar a variabilidade espacial na bacia quase sempre é o meio mais utilizado, desde que são eles os fatores mais importantes na estimativa da Curva Número, 
utilizada pelo SWAT para estimar o escoamento. A escolha de uma resolução espacial adequada para a aplicação de modelos de simulação em bacias hidrográficas é de fundamental importância nos processos hidrológicos e hidrogeoquímicos. Uma alta resolução dos dados pode significar a inclusão de maior variação espacial na análise do modelo. A resolução espacial e o aumento do processamento computacional do modelo são interrelacionados.

Mamillapallii (1997) citado por Manguerra \& Engel (1998), utilizou o SWAT para simular o escoamento em oito bacias hidrográficas com áreas variando de 2000 a $5000 \mathrm{~km}^{2}$, cada uma dessas bacias apresentando significativas diferenças climáticas, uso da terra, solo e relevo. Segundo o autor, estimativas de escoamento para várias decomposições não foram significativamente diferentes em muitas situações, quando muitas sub-bacias virtuais (HRU's) foram consideradas. O autor encontrou estimativas razoáveis de escoamento nessas bacias, quando comparadas aos dados observados.

Os resultados indicaram que o modelo gerou uma boa estimativa em relação aos dados observados (Figura 15). O COE foi 0,90 (considerando a área limite de $40 \mathrm{ha}$ ), o qual indica que o modelo é melhor preditor do que a média dos dados medidos. Um COE com o valor 1 (um) indica que o modelo é perfeito, enquanto o valor zero ou negativo indica que a média é igual ou melhor estimador que o modelo. Um COE variando entre 0,70-0,80 geralmente indica um bom ajuste (Krysanova et al., 1998). No presente estudo, a eficiência na simulação do escoamento variou entre $0,80-0,90$, com intervalo de tempo mensal. Como pode-se observar, a avaliação estatística dos resultados da simulação foi muito satisfatória. 


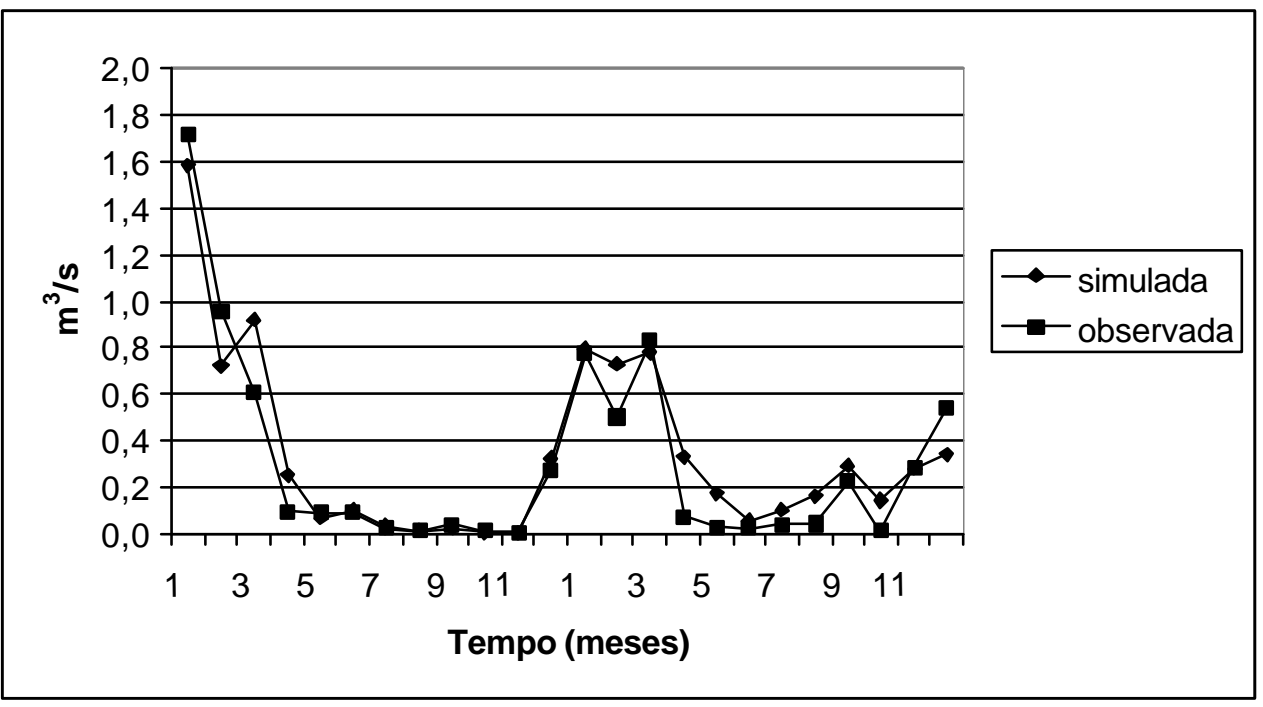

Figura 15 - Hidrógrafas observada e simulada, considerando a área limite de 40 ha.

Esses resultados foram similares aos encontrados na literatura. Srinivasan et al. (1993) aplicaram o modelo SWAT à bacias dos rios Seguin $\left(24.469 \mathrm{~km}^{2}\right)$ e Naches $\left(25.161 \mathrm{~km}^{2}\right)$, no Estado do Texas, EUA. Eles relataram que o coeficiente de Nash-Sutcliffe (COE) foi de 0,86 e 0,82 entre os escoamentos mensais observados e simulados para as duas bacias, respectivamente. Srinivasan \& Arnold (1994) usaram o SWAT para modelar a bacia do rio Seco $\left(114 \mathrm{~km}^{2}\right)$, também no Estado do Texas, sendo que $98 \%$ da área da bacia estava sendo utilizada com pastagem, e registraram que o escoamento mensal médio simulado pelo modelo foi $12 \%$ menor do que os valores medidos. Binger (1996) também registrou razoável concordância entre volumes anuais simulados e medidos, com $90 \%$ para muitas bacias. Rosenthal et al. (1995) utilizaram o SWAT para avaliar o balanço de água na bacia do Rio Colorado, no Texas. Sem calibração, esse autores registraram uma relação significativa entre o escoamento mensal observado e o estimado $\left(R^{2}=0,75\right)$.

Embora a Figura 15 mostre que o modelo representou a variabilidade no regime de escoamento da microbacia razoavelmente bem como um todo $(\mathrm{COE}=0,90)$, os escoamentos simulados pelo SWAT no mês de abril de 1999 
e nos meses de abril a agosto de 2000 foram superestimados em relação aos dados observados. O total para os dois anos de simulação foi $12,7 \%$ maior do que os valores observados, considerando a área limite como 40 ha. Há também períodos onde 0 escoamento foi significativamente subestimado, particularmente nos meses de março a maio de 1999 e no mês de janeiro de 2000. A análise do dados mostraram que a quantidade de chuva sobre a microbacia não foi uniforme durante o mesmo período nos dois postos pluviográficos.

Embora os volumes de precipitação registrados nos dois postos durante o período da simulação tenham apresentado uma pequena diferença (42 mm), houve uma variação na distribuição da precipitação. Isso é demonstrado pela série temporal mensal da precipitação no período analisado nos dois postos, mostrado na Figura 16. O posto D4-118 está localizado na parte superior da microbacia, onde a atividade agrícola predominante é o cultivo da cana-de-açúcar, enquanto o posto D4-116 está localizado próximo ao posto hidrossedimentométrico (Figura 6). A distância entre ambos é de aproximadamente 4500m. Segundo Goodrich et al. (1995), na aplicação de modelos $\mathrm{H} / \mathrm{WQ}$, a precipitação é geralmente assumida como espacialmente uniforme e não é considerada a sua contribuição nas incertezas das respostas do modelo, além de que, as tormentas que causam os maiores movimentos de sedimentos e nutrientes raramente são uniformes. Essa variação no padrão da distribuição espacial da precipitação tem significativo impacto no escoamento e, conseqüentemente, na produção de sedimentos (Faures et al., 1995).

A Figura 17 mostra a relação entre o total precipitado (média dos dois postos) e o escoado no período analisado. Os dados de escoamento até o posto hidrossedimentométrico foram convertidos para milímetros. Os valores mensais do escoamento na microbacia tiveram uma boa correlação com a precipitação mensal, sendo o valor de $R^{2}(0,82)$, significativo ao nível de $1 \%$. $O$ valor do coeficiente da correlação da precipitação com o escoamento simulado pelo modelo (Figura 18) foi 0,90, também significativo ao nível de $1 \%$. 


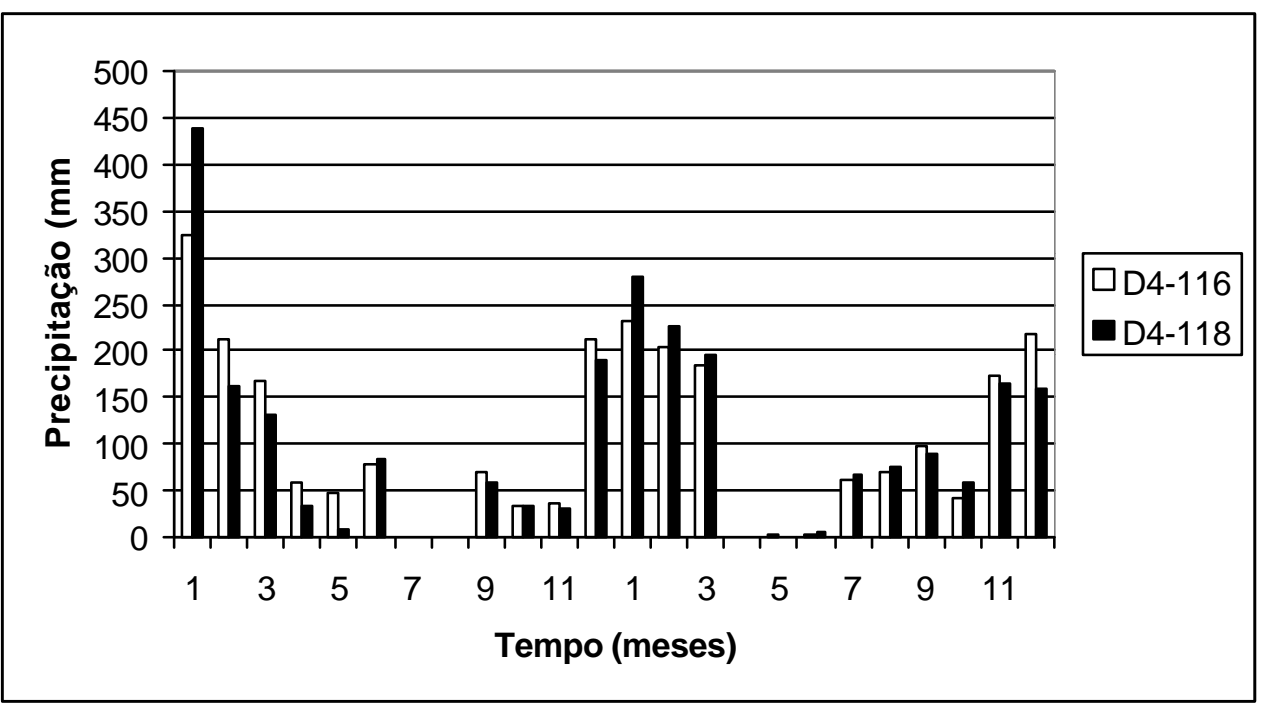

Figura 16 - Distribuição temporal da precipitação nos dois postos pluviográficos.

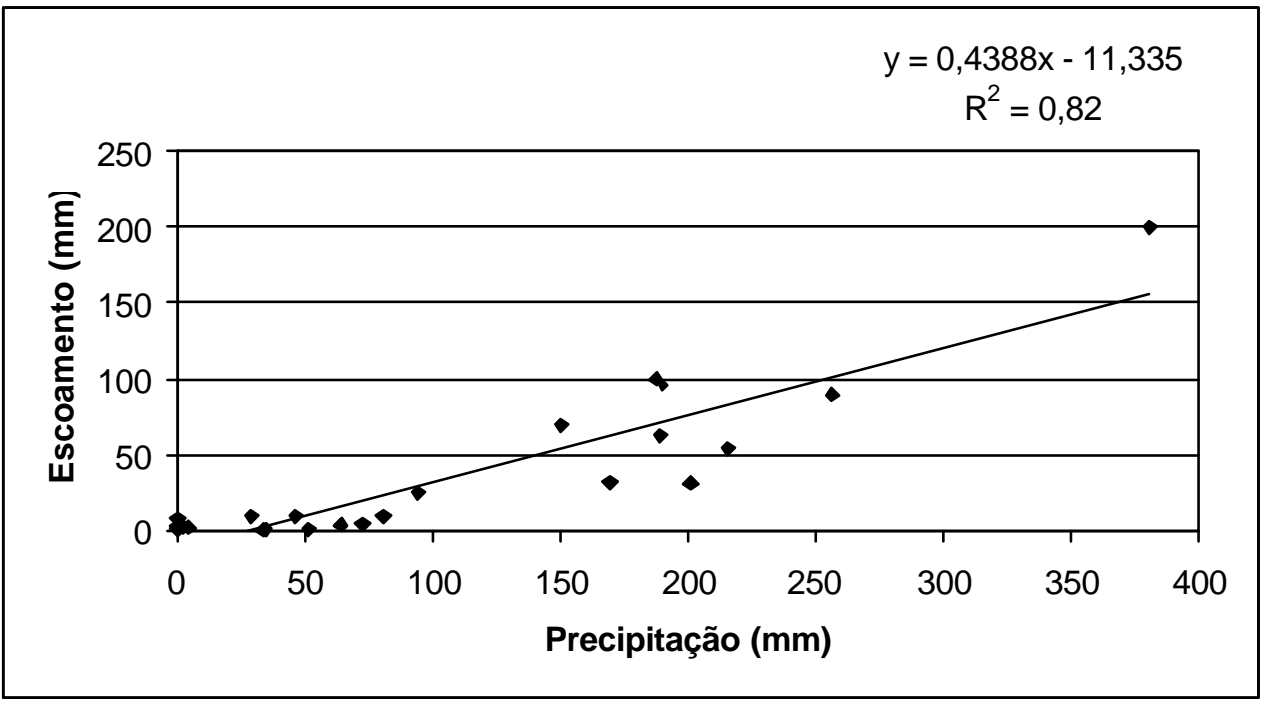

Figura 17 - Diagrama de dispersão entre a precipitação e o escoamento observado. 


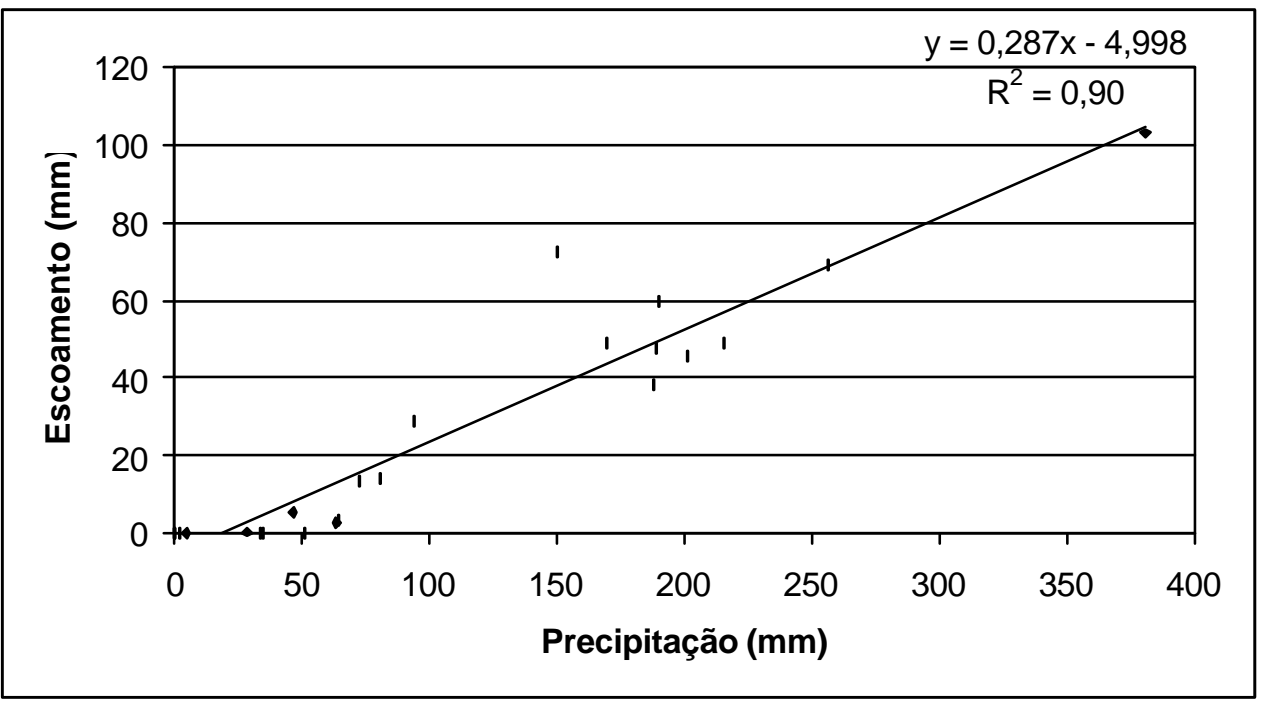

Figura 18 - Diagrama de dispersão entre a precipitação e o escoamento simulado.

\subsubsection{Produção de sedimentos}

A Tabela 11 e a Figura 19 mostram a comparação entre a produção de sedimentos simulada para os vários níveis de discretização da bacia. Quando a discretização torna-se maior, há um aumento da produção de sedimentos, ocorrendo o contrário quando menor é a discretização da bacia até um certo nível. Segundo Yitayew et al. (1999), quando muitas vertentes são combinadas em uma única sub-bacia, efeitos como a deposição e erosão em canais podem aumentar ou diminuir a produção de sedimentos. Como a USLE foi originalmente aplicada para rampas uniformes, uma de suas limitações é não considerar rampas desuniformes em bacias hidrográficas. De acordo o próprio conceito do fator $L S$, quanto maior o comprimento de rampa, maior será a perda de solo. Segundo Brown et al. (1981) e Jong et al. (1983), quando se consideram rampas não uniformes pode ocorrer o inverso, isto é, quanto maior o comprimento de rampa, maior a possibilidade de haver deposição de sedimentos ao longo dela. 
Tabela 11. Coeficiente de eficiência $(\mathrm{COE})$ e desvio $\left(D_{v}\right)$ resultantes dos níveis de discretização para a simulação da produção de sedimentos.

\begin{tabular}{ccccccc}
\hline \multicolumn{3}{c}{ Discretizações } & \multicolumn{2}{c}{ COE } & \multicolumn{2}{c}{ Dv } \\
\hline $\begin{array}{c}\text { Área } \\
\text { (ha) }\end{array}$ & $\begin{array}{c}\text { № sub- } \\
\text { bacias }\end{array}$ & № HRU & Dominante & $\begin{array}{c}10 \% \text { e } \\
20 \%\end{array}$ & Dominante & $\begin{array}{c}10 \% \text { e } \\
20 \%\end{array}$ \\
\hline 10 & 107 & 371 & $-0,06$ & $-0,04$ & 89,3 & 72,5 \\
20 & 57 & 225 & $-0,13$ & $-0,11$ & 94,5 & 74,2 \\
30 & 43 & 202 & 0,03 & 0,06 & $-26,9$ & $-2,2$ \\
40 & 39 & 167 & 0,78 & 0,75 & $-10,9$ & $-12,5$ \\
60 & 33 & 144 & 0,78 & 0,75 & $-10,9$ & $-12,5$ \\
80 & 25 & 112 & 0,78 & 0,75 & $-10,9$ & $-12,5$ \\
100 & 17 & 79 & 0,74 & 0,74 & $-23,2$ & $-24,2$ \\
120 & 15 & 74 & 0,74 & 0,74 & $-23,2$ & $-24,2$ \\
200 & 7 & 30 & $-1,63$ & $-0,53$ & $-105,4$ & $-90,5$ \\
\hline
\end{tabular}

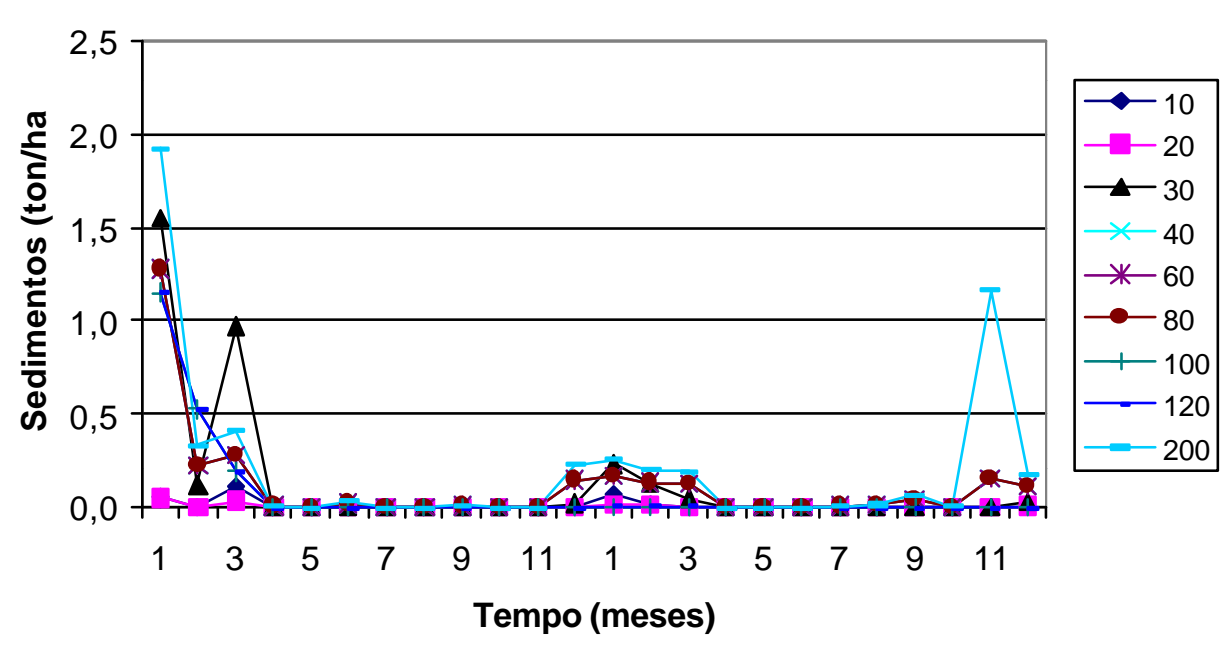

Figura 19 - Variação da produção de sedimentos para os diferentes níveis de discretização.

O COE variou entre -0,06 a 0,78 (dominante) (Figura 20) e o Dv entre $-105,4 \%$ a $94,5 \%$ (dominante) (Figura 21). Bons resultados foram obtidos usando a opção cobertura e solo dominante com 39 sub-bacias (área limite de 
40 ha) até a área limite de 80 ha (25 sub-bacias) e nenhum ganho na precisão do modelo foi conseguido com maior número de sub-bacias ou com mais combinações de uso da terra e solo. Ao contrário, com uma discretização mais detalhada, o modelo não melhorou a simulação da produção de sedimentos.

A produção de sedimentos mostrou uma variação com o tamanho da área limite; primeiro o COE foi menor para valores menores do que 30 ha, então aumentou até a área limite entre 40 ha e 80 ha e a partir desse intervalo há uma estabilização. A partir da área limite de 40 ha não há razão para aumentar o número de sub-bacias, já que substancialmente não melhorou a capacidade do modelo.

Quando o esquema de discretização varia de 10 ha a 120 ha, o número de sub-bacias conseqüentemente decresce. Significa que o SWAT irá calcular um comprimento de rampa médio em grandes áreas. Isso pode ser a razão para a variação na produção de sedimentos, principalmente para as menores discretizações. A produção de sedimentos pode permanecer constante em grandes discretizações uma vez que o SWAT considera o relevo mais uniforme.

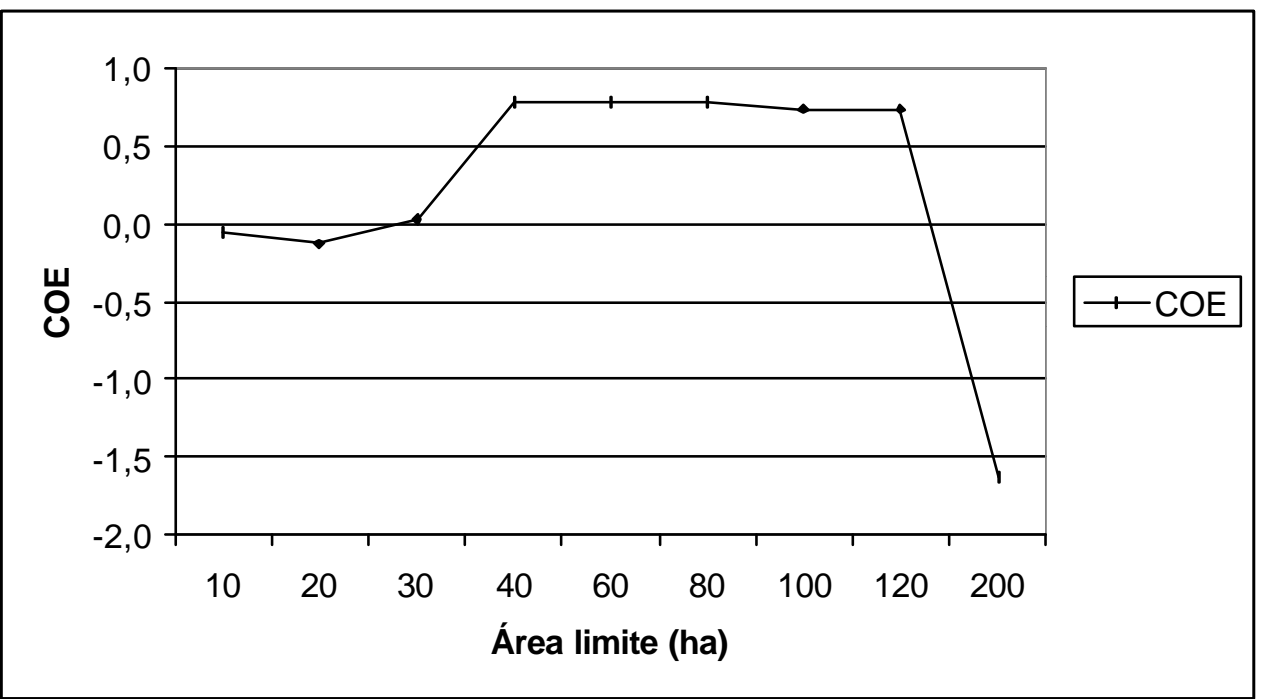

Figura 20 - Variação do coeficiente de eficiência (COE) entre os níveis de discretização. 


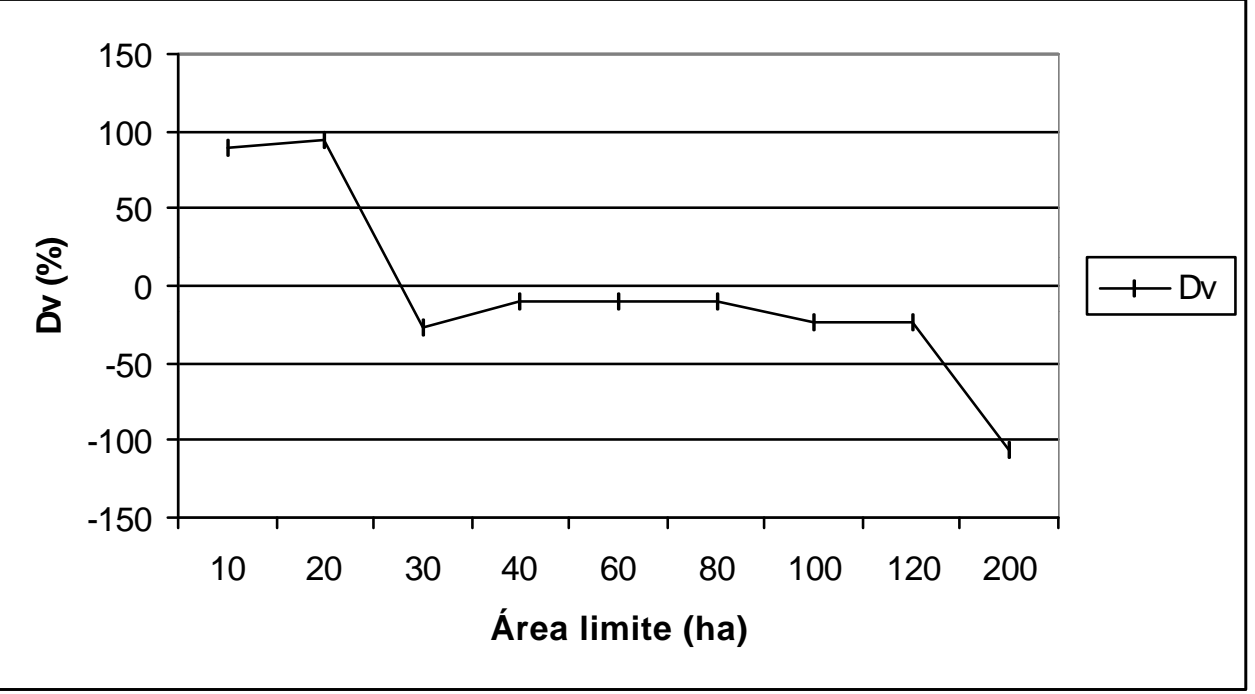

Figura 21 - Variação do desvio $\left(D_{v}\right)$ entre os níveis de discretização.

Diante desses resultados pode-se afirmar que: primeiro, a melhora na estimativa da produção de sedimentos pode ser obtida ou pelo aumento do número de sub-bacias na simulação ou pelo aumento do número de combinações de uso da terra e solo dentro de cada sub-bacia; segundo, há um limite na precisão que pôde ser obtida. Isso ocorreu entre as áreas limite de 40 ha a 80 ha.

Ao contrário do escoamento estimado, a produção de sedimentos foi afetada pelo nível de discretização da bacia. A escolha da área limite não deve ser uma escolha arbitrária. Ela deve ter como base uma escala necessária para capturar a variabilidade espacial da bacia. Portanto, é muito importante predizer eventos com alta produção de sedimentos o mais realisticamente possível, dado o seu impacto no sistema de drenagem e o transporte de nutrientes fixados aos sedimentos para dentro dos corpos d'água.

O diagrama de dispersão da produção de sedimentos simulada (40 ha) e a observada é apresentado na Figura 22. Os valores mensais da produção de sedimentos simulados tiveram uma boa correlação os valores medidos, sendo o valor de $\mathrm{R}^{2}$ entre as variáveis, 0,92 , significativo ao nível de $1 \%$. 


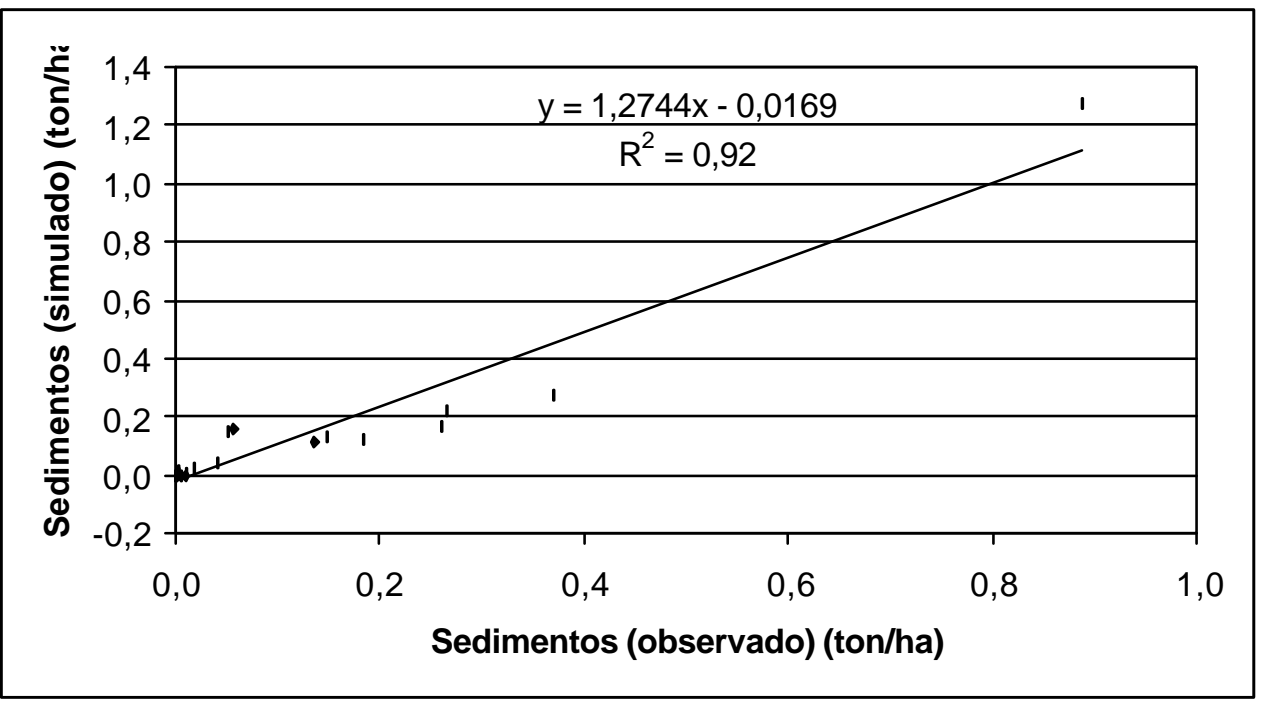

Figura 22 - Diagrama de dispersão entre a produção de sedimentos observada e simulada.

Nos meses de pouca produção de sedimentos (período seco) a estimativa pelo modelo SWAT foi nula (Tabela 12). Se os meses em que a estimativa é nula forem excluídos, o COE tem uma sensível piora $(0,75)$ e o $D_{v}$ dobra de valor $(21,3 \%)$. Como nesses meses há, naturalmente, pouca produção de sedimentos, por exemplo em maio e junho de 2000 , possivelmente nenhum modelo de simulação de sedimentos teria a sensibilidade suficiente para estimar esses valores.

Segundo Grunwald \& Frede (1999), é importante notar que outros fatores como o histórico dos eventos erosivos, variação espacial dos solos na paisagem e a morfologia do sistema de drenagem, podem influenciar as diferenças entre a produção simulada e a observada. Além de que, para diferentes condições locais (uso da terra, clima, solos e relevo) e em diferentes escalas, os processos dominantes influenciando o transporte de sedimentos não são os mesmos. 
Tabela 12. Produção de sedimentos (t/ha) observada e simulada no período de 1999-2000 para a área limite de 40 ha.

\begin{tabular}{cccccc}
\hline Meses (1999) & $\begin{array}{c}\text { Observada } \\
(\mathrm{t} / \mathrm{ha})\end{array}$ & $\begin{array}{c}\text { Simulada } \\
(\mathrm{t} / \mathrm{ha})\end{array}$ & Meses (2000) & $\begin{array}{c}\text { Observada } \\
(\mathrm{t} / \mathrm{ha})\end{array}$ & $\begin{array}{c}\text { Simulada } \\
(\mathrm{t} / \mathrm{ha})\end{array}$ \\
\hline 1 & 0,8859 & 1,2670 & 1 & 0,2596 & 0,1690 \\
2 & 0,2655 & 0,2240 & 2 & 0,1476 & 0,1330 \\
3 & 0,3697 & 0,2770 & 3 & 0,1830 & 0,1250 \\
4 & 0,0114 & 0,0070 & 4 & 0,0047 & 0,0000 \\
5 & 0,0097 & 0,0010 & 5 & 0,0009 & 0,0000 \\
6 & 0,0181 & 0,0220 & 6 & 0,0006 & 0,0000 \\
7 & 0,0018 & 0,0000 & 7 & 0,0023 & 0,0070 \\
8 & 0,0011 & 0,0000 & 8 & 0,0031 & 0,0130 \\
9 & 0,0028 & 0,0090 & 9 & 0,0411 & 0,0430 \\
10 & 0,0003 & 0,0000 & 10 & 0,0003 & 0,0000 \\
11 & 0,0001 & 0,0000 & 11 & 0,0577 & 0,1560 \\
12 & 0,0524 & 0,1480 & 12 & 0,1371 & 0,1150 \\
\hline
\end{tabular}

Uma questão levantada é se o manejo da terra significativamente afetou a produção de sedimentos de um ano para o outro no período de registro, ou se a variação foi simplesmente o resultado do padrão climático. No primeiro ano (1999), a produção de sedimentos observada e a simulada foram maiores do que a produção de sedimentos em 2000. No primeiro ano, pode ter havido uma maior movimentação de terra com a renovação de áreas (preparo do solo, plantio), enquanto no segundo ano (2000), a perturbação na superfície do solo pode ter sido menor. Em 1999 a produção de sedimentos observada foi aproximadamente 2 vezes maior do que em 2000, e a estimada foi 2,5 maior.

Como o modelo atualiza diariamente a $\mathrm{CN}$ com base na variação da umidade do solo, o usuário pode escolher variar a $\mathrm{CN}$ como resultado das operações de manejo (preparo do solo, cultivo, colheita etc.). As atualizações da CN podem ser implementadas com as práticas de manejo variando durante 
o período de crescimento da cultura. Nesse caso, a variação na predição de sedimentos pelo modelo é significativa. Essas práticas agrícolas usuais são ignoradas pelo modelo. Segundo Manguerra \& Engel (1998), a sensibilidade æ̀s variações temporais nas práticas de manejo é importante para parametrizar corretamente a bacia para a estimativa de produção de sedimentos.

O regime climatológico tem significativa importância na produção de sedimentos nas áreas cultivadas com cana-de-açúcar, desde que essa cultura é colhida nos meses de maio a novembro e o seu período inicial de crescimento coincide com o início da estação das chuvas. Por essa razão e considerando que a cana-de-açúcar é cultivada em toda a microbacia, em áreas de relevo ondulado, essas áreas contribuem significativamente para a produção de sedimentos. A variação temporal da produção de sedimentos é função do escoamento, o qual é, por sua vez, função do regime da precipitação. Para o período de dois anos, 94\% da produção de sedimentos anual na MHRM ocorreu no período de dezembro a março e $70 \%$ da precipitação anual registrada nos dois postos também ocorreu durante esse período de 4 meses.

Em geral, o teste de modelagem da erosão demonstrou a habilidade do modelo em simular a produção e o transporte de sedimentos na MHRM. Os processos hidrológicos claramente exercem um papel dominante na produção e transporte de sedimentos. Entretanto, a falta de uma série histórica de dados torna a comparação com os dados simulados pelo modelo menos confiável.

O processo erosivo que vem ocorrendo na microbacia dos Marins traz uma série de conseqüências ambientais, tanto no sentido de remoção do solo como no sentido do aporte de sedimentos aos corpos d'água. Segundo Tucci (1993), a qualidade de água dos mananciais que compõem uma bacia hidrográfica está relacionada com o uso do solo na bacia e com o grau de controle sobre as fontes de poluição. 


\subsubsection{Distribuição espacial da produção de sedimentos}

A distribuição espacial da produção de sedimentos anual na MBHM é apresentada na Figura 23, para os dois anos de simulação. Enquanto os maiores valores de produção de sedimentos ocorreram na maioria das vezes na parte alta da microbacia, devido ao relevo ondulado e uso intensivo dos solos com a cultura da cana-de-açúcar e pastagens, sub-bacias localizadas na parte média/baixa da microbacia também tiveram maiores valores de produção de sedimentos. Isso é provavelmente o resultado da contribuição de vários fatores -processos hidrológicos, erodibilidade do solo e uso da terra. Segundo Beuselinck (2000), parte do sedimento que é produzido durante os períodos de tormentas é parcialmente depositado na microbacia, mas uma considerável parte é transportada para a saída pelo sistema de drenagem. O transporte de sedimentos para a rede de drenagem é complexo, devido àinfluência de muitos processos como a erosão do solo, transporte de sedimentos e deposição dentro da bacia (Gburek et al., 2000). 

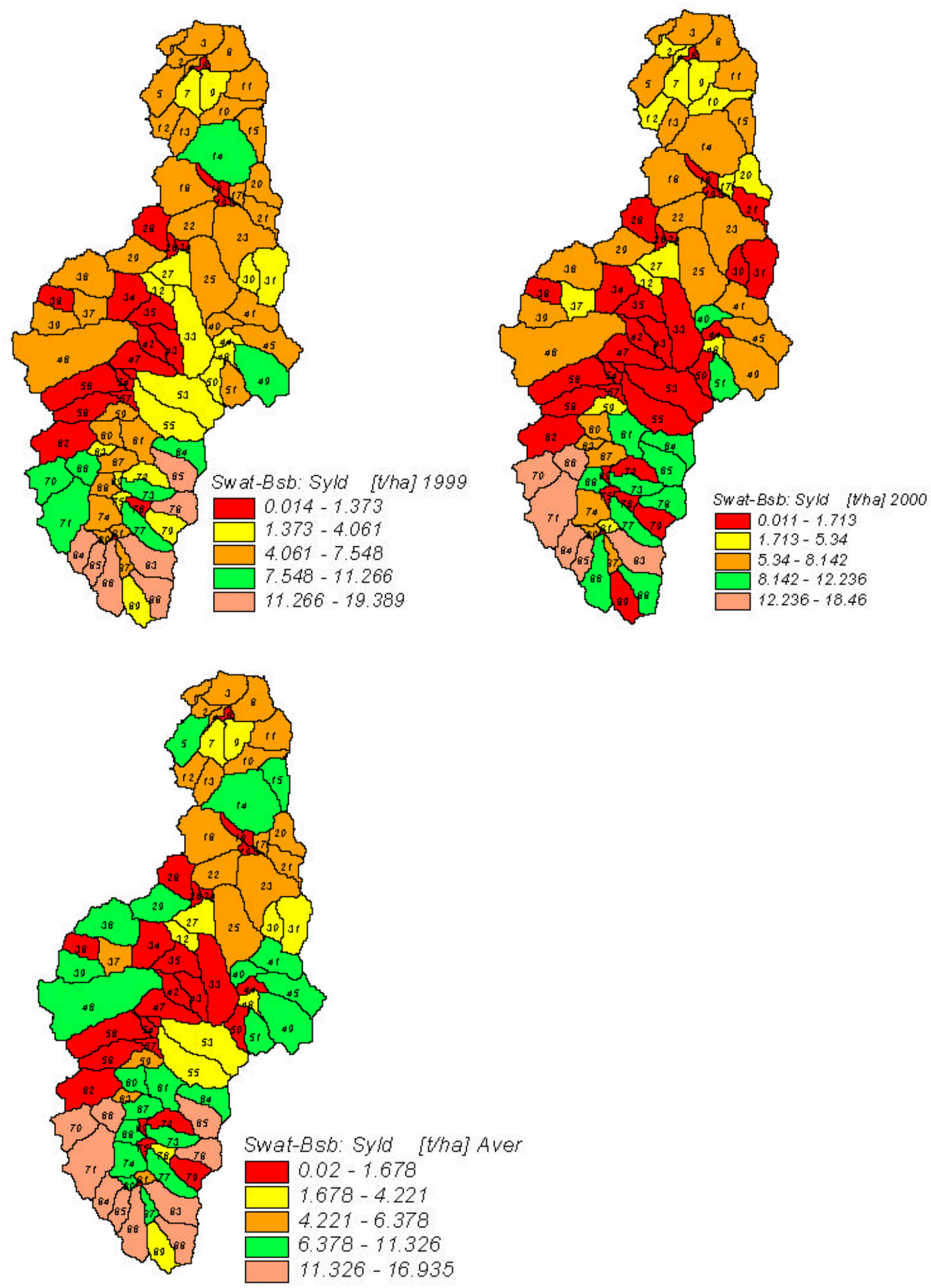

Figura 23 - Distribuição espacial da produção anual de sedimentos: a)1999; b) 2000 ; c) média para o biênio 1999/2000. 
Conforme os resultados mostraram, em algumas sub-bacias e de um ano para o outro, predominou o processo de deposição de sedimentos ao invés de transporte, ou seja, nem todo o sedimento removido pelo processo de erosão foi transportado pela rede de drenagem. Isso sugere que há forte deposição de sedimentos na parte média da microbacia da MBHM. Segundo Carvalho (1994), o comportamento de uma bacia em relação ao sedimento é muito variável desde as partes mais altas até as planícies. Isso depende das rochas e solos, da cobertura vegetal, das declividades, do regime de chuvas, bem como de diversos outros fatores. De um modo geral, na alta bacia há maior erosão e transporte de sedimentos. Na parte baixa da bacia normalmente há menor taxa de erosão, ocorrendo formação de depósitos com forte processo de agradação. Os resultados apresentaram-se concordantes e discordantes com esta teoria, pois se verifica que nas sub-bacias de cabeceiras a produção de sedimentos foi realmente maior, à exceção da sub-bacia no 89 , diminuindo conforme decresce a altitude até a parte média da microbacia. Na parte baixa há um aumento da produção de sedimentos em relação à parte média. Provavelmente o fator que pode estar mais intimamente ligado a isto é a intensificação do uso do solo nessas regiões. Entretanto, a conexão entre a geração, o transporte e a produção de sedimentos é complexa pela combinação de fatores citados acima e também pela variação temporal da capacidade da rede de drenagem em transportar sedimentos.

Para a sub-bacia no 1, a dinâmica de saída de água e sedimentos representa o resultado dos processos erosivos e sedimentológicos ocorrendo em toda a MBHM durante o período de estudo, ou seja, 6,1 t/ha. Nessa subbacia, o processo de erosão parece atuar de forma branda. $O$ relevo é plano e boa parte dos sedimentos destacados nas sub-bacias à montante foi depositados nas sub-bacias intermediárias.

As sub-bacias de montante apresentaram as maiores taxas de produção de sedimentos dentre todas as sub-bacias, no período analisado. Os fatores que contribuíram para a obtenção dessa expectativa de maior produção 
foram principalmente a ocorrência de relevo movimentado e de solos pouco resistentes à erosão. Essas sub-bacias são cultivadas com cana-de-açúcar e pastagens sobre solos litólico e podzólico, sendo susceptíveis ao processo erosivo. A localização espacial de áreas agrícolas em relação a vários fatores, como relevo, solos, clima etc. é de fundamental importância no controle do processo erosivo em microbacias.

$\mathrm{Na}$ Tabela 13 são apresentadas as taxas máximas aceitáveis consideradas como "tolerância de perda de solo" para o Estado de São Paulo, elaboradas por Leinz \& Leonardos (1977). Essa tolerância é variável com o tipo de solo, correspondendo ao valor que permite o uso contínuo do solo sem que o seu potencial produtivo seja comprometido (Carvalho, 1994). Os autores salientam que o critério adotado para a escolha das propriedades do solo consideradas essenciais ao estabelecimento de padrões de limites de tolerância foi subjetivo, com base na profundidade favorável para o desenvolvimento do sistema radicular e na relação textural dos horizontes da superfície e subsuperfície.

Verificou-se, de uma forma geral, uma maior produção de sedimentos em locais concentrados, mais especificamente na parte alta da microbacia dos Marins, isto devido principalmente ao relevo movimentado. Também os tipos de solos ocorrentes na região são rasos ou pouco profundos (litólicos e podzólicos), agravando o processo. Sobre esses solos são cultivadas extensas áreas com cana-de-açúcar e pastagens, nos terrenos íngremes, com ausência quase total da mata ciliar. Isso confirma um forte argumento técnico de se utilizar áreas de ocorrência desses solos e quase sempre em relevo movimentado, somente com culturas perenes ou como Áreas de Preservação Permanente.

O modelo SWAT forneceu estimativas de onde e quando a produção de sedimentos ocorreu e que medidas de conservação podem ser tomadas para controlar mais efetivamente a perda de sedimentos na microbacia. Essa é a vantagem de se fazer simulações com base em modelos. Entretanto, 
precauções devem ser tomadas quando da interpretação quantitativa dos resultados, com maior atenção devendo ser direcionada para os resultados qualitativos.

Tabela 13. Limites de tolerância de perdas de solo por erosão para solos de São Paulo (Leinz \& Leonardos, 1977)

\begin{tabular}{cc}
\hline Unidade de Solo & Tolerância de perda de solo \\
Média ponderada em relação à \\
profundidade (t/ha)
\end{tabular}

COM B TEXTURAL

$\begin{array}{lc}\text { Podzólico v.-a., orto } & 6,6 \\ \text { Podzólico v.-a., v. Piracicaba } & 7,9 \\ \text { Podzólico v.-a., v. Laras } & 9,1 \\ \text { Podzólico em cascalho } & 5,7 \\ \text { Podzólico Lins Marília, v. Lins } & 4,5 \\ \text { Podzólico Lins Marília, v. Marília } & 6,0 \\ \text { Mediterrâneo vermelho-amarelo } & 12,1 \\ \text { Terra roxa estruturada } & 13,4\end{array}$

COM B TEXTURAL

$\begin{array}{lc}\text { Latossolo roxo } & 12,0 \\ \text { Latossolo vermelho-escuro, orto } & 12,3 \\ \text { Latossolo vermelho-escuro, f. arenosa } & 15,0 \\ \text { Latossolo vermelho-amarelo, orto } & 12,6 \\ \text { Latossolo vermelho-amarelo, f. rasa } & 9,8 \\ \text { Latossolo vermelho-amarelo, f. arenosa } & 14,2 \\ \text { Latossolo vermelho-amarelo, f. terraço } & 12,6 \\ \text { Latossolo vermelho-amarelo, húmico } & 11,2 \\ \text { Solos Campos do Jordão } & 9,6\end{array}$

SOLOS POUCO DESENVOLVIDOS

Litossolo $\quad 4,2$

Regossolo 14,0




\subsection{Calibração do modelo}

O modelo SWAT é sensível para mais de 100 variáveis de entrada relacionadas à vegetação, manejo da terra, solos, clima, aqüífero, canal e reservatório (Arnold, 2000). Entretanto, para uma melhor eficiência na calibração dos parâmetros, uma análise de sensibilidade deve ser feita para determinar a importância relativa de cada um deles na resposta do modelo. Devido ao grande número de parâmetros de entrada, não é possível estudar a incerteza de todos eles. Também, a resposta do modelo não é igualmente sensível para todos os parâmetros (Arnold, 2000).

Segundo Peterson \& Hamlett (1998), o parâmetro mais sensível no modelo é a Curva Número a qual tem relação com o solo e a vegetação. A CN reflete o potencial de escoamento direto que pode ser gerado a partir de eventos de precipitação. Nesse período, o modelo representou bem o processo hidrológico que ocorreu durante o período de chuvas. Eliminando-se os meses de menor escoamento, o COE apresentou uma sensível melhora $(0,94)$ e o $D_{v}$ também $(-0,46)$.

A porção da chuva que não é convertida em escoamento direto pode vir posteriormente a sê-lo. O modelo simula a água que percolou para o interior do solo retornando para o escoamento direto através do fluxo lateral, a partir do perfil do solo e/ou do fluxo de retorno a partir do aqüífero raso. A água que percolou para o aqüífero profundo é considerada perdida no sistema e não pode retornar. A quantidade do fluxo que retorna é dependente dos parâmetros regionais da água subterrânea. O modelo fornece valores padrões (default). Entretanto, esses valores podem ser corretamente parametrizados para as condições, e assim melhorar a estimativa do escoamento, caso esses dados estejam disponíveis, o que é muito difícil na prática.

Conforme os resultados apresentados anteriormente na Figura 15, o modelo superestimou os menores escoamentos comparativamente aos valores observados, especificamente no ano de 2000. Como nesse período o regime 
hídrico foi governado pelo escoamento de base, esses valores indicam que os resultados da simulação nesse período estão relacionados mais a esse tipo de escoamento do que com o escoamento superficial. O modelo gera um default dos valores das variáveis (13 variáveis) relacionadas àágua subterrânea. Caso os valores reais desses parâmetros estejam disponíveis, pode-se fazer a edição dessas variáveis, o que não ocorreu neste caso. Desses parâmetros, segundo Spruill et al. (2000), o fator alfa é o mais sensível. Adotando o valor do fator como zero, virtualmente elimina-se a contribuição do fluxo de retorno (Manguerra \& Engel, 1998).

Para melhor simular o escoamento, algumas modificações foram feitas nos parâmetros de entrada utilizados na simulação não calibrada. Primeiramente os valores de default da $\mathrm{CN}$ obtidos a partir da interface ArcView/SWAT foram modificados para melhor representar as condições de uso da terra e solo na microbacia do Ribeirão dos Marins. Isso foi feito pela redução dos valores da $\mathrm{CN}$ em $10 \%$, conforme as recomendações sugeridas por Mockus (1972).

Desde que a infiltração decresce com o aumento do escoamento, o fluxo base e a recarga são ambos inversamente correlacionados com a Curva Número. O fator alpha foi modificado a partir do valor do default do modelo (-25\%). Para também diminuir o volume do fluxo de base, a capacidade água disponível (AWC) foi aumentada em 5\%. Segundo Finch (1998), os parâmetros mais críticos em modelos de balanço de água, para estimativa da água subterrânea, são aqueles requeridos pelos componentes do solo (particularmente capacidade de água disponível). Warrick \& Nielsen (1980) compilaram o resultado de diferentes estudos a respeito da variabilidade de parâmetros do solo. Eles encontraram coeficientes de variação de 90-190\% e $170-400 \%$ para condutividade hidráulica saturada e não saturada, respectivamente.

Com o aumento da AWC, estimativas do escoamento, fluxo de base e recarga decrescem, enquanto a evapotranspiração (ET) aumenta (Arnold et al., 
2000). Com o aumento da ET, menor quantidade de água estará disponível para o escoamento superficial, fluxo de base e recarga. Por outro lado, com menor armazenamento, maior quantidade de água irá escoar na superfície ou percolar, e conseqüentemente, menor quantidade irá ser armazenada no solo, ficando disponível para a ET. Outras propriedades do solo permaneceram a mesma, como na simulação sem calibração.

Na Figura 24, o escoamento simulado após a calibração do modelo é comparado aos dados observados. Exceto para os meses 4, 5, 8 e 10 de 2000, o valor do escoamento simulado está geralmente em boa concordância com os valores medidos. Esses resultados sugerem que o SWAT tendeu a superestimar o fluxo de base nas condições do estudo. Isso não é surpreendente, desde que a estimativa dos parâmetros de aqüífero é difícil de ser feita e quase sempre não é disponível. Também somente o escoamento total foi calibrado. Nenhuma tentativa foi feita para calibrar o fluxo de base. Segundo ${ }^{1}$ Butcher, o SWAT não contém um completo balanceamento de massa dos componentes que simulam a água subterrânea. Isso é um problema comum em modelos para bacia hidrográfica, pois a representação do tempo de resposta da água subterrânea é maior que o passo de tempo para simulação dos processos na superfície. O COE, o $D_{v}$ e o coeficiente de correlação $R^{2}$ entre valores observados e simulados, antes e após a calibração, são listados na Tabela 14. O escoamento total no período foi superestimado em $0,7 \%$ após a calibração. $O$ valor do COE foi 0,92 e o da correlação 0,94 . Resultados de trabalhos anteriores podem dar uma idéia do nível aproximado de eficiência alcançado. Por exemplo, Cho et al. (1995) chegaram a um coeficiente de determinação $\left(R^{2}\right)$ de 0,83 entre valores de escoamento mensais simulados e observados, usando o modelo SWAT calibrado aplicado na bacia Brodhead $\left(250 \mathrm{~km}^{2}\right.$ ), localizada no nordeste do Estado da Pensilvânia (EUA). Srinivasan et al. (1998) obtiveram COE's de 0,77 e 0,84 durante o período de calibração, para duas bacias de mesoescala nos EUA. 


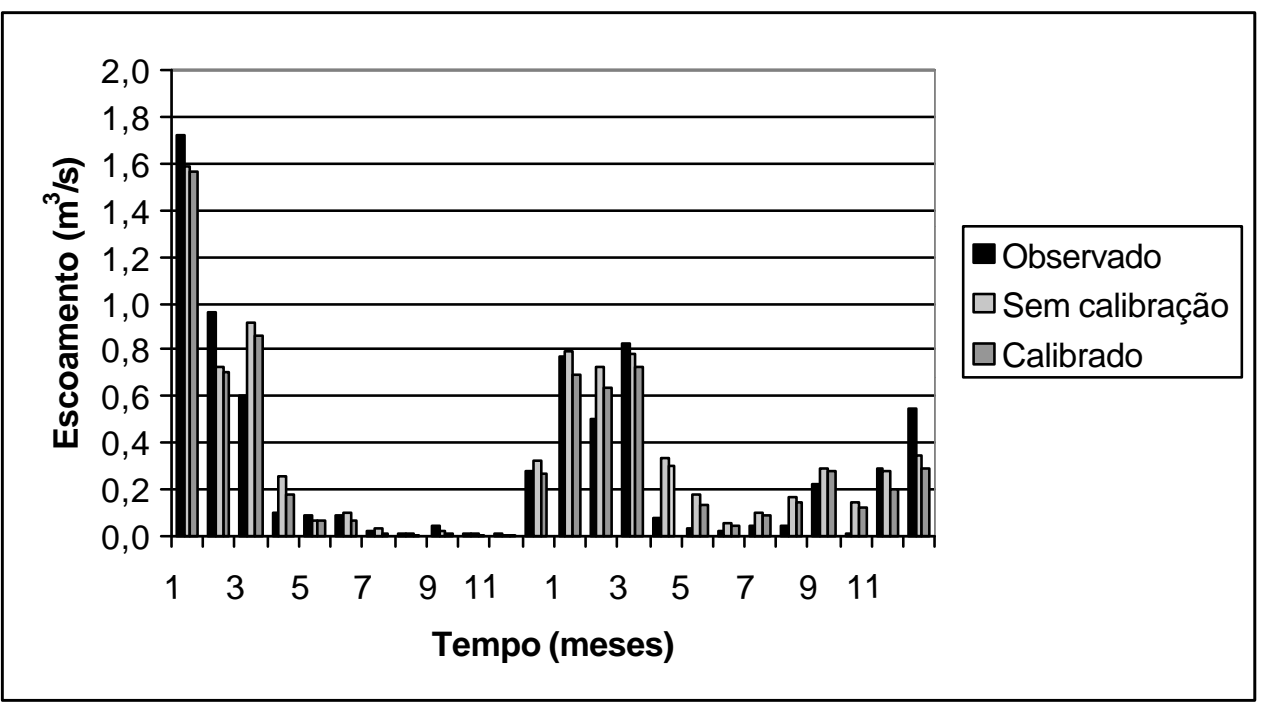

Figura 24 - Escoamentos observado e simulado, antes e após calibração.

Tabela 14. Valores do COE, $D_{v}(\%)$ e $R^{2}$, antes e após a calibração.

\begin{tabular}{ccc}
\hline & Sem Calibração & Calibrado \\
\hline COE & 0,90 & 0,92 \\
Dv & $-12,7$ & $-0,7$ \\
$R^{2}$ & 0,91 & 0,94 \\
\hline
\end{tabular}

Com a diminuição do comprimento de rampa em 10\% e com a melhora na simulação do escoamento pelo modelo, a simulação da produção de sedimentos também melhorou, o COE subiu para 0,83 e o $D_{v}$ diminui para $-3,2$.

Em áreas de pesquisa e outras situações de aplicação de modelos, todos ou muitos dos dados de entrada necessitam estar disponíveis para sua aplicação. Entretanto, alguns desses dados podem estar faltando, e alguns métodos têm sido utilizados para estimá-los a partir de informações disponíveis, como o uso da terra, solos e outros dados das características físicas da área a ser modelada. Esse procedimento foi adotado para estimar a condutividade

\footnotetext{
${ }^{1}$ BUTCHER, J. Comunicação pessoal, 2001.
} 
hidráulica saturada (Ko) e a capacidade de água disponível (AWC), o que nem sempre reflete as características reais. Quando se trabalha com modelos de simulação em escala de bacia hidrográfica e do porte do SWAT, que contempla em sua formulação todo o ciclo hidrológico, é difícil ter todos esses dados disponíveis, principalmente para as nossas condições; primeiro pelo tempo e recursos financeiros e, segundo, pela grande variabilidade espacial de alguns parâmetros, principalmente as mencionadas.

$\mathrm{Na}$ maioria das vezes, modelos são aplicados em áreas onde não existem dados de escoamento ou sedimentos disponíveis, o que torna a calibração impossível. Nesses casos, é importante que o modelo possa ser aplicado em situações onde nem todos os dados de entrada estejam disponíveis e que resultados razoáveis possam ser obtidos sem calibração, o que é um dos objetivos do modelo SWAT, isto é, ser aplicado em bacias hidrográficas não monitoradas. Deve estar claramente entendido, entretanto, que a calibração quase sempre é necessária e que erros na simulação são maiores sem calibração (Grunwald \& Frede, 1999).

\subsection{Simulação de cenários}

Como mencionado anteriormente, o objetivo da simulação de cenários nesse estudo não é caracterizar, de maneira completa, a eficiência das alternativas de manejo do uso da terra, mas sim exemplificar a aplicação e as vantagens da utilização da integração de modelos e SIG. Essa integração basicamente permite que se varie somente o PI de uso e ocupação da terra. Outras simulações podem ser feitas não somente considerando a redução da produção de sedimentos, mas também as fazendo em conjunto com outras análises, como a econômica e social, o que não foi o nosso objetivo.

Devido àincorporação direta de dados de clima, da cultura e manejo, há a possibilidade de uso do modelo em simulação de cenários de uso da terra que tragam menores impactos na hidrologia e na qualidade da água da bacia. 
Assim, os efeitos da variação no uso da terra sobre a produção de sedimentos foram calculados fazendo as simulações para os dois cenários e comparandoos com o cenário de uso atual.

$\mathrm{Na}$ Tabela 15 são apresentadas as áreas totais e relativas de ocupação de cada cobertura da terra na MHRM, para o cenário de uso atual e para os outros dois cenários, até o posto hidrossedimentométrico. Com a passagem do cenário atual para o cenário 1, há uma diminuição nas áreas ocupadas por cana-de-açúcar $(-7,74 \%)$ e pastagem $(-10,83 \%)$ e um ganho na área ocupada por vegetação nativa $(+18,57 \%)$. No cenário 2 , a área ocupada por cana-de-açúcar permaneceu inalterada. A área ocupada com vegetação nativa passou a ocupar $41,23 \%$ da bacia contra os $8,10 \%$ do cenário de uso atual, já que passou a ocupar toda a área antes ocupada por pastagem.

Tabela 15. Uso e ocupação da terra para os três cenários.

\begin{tabular}{ccccccc}
\hline Uso da terra & \multicolumn{2}{c}{ Cenário atual } & \multicolumn{2}{c}{ Cenário 1 } & \multicolumn{2}{c}{ Cenário 2} \\
\hline \multirow{2}{*}{ Cana-de-açúcar } & Área (ha) & Área (\%) & Área (ha) & Área (\%) & Área (ha) & Área (\%) \\
\cline { 2 - 7 } & 1310,37 & 58,78 & 1137,77 & 51,04 & 1310,23 & 58,78 \\
Pastagem & 738,15 & 33,12 & 496,86 & 22,29 & - & - \\
Veg. nativa & 180,76 & 8,10 & 594,65 & 26,67 & 919,05 & 41,23 \\
\hline Total & 2229,28 & 100,00 & 2229,28 & 100,00 & 2229,28 & 100,00 \\
\hline
\end{tabular}

Comparado os resultados das simulações dos 3 cenários de uso da terra, o modelo geralmente diminui a predição da perda de solos sobre a maioria das sub-bacias no cenário 1 . No cenário 2 , os resultados da produção de sedimentos foram ainda menores. No cenário de uso da terra atual, a produção de sedimentos simulada variou a partir de 0,00 a 1,28 t/ha, no período analisado, com uma média de 0,11 t/ha. No cenário 1, quando a vegetação nativa foi considerada em toda a extensão da rede de drenagem e nas nascentes, a produção de sedimentos variou de 0,00 a 0,83 t/ha. $O$ valor médio 
foi de 0,10 t/ha. No cenário 2, com a substituição por vegetação nativa nas áreas ocupadas por pastagens, a produção média foi de 0,02 t/ha por ano com um valor máximo observado de 0,14 t/ha (Figura 25).

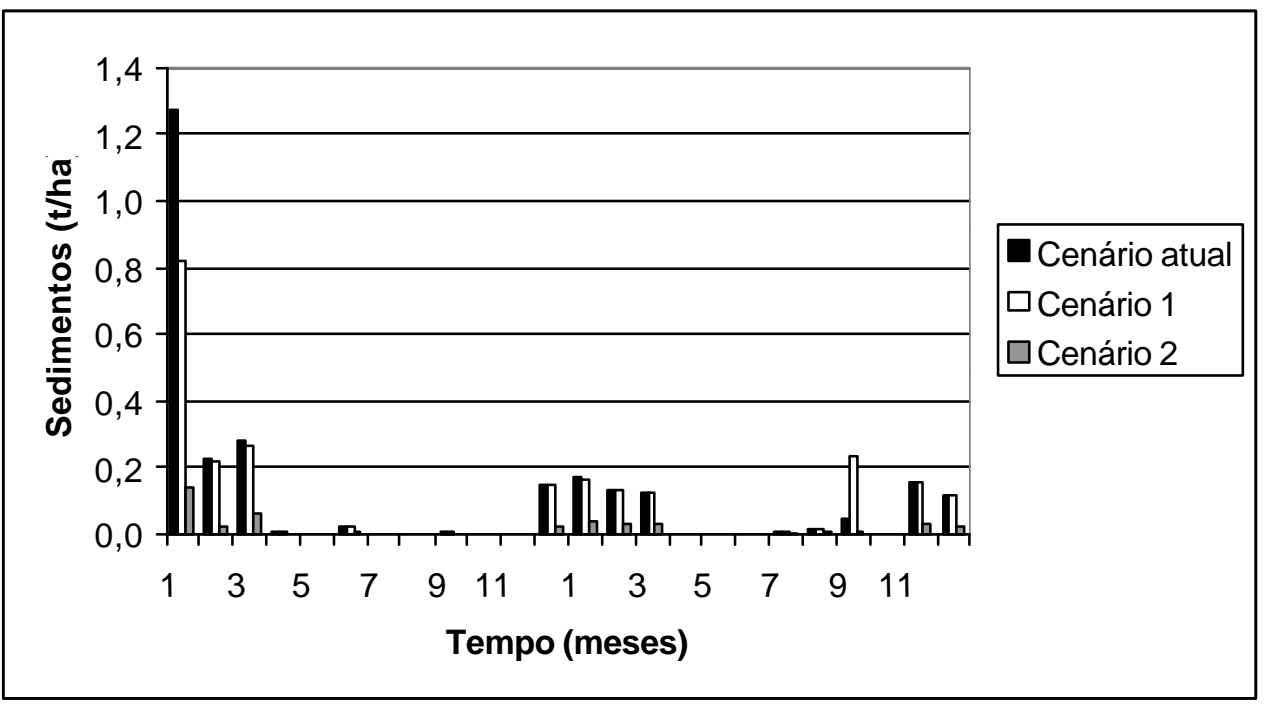

Figura 25 - Comparação da variação temporal da produção de sedimentos entre os três cenários.

A distribuição espacial da produção de sedimentos para o mês de janeiro de 1999 (o mês com maior produção de sedimentos), em t/ha, considerando o uso atual e os outros 2 cenários, é apresentada na Figura 26. O cenário 1 mostrou uma diminuição de $10,8 \%$ na produção de sedimentos comparativamente ao uso atual nos dois anos de simulação, enquanto para o cenário 2 , a diminuição foi de $84,4 \%$. Isso foi devido ao diferente fator $\mathrm{C}$ associado com o tipo de cobertura atual. Nesse cenário, a perda de solo ficou abaixo da perda de solo tolerável para todos os tipos de solo.

A introdução das variações do uso da terra a partir das áreas ocupadas por pastagem, para Áreas de Preservação Permanente, diminuiu a exposição dos solos mais susceptíveis àerosão. Desse modo, o uso dos solos litólicos e podzólicos para fins agrícolas foi reduzido. Segundo Books et al. (1991), o pastoreio em condições adequadas normalmente não aumenta a quantidade de sedimentos nos corpos d'água após chuvas intensas. Mas o 
pastoreio intensivo, em terrenos inclinados e solos frágeis, pode causar sérios problemas erosivos. Ainda segundo os autores, os níveis de sedimentos aumentam quando a área ripária também é utilizada como pastagem, o que leva àerosão das margens dos rios e àdeposição dos sedimentos diretamente no leito. A erosão proveniente das áreas cultivadas responde por cerca de $38 \%$ e a erosão proveniente de pastagens por cerca de $26 \%$ dos sedimentos que atingem os corpos d'água (USDA, 1991).

O impacto total do cenário 2 na redução de sedimentos é muito maior do que o cenário 1. Entretanto, as diferentes respostas comparando 2 e 1 não são lineares, principalmente pela diferente posição geográfica ocupada pela vegetação nativa nos cenários 1 e 2 . Acumulando o efeito sobre o período de 2 anos, infere-se que o cenário 2 reduziu em $82,6 \%$ a produção de sedimentos em relação ao cenário 1. Aparentemente, o efeito da variação do uso da terra no cenário 2 causou menos erosão e muito mais deposição do que a variação do uso atual para o cenário 1.

Comparando o cenário de uso atual com o cenário 2 é esperado que a vegetação nativa possa diminuir a erosão uma vez que, diretamente, altera os parâmetros de infiltração e especialmente a proteção dada ao solo contra o impacto direto das gotas de chuva e o aumento da rugosidade superficial. Segundo Larson (1997), a rugosidade superficial é um importante fator na redução do runoff $\mathrm{e}$, conseqüentemente no transporte de sedimentos. Naturalmente, essa diminuição não é uniforme e a visualização do padrão da produção de sedimentos nas sub-bacias mostra uma importante relação com o declive. Nesse caso, a produção de sedimentos nas sub-bacias sob a cultura da cana-de-açúcar pode aumentar ou diminuir o transporte de sedimentos para outras sub-bacias, dependendo da sua posição geográfica. 

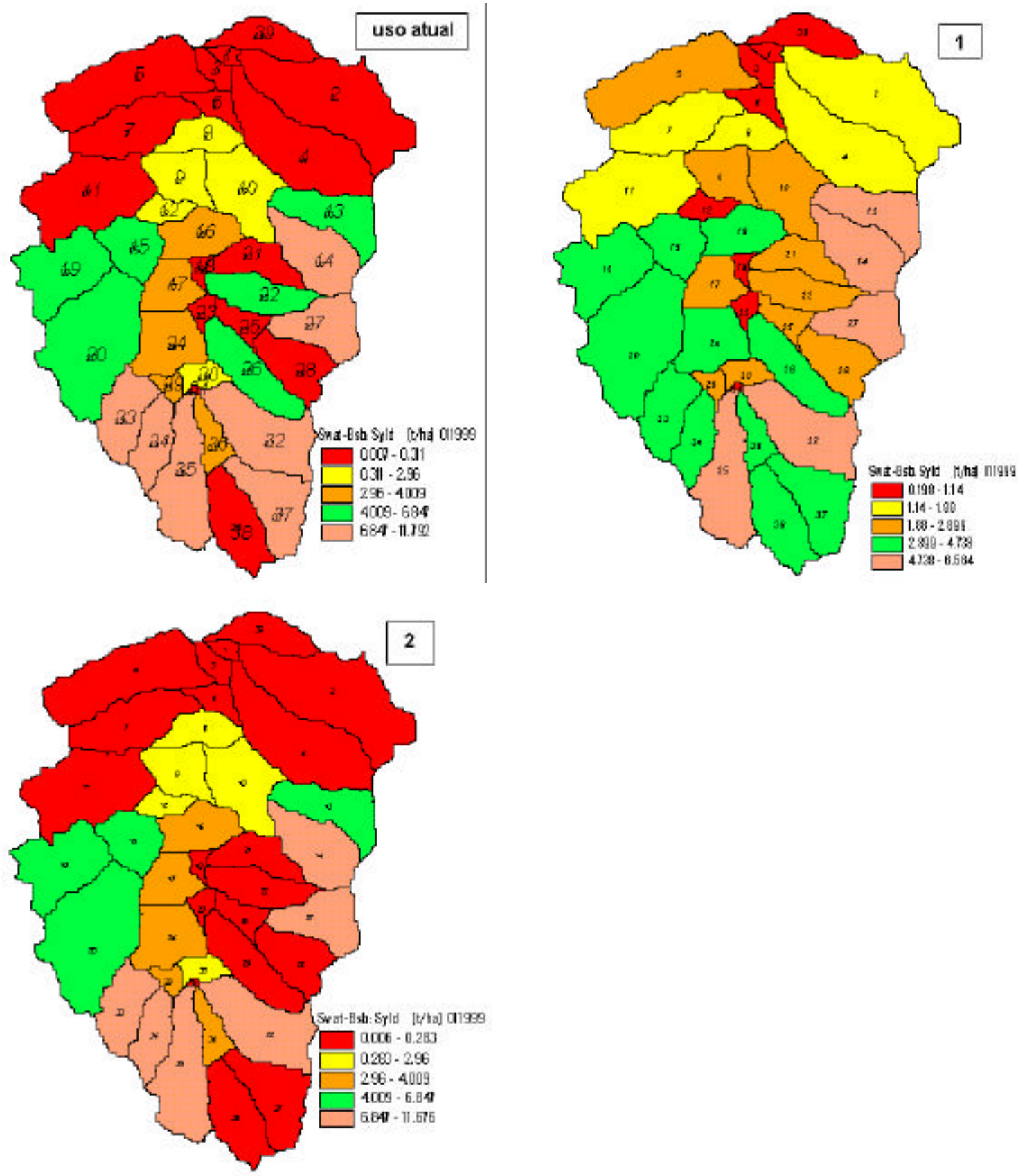

Figura 26 - Distribuição espacial da produção de sedimentos no mês de janeiro de 1999 para os três cenários. 
Desde que o potencial topográfico move a água e sedimentos declive abaixo, somente áreas localizadas na paisagem abaixo das áreas ocupadas com cana-de-açúcar irão ser afetadas. A vegetação nativa, desse modo, é afetada, visto que, as áreas ocupadas com vegetação nativa estão localizadas na paisagem, no cenário 2, abaixo das áreas ocupadas com cana-de-açúcar.

Como o tipo de cobertura do solo que passou a predominar nas áreas íngremes foi a vegetação nativa, é fácil compreender a atuação desse tipo de cobertura não somente como barreira aos sedimentos, mas também como áreas de baixíssimo nível de produção de sedimentos. Quando o escoamento superficial passa de uma área cultivada com cana-de-açúcar para a área ocupada com a vegetação nativa, ocorre uma diminuição na velocidade do fluxo pela rugosidade superficial e maior resistência da vegetação. A diminuição da velocidade, por sua vez, resulta na diminuição da capacidade de transporte de sedimentos, impedindo que estes cheguem à rede de drenagem através da deposição antecipada de sedimentos. Os poluentes adsorvidos aos sedimentos, são também aí depositados.

Contudo, no cenário 1, ao longo do ribeirão dos Marins, supondo-se que a mata ciliar encontra-se em bom estado de preservação, infere-se que esta atuaria como uma barreira de proteção aos sedimentos, principalmente no sentido de reduzir a velocidade de escoamento e, conseqüentemente, agir como um filtro, retendo parte dos sedimentos.

A eficiência das matas ciliares ou ripárias é motivo de muita discussão dentro da comunidade científica. Segundo Bren (1993), as matas ciliares ocupam as áreas mais dinâmicas da paisagem, em termos ecológicos, geomoforlógico, e hidrológico, que por sua vez podem ser consideradas como excelentes locais de armazenamento de água visando àgarantia do suprimento contínuo. Elmore \& Beschata (1987) citam que a recuperação da vegetação ciliar contribui para o aumento da capacidade de armazenamento da água na zona ripária, o que contribui para o aumento da vazão na estação seca do ano. Books et al. (1991) entretanto, afirmam que a vegetação ripária consome 
grande quantidade de água. O consumo anual de comunidades dessas plantas representa uma significativa perda de suprimento de água subsuperficial, incluída a água subterrânea. Geralmente, a alta perda por evapotranspiração ocorre quando o nível da água está baixo (Books et al., 1991). Embora, segundo o autor, a vegetação ripária consuma grandes quantidades de água, ela oferece uma valiosa proteção æ̀ margens dos rios, habitat da vida animal, e a proteção de ecossistemas aquáticos adjacentes. Sob muitas condições, a vegetação ripária deve ser protegida do pastoreio e outros tipos de exploração.

No entanto, ainda existem dúvidas em relação à eficiência das florestas ripárias como filtros de poluição difusa para outras regiões, já que a maior parte dos estudos foi realizada para bacias do Cinturão do Milho e Nordeste dos Estados Unidos, sendo ainda necessários dados mais detalhados sobre sua eficiência em outras condições ambientais. Apesar de toda essa discussão, a mata ciliar constitui um dos fatores que, em conjunto com outras práticas conservacionistas, compõem o manejo adequado da bacia para fins de garantir a quantidade e qualidade dos recursos hídricos.

A largura de vegetação ripária é um dos fatores que pode ser mais facilmente manipulado, mas ainda tem sido objeto de estudo nas mais diversas condições ambientais. Castelle et al. (1994) fizeram uma ampla revisão da bibliografia pertinente à largura de vegetação ripária e encontraram larguras eficientes variando entre $3 \mathrm{~m}$ e $200 \mathrm{~m}$, dependendo das condições específicas do local. Wong \& Mccuen (1982) derivaram uma equação para determinar larguras eficientes de zona tampão, com base no tamanho da partícula de solo, declividade, rugosidade superficial e características do escoamento. Os autores encontraram uma relação não-linear entre largura e percentual de remoção de sedimentos, onde larguras desproporcionalmente maiores seriam necessárias para aumentar a remoção de sedimentos. Como exemplo, para ganhar $5 \%$ de eficiência na remoção, numa declividade de $2 \%$, a largura deveria dobrar de $30,5 \mathrm{~m}$ para $61 \mathrm{~m}$, para as condições estudadas. A legislação brasileira adota uma largura mínima de acordo com a largura do curso de água, mas não deixa 
claro em que bases são feitas essas recomendações. Apesar de facilitar o trabalho de recomposição da mata ciliar generalizando para todas as bacias hidrográficas, esse tipo de delimitação não considera as diferenças regionais ( $p$. e., clima, condições da superfície, relevo, solos, atividades agrícolas) o que pode não garantir a eficiência necessária como barreira de retenção de sedimentos.

Dentro dos limites de uma bacia hidrográfica podem ocorrer áreas que requerem maior atenção, seja por estar localizadas em terrenos íngremes, ou porque nessas áreas há solos altamente susceptíveis à erosão, ou a combinação de ambos os fatores. Nas bacias hidrográficas onde há a ocorrência desse tipo de área, consideradas como "áreas ambientalmente sensíveis", um meio efetivo de diminuir a intensidade da produção de sedimentos é fazer com que esses locais fiquem fora da agricultura intensiva e sejam mantidos como Áreas de Preservação Permanente, assim, os programas de conservação de solo e água podem ser mais eficientes, em vez de considerar somente as matas ciliares, desde as nascentes até a foz, como único sistema de proteção dos recursos hídricos, o que ficou demonstrado nesse estudo. Práticas agrícolas intensivas são usualmente associadas a altos níveis de uso de fertilizantes, resultando em poluição potencial das águas superficiais e subterrâneas (poluição de origem difusa).

De outro modo, em bacias hidrográficas, muitos sistemas de uso da terra podem ser espacialmente representados, incluindo proteção florestal, produção florestal, agricultura, pastagens, e agroflorestas. Segundo Books et al. (1991) um uso da terra adequado em bacias hidrográficas para se conseguir produtividade, e ao mesmo tempo, qualidade de água, envolve a utilização de agroflorestas. Agrofloresta é um sistema de uso da terra onde a vegetação nativa está dividindo a mesma unidade de terra com as culturas agrícolas ou criação de animais, ou seqüencialmente ou simultaneamente. Práticas agroflorestais representam sistemas de produção no manejo integrado de bacias hidrográficas. Em áreas ambientalmente críticas, a preservação da 
vegetação nativa nessas áreas, pode ser uma alternativa, como ficou representado no cenário 2 .

O conhecimento do efeito da variação no uso da terra sobre o movimento de sedimentos e água em bacias hidrográficas é muito importante para a tomada de decisões de manejo. Segundo Valério Filho (1994), a partir das informações obtidas com o mapa de potencial de erosão, é possível estipular quais seriam os tipos de coberturas recomendados conforme a classe de periculosidade. Desse modo, por exemplo, para as localidades enquadradas na classe de menor potencial de perdas de solo, uma cobertura cujo fator $\mathrm{C}$ seja de 0,05 , já reduziria as perdas de 400 t/ha $x$ ano para 20 t/ha $x$ ano, isto ainda mantendo-se o fator $P$ igual a 1,0, ou seja, sem adoção de nenhuma prática conservacionista. Sendo assim, verifica-se nesse tipo de produto resultante da integração de informações do modelo via SIG, o aparecimento de áreas onde se recomenda uso com restrição moderada, uso com fortes restrições e uso somente como área de preservação, conforme o grau de potencial a desencadear o processo erosivo na área.

As simulações de cenários indicaram que as variações no uso da terra podem diminuir ou aumentar a produção de sedimentos na MHRM. Nesse estudo, foram modelados os possíveis efeitos da vegetação nativa na produção de sedimentos. A qualidade de futuras simulações pode ser melhorada se um completo espectro da maioria das culturas possa ser considerado e a área de estudo possa ser expandida para incluir a totalidade da microbacia.

A principal vantagem do uso do SIG para modelar a perda de solos é a habilidade para analisar a variabilidade espacial do potencial de erosão na microbacia, com base na influência de fatores como a declividade, tipo de solo, uso da terra, precipitação, entre outros. Entretanto, é importante considerar algumas das limitações na representação e interpretação dos resultados.

Um dos tópicos de discussão entre aqueles que desenvolvem modelos de simulação, é se os modelos podem fazer predições razoavelmente precisas das quantidades absolutas de erosão ou se eles podem somente fazer 
predições relativamente adequadas. Se a última afirmação for verdadeira, então o modelo pode somente fornecer uma classificação relativa dos efeitos dos manejos alternativos e de medidas de controle da erosão (Garen et al., 1999). Essa incerteza deve ser levantada quando da interpretação dos resultados de uma modelagem e, especialmente, quando as decisões são tomadas com base em seus resultados.

Apesar de somente exemplificar a aplicação e as vantagens da utilização da integração de modelos e SIG, essa investigação pode servir como base para avaliar riscos de erosão em microbacias hidrográficas, e por meio da simulação de cenários, propor práticas alternativas de manejo.

\subsection{Considerações finais}

Com a integração entre SIG e modelos de parâmetros distribuídos, a bacia hidrográfica pode ser dividida em muitas sub-bacias. Entretanto, o efeito da discretização na qualidade das respostas do modelo não tem sido muito estudado.

Uma das maiores limitações dos modelos hidrológicos, principalmente quando aplicados em grandes bacias hidrográficas, é a variabilidade espacial da precipitação. Há a possibilidade (Srinivasan, 1998) de se utilizar radares meteorológicos para determinar a variabilidade na distribuição da precipitação.

O comportamento do parâmetro Curva Número $(\mathrm{CN})$ não permitiu ao modelo responder às discretizações da bacia para a simulação do escoamento. $\mathrm{Na}$ versão atual (SWAT2000), há a opção de simular o escoamento superficial pelo método de infiltração de Green \& Ampt; nesse caso, o método requer dados de precipitação sub-diários.

O modelo utiliza a Modified Universal Soil Loss Equation-MUSLE para o cálculo da produção de sedimentos na bacia, sabe-se que esta não é uma equação de erosão e sim de perda de solo, que se processa na sua maior parte como erosão laminar, não considerando outros tipos de erosão como a erosão 
em voçorocas (Seixas, 1984). Entretanto, o modelo considera esse tipo de erosão como uma fonte de origem pontual.

O valor do fator de uso e manejo do solo (C) adotado para mata, de 0,0010, é um valor considerado alto para matas tropicais segundo Dutra (1997) O autor sugere a adoção do valor 0,0004; entretanto, o SWAT apresenta uma limitação de 3 (três) casas decimais na entrada de dados. Apesar de na versão atual ser possível variar os valores máximos e mínimos dos dados de entrada, quando essa tentativa foi feita, o modelo acusava valor fora do intervalo.

Apesar das limitações expostas acima, o modelo SWAT apresenta características importantes, tais como: representa todos os processos envolvidos na transformação de chuva em escoamento; permite a subdivisão da bacia hidrográfica segundo critérios relacionados às suas características físicas e tem sido testado e aplicado em projetos em diferentes partes do mundo. 


\section{CONCLUSÕES}

Para as condições específicas em que esse trabalho foi realizado e pelos resultados obtidos, pode-se concluir que:

- O nível de discretização adotado na microbacia para esse estudo foi suficiente para a modelagem do escoamento e da produção de sedimentos, considerando a opção de uso da terra e solo dominante. Quando comparados com os dados observados no posto hidrossedimentométrico localizado na microbacia, os resultados das simulações foram satisfatórios.

- Nesse contexto, verificou-se que o uso de modelos simuladores e SIG permite, não somente avaliar dados simulados contra dados observados, conforme os resultados desse trabalho, mas também fazer simulações de cenários para explorar os possíveis efeitos de variações de uso da terra no contexto da dinâmica da paisagem;

- Nos exemplos testados de mudança de cenário, o maior impacto na redução da produção de sedimentos foi obtido pela substituição de pastagens por vegetação nativa em áreas de maior suscetibilidade àerosão.

- Os resultados obtidos nesse trabalho podem servir de base para análise de manejos alternativos, visando à redução do impacto das atividades antrópicas em bacias hidrográficas. 


\section{REFERÊNCIAS BIBLIOGRÁFICAS}

ALVES, D.S. Sistema de Informação Geográfica In: SIMPÓSIO BRASILEIRO DE SENSORAMENTO REMOTO, 1., São Paulo, 1990. Anais. São Paulo: USP, Escola Politécnica, 1990. p.66-78.

ANDERSON, J.R.; HARDY, E.E.; ROACH, J.T.; WITMER, R.E. A land use and land cover classification system for use with remote sensor data. Washington: USGS, 1979. 28p.

ARNOLD, J. G.; SRINIVASAN, R.; MUTTIAH, R. S.; WILLIAMS, J. R. Large area hydrologic modeling and assessment part I: model development. Journal of the American Water Resources Association, v.34, n.1, p.7389, 1998.

ARNOLD, J.G.; WILLIAMS, J. R.; NICKS, A. D.; SAMMONS, N. B. SWRRB: A basin scale simulation model for soil and water resources management. Texas: A\&M Univ. Press, College Station, 1990. 115p.

ARNOLD, J.G.; MUTTIAH, R.S.; SRINIVASAN, R.; ALLEN, P.M. Regional estimation of base flow and groundwater recharge in the Upper Mississippi river basin. Journal of Hydrology, v.227, p.21-40, 2000.

ARNOLD, J.G.; WILLIAMS, J.R.; MAIDMENT, D.R. Continuos-time water ans sediment routing model for large basins. Journal of Hydraulic Engineering, v.121, n.2, p.171-183, 1995. 
American Society of Civil Engineers. Task Committee on Definition of Criteria for Evaluation of Watershed Models of the Watershed Management Committee, Irrigation and Drainage Division. Journal of Irrigation and Drainage Engineering, v.119, n.3, p.429-442, 1993.

AZEVEDO NETTO, J.M. de. Manual de saneamento de cidades e edificações. São Paulo: PINI Editora, 1991. 220p.

BACELLAR, A. A. A. Estudo da erosão na microbacia hidrográfica do Ribeirão da Cachoeirinha - Município de Iracemápolis, utilizando um Sistema de Informação Geográfica. Campinas: Universidade Estadual de Campinas, 1994. 54p. (Relatório Técnico)

BAGNOLD, R.A. Bedload transport in natural rivers. Water Resources Research, v.13, p.303-312, 1977.

BAHIA, V. G.; CURI, N.; CARMO, D. N. Fundamentos de erosão do solo. Informe Agropecuário, v. 16, n. 176, p.25-31, 1992.

BAND, L. E. Topographic partition of watershed with digital elevation models. Water Resources Research, v.22, n.1, p.15-24, 1986.

BATCHELOR, P. Models as metaphors: The role of modeling in pollution prevention. Waste Management, v.14, n.3, p.243-251, 1994.

BEASLEY, D. B.; HUGGINS, L. F.; MONKE, E. J. ANSWERS: a model for Watershed Planning. Transactions of the ASAE, v.23, n.4, p.938-944, 1980. 
BELLINAZZI Jr., R.; BERTOLINI, D.; ESPÍNDOLA, C.R.; LEPSCH, I.F. Manual para levantamento utilitário do meio físico e classificação de terras no sistema de capacidade de uso. Campinas: Sociedade Brasileira de Ciência do Solo, 1991. 176p.

BERTOLINI, D.; LOMBARDI NETO, F.; DRUGOWICH, M.I. Programa estadual de microbacias hidrográficas. Campinas: CATI, $1993.16 \mathrm{p}$.

BERTOLINI, F. Perspectivas de falta de madeira em futuro próximo. In: CONGRESSO FLORESTAL PANAMERICANO, Curitiba, 1993. Anais. Curitiba: UFPR, 1993. v.3, p.1-40.

BERTONI, J.; LOMBARDI NETO, F. Conservação do solo. São Paulo: Ícone, 1990. 355p.

BEUSELINCK, L.; STEEGEN, A.; GOVERS, G; NACHTERGAELE, J.; TAKKEN, I.; POESEN, J. Characteristics of sediment deposits by major rainfall events in small catchments in the Belgian Loam Belt. Geomorphology, v.32, p.6982, 2000.

BEVEN, K. Distributed models. In: ANADERSON, M. G.; BURT, T. P. Hidrological forecasting. Chichester: John Wiley, 1985. cap.13, p. 405-435.

BEVEN, K. Changing ideas in hydrology-the case of physically based models. Journal of Hydrology, v.105, p.157-172, 1989.

BINGER, R. L. Runoff Simulated from Goodwin Creek Watershed Using SWAT. Transactions of the ASAE, v.39, n.1, p.85-90, 1996. 
BLACKIE, J. R.; EELES, C. W. Lumped catchament models, In: ANDERSON, M. G.; BURT, T. P. (Ed.). Hydrological forecasting. Chichester: John Wiley, 1985. cap. 9, p.311-345.

BRASIL. Ministério da Agricultura. Levantamento de reconhecimento dos solos do Estado de São Paulo. Rio de Janeiro, 1960. 634p. (Boletim Técnico, 12)

BREN, L.J. Riparian zone, stream, and floodplain issues: a review. Journal of Hydrology, v.150, p.277-299, 1993.

BROOKS, K. N.; FFOLLIOTT, P. F.; GREGERSEN, H. M.; THAMES, J. L. Hydrology and the management of watersheds. Ames: lowa State University Press, 1991. 392p.

BROWN, R.B.; CUTSHALL, N.H.; KLING, G.F. Agricultural erosion indicated by ${ }^{137} \mathrm{Cs}$ redistribution: I. levels and distribution of activity in soils. Soil Science Society of American Journal, v.45, n.5, p. 1184-1190. Sept./Oct. 1981.

BUSSCHER, W. J.; REEVES, D. W.; KOCHHANN, R. A. et al. Conservation farming in southern Brazil: using cover crops to decrease erosion and increase infiltration. Journal of Soil and Water Conservation, v.51, n.3, p.188-192, 1996.

CALIJURI, M. L.; MEIRA, A. D.; PRUSK, F. F. Geoprocessamento Aplicado aos Recursos Hídricos. In: CONGRESSO BRASILEIRO DE ENGENHARIA AGRíCOLA, 27., Poços de Caldas, 1998. Cartografia, Sensoriamento e Geoprocessamento. Lavras: UFLA, SBEA, 1998, p200-225. 
CARVALHO, N de O. Hidrossedimentologia prática. Rio de Janeiro: CPRM, 1994. 372p.

CARVER, S.; HEYWOOD, I.; CORNELIUS, S.; SEAR, D. Evaluating field-based GIS for environmental characterization, modeling decision support. International Journal of Geographical Information Systems, v.9, n.4, p.475-486, 1995.

CASTELLE, A.J.; JOHSON, A.W.; CONOLLY, C. Wetland and stream buffer size requirement: a review. Journal Environmental Quality, v.23, p.878882, 1994.

CHAUBEY, I.; HANN, C.T.; GRUNWALD, S.; SALISBURY, J.M. Uncertainty in the model parameters due to spatial variability of raifall. Jounal of Hydrology, v.220, p.48-61, 1999.

CHAVES, H. M. L. Adaptação do modelo WEPP para as condições brasileiras. p. 213-221. In: PEREIRA, V. P.; FERREIRA, M. E.; CRUZ, M. C. P. Solos altamente suscetíveis `a erosão. Jaboticabal: UNESP; FCAV, 1994, p213221.

CHAVES, H.M.L. Análise global de sensibilidade dos parâmetros da Equação Universal de Perda de Solo Modificada (MUSLE). Revista Brasileira de Ciência do Solo, v.15, p.345-350, 1991.

CHAVES, L.H.M. Aplicação de modelos na previsão da erosão. Resumo da mesa redonda. In: SIMPÓSIO NACIONAL DE CONTROLE DE EROSÃO, 5., Bauru, 1995. Anais. Bauru: SBEA, 1995. p.49-54. 
CHAVES, L.H.M. Novo enfoque para o dimensionamento da área de seção transversal de terraços de retenção. Revista Brasileira de Ciência do Solo, v.20, p.141-150, 1996.

CHO, S. M.; JENNINGS, G. D.; STALLINGS, C.; DEVINE, H. A. GIS-basead water quality model calibration in the Delaware River basin. ASAE, St. Joseph, Michigan, 1995. (ASAE Microfiche, 952404)

CHOROWICZ, J.; ICHOKU, C.; RIAZANOFF, S.; YOUN-JONG, K.; CERVELLE, B. A combined algorithm for automated drainage network extraction, Water Resources Research, v.28, p.1293-1302, 1992.

CHOW, V. T.; MAIDMENT, D. R. Applied hydrology. New York: McGraw-hill Book, 1988. 572p.

COCHRANE, T.A.; FLANAGAN, D.C. Assessing water erosion in small watersheds using WEPP with GIS and digital elevation models. Journal of Soil and Water Conservation, v. 54, p.678-685, 1999.

COCHRANE, T.A; FLANAGAN, D. C.; NORTON, L. D.; ENGEL, B. A. WEPP watershed modeling using ArcView 3.0 (GIS). Madison: ASA, 1997. 61p.

COELHO NETTO, A.L. Hidrologia de encosta na interface com a geomorfologia. In: GUERRA, A.J.T.; CUNHA, S.B. Geomorfologia: uma atualização de bases e conceitos. Rio de Janeiro: Bertrand Brasil, 1995. cap.3, p. 93-148.

COGO, N. P. Erodibilidade de alguns solos do Rio Grande do Sul avaliada pelo método do nomograma. In: ENCONTRO NACIONAL DE PESQUISAS SOBRE CONSERVAÇÃO DO SOLO, 2., Passo Fundo, 1978. Anais. Passo Fundo: SBCS, 1978. p.215-217. 
CRÓSTA, A. P. Processamento digital de imagens de sensoriamento remoto. Campinas: UNICAMP, IG, 1993. 170p.

DI LUZIO, M.; SRINIVASAN, R.; ARNOLD, J. ArcView interface for SWAT2000 - User's Guide. Temple: Blackland Research Center, Texas Agricultural Experiment Station, 2001. 337p.

DOLABELLA, R.H.C. Caracterização agroambiental e avaliação da demanda e da disponibilidade dos recursos hídricos para a agricultura irrigada na bacia hidrográfica do rio Jardim - DF. Brasília, 1996. 108p. Dissertação (Mestrado)-Universidade de Brasília.

DUTRA, K. Estimativa de Perda de Solo por Erosão Superficial em Bacia Hidrográfica Utilizando Sistema de Informação Geográfica - SIG. Vitória, 1997. Dissertação (Mestrado) - Universidade Federal do Espírito Santo.

EASTMAN, J.R. Idrisi for windows user's guide. Worcester: Clark University, 1995. 109p.

ELMORE, W.; BESCHTA, R.L. Riparian areas: perceptions in management. Rangelands, v.96, p.290-265, 1987.

EMPRESA BRASILEIRA DE PESQUISA AGROPECUÁRIA. Centro Nacional de Pesquisa de Solos. Sistema Brasileiro de Classificação de Solos. Brasília: EMBRAPA Produção de Informação; Rio de Janeiro: Embrapa solos, 1999. 412p.

FAURES, J.; GOODRICH, D.C.; WOOLHISER, D.A.; SOROOSHIAN, S. Impact of small-scale spatial on runoff modeling. Journal of Hydrology, v.173, p.309-326, 1995. 
FEDRA, K. Models, GIS, expert systems: Integrated water resources models. In: KOVAR, K., NACHTNEBEL, H. P. Application of geographic information systems in hydrology and water resources management. Vienna: International Association of Hydrological Sciences, 1993. p.297-308. (Publication, 211)

FINCH, J.W. Estimating direct groundwater recharge using a simple water balance model - sensitivity to land surface parameters. Journal of Hydrology, v.211, p.112-125, 1998.

FITZHUGH, T.W.; MACKAY, D. S. Impacts of inputs parameter spatial aggregation on an agricultural nonpoint source pollution model. Journal Hydrological, v.256, p.35-53, 2000.

FRAISSE, C. W.; CAMPBELL, K. L.; JOVES, J. W.; BOGGESS, W. G. Integration of GIS and GLEAMS for alternative dairy waste management analysis. St. Joseph: ASAE, 1994. 154p. (ASAE Paper, 94-205)

GAREN, D.; WOODWARD, D.; GETER, F. A user agencies view oh hydrologic, soil erosion and water quality modeling. Catena, v.37, p.277-289, 1999.

GBUREK, W.J.; SHARPLEY, A.N.; HEATHWAITE, L.; FOLMAR, G.J. Phosphorus management at the watershed scale: A modification of the phosphorus index. Journal of Environmental Quality, v.29, p.130-144, 2000.

GENOVEZ, A.B. Avaliação dos métodos de estimação das vazões de enchente para pequenas bacias rurais do Estado de São Paulo. Campinas, 1991. 248p. Tese (Livre-Docência) - Universidade Estadual de Campinas. 
GOODCHILD, M. F.; PARKS, B. O.; STEYAERT, L. T. Environmental Modeling with GIS. New York: Oxford University Press, 1993. 488p.

GOODRICH, D.C.; FAURES, J.; WOOLHISER, D.A.; LANE, L.J.; SOROOSHIAN, S. Measurement and analysis of small-scale convective storm rainfall variability. Journal of Hydrology, v.173, p.283-308, 1995.

GRAYSON, R. B.; MOORE, I. D.; McMAHON, T. A. Physically-based hydrologic modeling: II. Is the concept realistic? Water Resources Research, v.26, n.10, p.2659-2666, 1992.

GRIGG, N. S. Water resources management: principles, regulations, and cases. New York: McGraw-Hill Book, 1996. 540p.

GROVE, M.; HARBOR, J.; ENGEL, B. Composite Vs. Distributed Curve Number: effects on estimates of storms runoff depths. Journal of the American Water Resources Association, v.34, n.5, p.1015-1023, 1998.

GRUNWALD, S.; FREDE, H. G. Using the modified agricultural non-point source pollution model in German watersheds. Catena, v.37, p.319-328, 1999.

GUERRA, A. J. T.; CUNHA, S. B. Geomorfologia: uma atualização de bases e conceitos. 2. ed. Rio de Janeiro: Bertrand Brasil, 1995, 472p.

HAMLETT, J.M.; MILLER, R.L.; PETERSON, G.W.; BAUMER, G.M.; RUSSO, J. Statewide GIS-based ranking of watersheds for agricultural pollution prevention. Journal of Soil and Water Conservation, v.47, n.5, p.399-404, 1992. 
HARLIN, J. M.; LANFEAR, K. J. Geographic Information Systems and Water Resources. Bethesda: American Water Resources Association, 1993. 432p.

HARTKAMP, A. D.; WHITE, J. W.; HOOGENBOOM, G. Interfacing geographical information systems with agronomic modeling: a review. Agronomy Journal, v.91, p.761-772, 1999.

HASSUDA, S. Modelagem matemática: elaboração do modelo conceitual. Informática em Águas Subterrâneas. Informativo da Sociedade Brasileira de Águas Subterrâneas, n.10, p.2-3, março, 2000.

HAWKINS, R.H.; HJELMFELT, A.T.; ZEVENBERGEN Runoff probability, storm depth, and curve numbers. Journal of Irrigation and Drainage Engineering, v.111, n.4, p.330-340, 1985.

HELMLINGER, K. R.; KUMAR, P.; FOUFOULA-GEORGIOU, E. On use of digital elevation model data for Hortonian and fractal analyses of channel networks, Water Resources Research, v.29, p.2599-2613, 1993.

HENKLAIN, J. C.; FREIRE, O. Avaliação do método nomográfico para determinação da erodibilidade de Latossolos do Estado do Paraná. Revista Brasileira de Ciência do Solo, v.7,n.2, p.191-195, 1983.

HESSION, C. W.; SHANHOLTZ, V. O. A geographical information system for targeting nonpoint source agricultural pollution. Journal of Soil Water Conservation, v.43, p.264-266, 1988.

HILL, A.R. Stream nitrate-N loads in relation to variations in annual and seasonal runoff regimes. Water Resources Bulletin, v.22, p.829-839, 1986. 
HUDSON, W.D.; RAMM, C.W. Correct formulation of the Kappa coefficient of agreement. Photogrammetric Engineering and Remote Sensing, v.53, n.4, p. 421-422, 1987.

INSTITUTO DE PESQUISAS TECNOLÓGICAS. Divisão de Minas e Geologia Aplicada do Instituto de Pesquisas Tecnológicas do Estado de São Paulo. Mapa geológico do Estado de São Paulo. Escala 1:1.000.000. São Paulo, 1981.

JAMES, L.D.; GURGES, S.J. Selection, calibration and testing of hydrologic models. In: HAAN, C.T. (Ed.) Hydrologic modeling of small watersheds. St. Joseph: ASAE, 1982. p.437-472.

JENKINS, A.; PETERS, N. E.; RODHE, A. Hydrology. In: MOLDAN, B. CERNY, J. Biogeochemistry of small catchments: a tool for environmental research. Chichester: John Wiley, 1994. cap.2. p.31-54.

JENSON, S. K.; DOMINGUE, J. O. Extracting topographic structure from digital elevation data for geographical Information System Analysis. Photogrametric Engineering and remote Sensing, v.54, n.11, p.15931600, 1988.

JONG, E. de; BEGG, C.B.M.; KACHANOSKI, R.G. Estimates of soil erosion and deposition for same Saskatchewan soils. Canadian Journal of Soil Science, v.63, p.607-617, 1983.

KING, K. W.; ARNOLD J. G.; WILLIAMS, J. R.; SCRINIVASAN R. Soil and Water Assessment Tool-SWAT. Texas: USDA, Agricultural Research Service, 1996. 450p. 
KNISEL, W.G. CREAMS, a field scale model for chemicals, runoff and erosion from agricultural management systems. Washington: USDA Conservation, 1980. 89p. (Research Report, 26)

KOVAR, K.; NACHTNEBEL, H. P. Application of geographic information systems. In: Hydrology and water resources management. Vienna: International Association of Hydrological Sciences, 1993. cap. 14, p. 168179. (Publication, 211)

KRESNOR, W. R.; OLSON, K. R.; JOHNSON, D. L. Fields evaluation of methods to estimate soil erosion. Soil Science, v.153, n.1, p.69-81, 1992.

KRYSANOVA, V.; MÜLLER-WOHLFEIL, D.; BECKER, A. Development and Test of a Spatially Distributed Hydrological/Water Quality Model for Mesoscale Watersheds. Ecological Modeling, v.106, p.261-289, 1998.

LAL R. Soil erosion and land degradation: the global risks. Advances in Soil Science, v.7, p.129-172, 1990.

LAM, D.C.L.; SWAYNE, D.A.; MAYFIELD, C.I.; COWan, D.D. integration of SIG with other software systems: Integration versus interconnection. In: INTERNATIONAL CONFERENCE/WORKSHOP ON INTEGRATING GIS AND ENVIRONMENTAL MODELING, 3., Santa Fe, 1996. Proceedings. National Center for Geographic Information and Analysis, Santa Barbara, CA, USA. http:// www.ncgia.ucsb.edu/conf/SANTA_FE_CD-ROM/main.html. (25 jan 1999).

LANDIS, J.R.; KOCH, G.G. The measurement of observer agreement for categorical data. Biometrics, v.33, n.1, p.159-174, 1977. 
LANE, L. J.; RENARD, K. G.; FOSTER, G. R.; LAFLEN, J. M. Development and application of modern soil erosion prediction technology. Australian Journal of Soil Research, v.30, n.6, p.893-912, 1992.

LARSON, W.E.; LINDSTROM, M.J.; SCHUMACHER, T.E. The role of severe storms in soil erosion: A problem needing consideration. Journal of Soil and Water Conservation, v.52, n.2. p.90-95, 1997.

LEINZ, V.; LEONARDOS, O. H. Glossário geológico. 2. ed. São Paulo: Companhia Editora Nacional, 1977. 236p.

LEONARD, R.A.; KNISEL, W.G.; STILL, D.A. GLEAMS: groundwater loading effects of agricultural management systems. Transaction of the ASAE, v.30, p.1403-1418, 1987.

LEPSCH, I.F. Manual para levantamento utilitário do meio físico e classificação de terras no sistema de capacidade de uso. Campinas: Sociedade Brasileira de Ciência do Solo, 1983. 175p.

LOMBARDI NETO, F.; BELLINAZZI, R.J.; GALETI, P.A.; BERTOLINI, D.; LEPSCH, I.F.; OLIVEIRA, J.B. de Nova abordagem para o cálculo de espaçamento entre terraços. In: SIMPÓSIO SOBRE TERRACEAMENTO AGRíCOLA, Campinas, 1989. Campinas: Fundação Cargill, 1989. p.99-124.

MACEDO, J. Solos do cerrado. In: PEREIRA, V.P; FERREIRA, M.E.; CRUZ, M.C.P. Solos altamente suscetíveis à erosão. Jaboticabal: UNESP, FCAV; SBCS, 1994. cap. 2, p. 69-76. 
MACK, M.J. HER - hydrologic evaluation of runoff; the Soil Conservation Service curve number as an interactive computer model. Computers \& Geosciences, v.21, n.8, p. 929-935, 1995.

MAGALHÃES, P.C. Hidrologia superficial. In: RAMOS, F. Engenharia hidrológica. Rio de Janeiro: ABRH, 1989. cap. 3, 201-289.

MAIDMENT, D. R. GIS and hydrologic modeling. In: GOODCHILD, M. F.; PARKS, B. O.; STEYAERT, L. T. (Ed.) Environmental modeling with GIS. New York: Oxford Univ. Press, 1993. cap. 13, p. 147-167.

MAMILLAPALLI, S. Effect of spatial variability in modeling river basin runoff. West Lafayette, 1977. 137p. Thesis (Ph.D) - Purdue University.

MANGUERRA, H.B.; ENGEL, B.A. Hydrologic Parameterization Of watersheds for runoff prediction using SWAT. Journal of the American Water Resources Association, v.34, n.5, p.1149-1162, 1998.

MARIANO, M. T. Uma análise da participação da sociedade civil na gestão dos recursos hídricos do Estado de São Paulo. São Carlos, 1996. 144p. Dissertação (Mestrado) - Escola de Engenharia de São Carlos, Universidade de São Paulo.

MENDES, C. A. B. Planejamento Nacional de Recursos Hídricos Baseado no Uso de Técnicas de Geoprocessamento, 9p. http//www.iica.org.Br/AguaTrab/Carlos\%20andre\%20bublões/P1TB08.htm. (15 ago. 1998). 
MOCKUS, V. Estimation of direct runoff from storm rainfall. In: United States Department of Agriculture, Agricultural Research Service. National engineering handbook. Washington: USDA, 1972. cap.10, p.1-24.

MOLDAN, B.; CERNY, J. Small Catchments Research. In MOLDAN, B.; CERNY, J. Biogeochemistry of small catchments: a tool for environmental research. Chicester: John Wiley, 1994. p. 1-29.

MONTGOMERY, D. R.; FOUFOULA-GEORGIOU, E. Channel network source representation using digital elevation models. Water Resources Research, v.29, p.925-3934, 1993.

MOORE, I. D.; GALLANT, J. C. Overview of hydrologic and water quality modeling. In: MOORE, I. D. (Ed.) Modeling the fate of chemicals in the environment. Canberra: Australian National University, 1991. cap.1, p.1-9.

MOORE, I. D.; TURNER, A. K.; WILSON, J. P. et al. GIS and land surfacesubsurface modeling. In: GOODCHILD, M. F.; PARKS, B. O.; STEYAERT, L. T. (Ed.) Environmental modeling with GIS. New York: Oxford University Press, 1993. cap.19, p.196-230.

MOORE, I. D.; BURCH, G. L. Modeling erosion and deposition: topographic effects. Transaction of the ASAE, v.20, n.6, p.1624-1630, 1986.

MORTATTI, J. Erosão na Amazônia: Processos, Modelos, e Balaço. Piracicaba, 1995. 155p. Tese (Livre-Docência) - Escola Superior de Agricultura "Luiz de Queiroz", Universidade de São Paulo. 
MOUSSA, R.; BOCQUILLON, C. Fractal Analyses of tree-like channel networks form digital elevation model data. Journal of Hydrology, v.187, p.157-172, 1996.

NEITSCH, S.L.; ARNOLD, J.G.; WILLIAMS, J.R. Soil and water assessment tool - User's Manual: Version 2000. Temple: Blackland Research Center, Texas Agricultural Experiment Station, 2000. 458p.

ODUM, E. P. Fundamentos de ecologia. 4. ed. Lisboa: Fund Calouste Gulbenkian, 1971. 927p.

OLIVEIRA, J. B. Solos da folha de Piracicaba. Campinas, Instituto Agronômico, 1999. 173p. (Boletim Científico, 48).

PESSOA, M. C. P. Y.; LUCHIARI, A. J.; FERNANDES, E. N.; LIMA, M. A. Principais modelos matemáticos e simuladores utilizados para análise de impactos ambientais das atividades agrícolas. Jaguariúna: EMBRAPA, CNPMA, 1997. 83p. (EMBRAPA. CNPMA. Documentos, 8).

PETERSON, J. R.; HAMLETT, J. M. Hydrologic calibration of the SWAT model in a watershed containing fragipan soils. Journal of the American Water Resources Association, v.34, n.3, p.531-544, 1998.

POLARSKI, M. Distributed rainfall - runoff model incorporating channel extension and gridded digital maps. Hydrological Processes, v.11, p.1-11, 1997.

PONCE, V.M. Engineering hydrology: principles and practices. New Jersey: Prentice-Hall, 1989. 640p. 
PONCE, V.M; HAWKING, R.H. Runoff curve number: has it reached maturity? Journal of Hydrologic Engineering, v.1, n.1, p.11-19, 1996.

PONZONI, J.F.; ALMEIDA, E.S. A estimativa do parâmetro Kappa (K) da análise multivariada discreta no contexto de um SIG. In: SIMPÓSIO BRASILEIRO DE SENSORIAMENTO REMOTO, 8., Salvador. 1996. Anais. São José dos Campos: INPE; SELPER, 1996. p. 52-58.

PROJETO PIRACENA. Banco de dados "Geoprocessamento". http:/www.cena.usp.br/piracena. (15 jan. 2001).

QUINN, P.; BEVEN, K.; CHEVALIER, P.; PLANCHON, O. The prediction of hillslope flow paths for distributed hydrological modeling using digital terrain models. Hydrological Processes, v.5, p.59-79, 1991.

RAWLS W.J.; BRAKENSIEK, D.L. Prediction of Soil Properties for Hydrologic Modeling In: JONES, E.B.; WARD, T.J. (Ed.). Watershed management in the 80's. New York: ASCE, 1985. cap.13, p. 293-299.

RENARD, K. G.; FOSTER, G. R.; WEesies, G. A.; PORTER, J. P. Revised Universal Soil Loss Equation. Journal of Soil and Water Conservation, v.46, n.3, p.30-33, 1991.

RENARD, K. G.; MAUSBACH, M. J. Tools of conservation. In: LARSON, W. E.; FOSTER, G. R.; ALLMARAS, R. R.; SMITH, C. M. (Ed.) Proceedings of soil erosion a productivity workshop. Minnesota: University of Minnesota, 1990. cap.4, p. 55-64. 
RODRIGUES, M. Introdução ao geoprocessamento. In: SIMPÓsIO BRASILEIRO DE SENSORAMENTO REMOTO, 1., São Paulo, 1990. Anais. São Paulo: Escola Politécnica, 1990. p.1-26.

ROSENTHAL, W. D.; SRINIVASAN R.; ARNOLD, J. G. Alternative River Management Using a Linked GIG-Hydrology Model. Transactions of the ASAE, v.38, n.3, p.783-790, 1995.

SALEH, A.; ARNOLD, J.G.; GASSMAN, P.W.; HAUCK, L.M.; ROSENTHAL, W.D.; WILLIAMS, J.R.; McFARLAND, A.M.S. Application of SWAT for the upper north Bosque River watershed. Transactions of the ASAE, v.43, n.5, p.1077-1087, 2000.

SCHROEDER, S.A. Reliability of SCS curve number method on semi-arid, reclaimed minelands. International Journal of Surface Mining, Reclamation and Environmental, v.8, n.2, p.41-45, 1994.

SEIXAS, B. L. S. Fundamentos do manejo e da conservação do solo. Salvador: Centro Editorial e Didático da UFBa, 1984. 275p.

SETZER, J. PORT, R.L.L. Tentativa de avaliação do escoamento superficial de acordo com o solo e seu recobrimento vegetal nas condições do Estado de São Paulo. Boletim Técnico DAEE, v.2, n.2, p.81-104, 1979.

SHARPLEY, A.N.; WILLIAMS, J.R. EPIC - Erosion Productivity Impact Calculator, 1. Model documentation. Washington: U.S. Department of Agriculture, Agricultural Research Service, 1990. 145p. (Technical Bulletin, 1798) 
SHIRMOHAMMADI, A.; MAGETTE, W. L.; BEKDASH, F. A. 1994. Environmental evaluation of agricultural practices using modeling and GIS technologies. In: WORD CONGRESS AND AGENG'94 CONFERENCE ON AGRICULTURAL ENGINEERING, 12., Milan, 1994. Milan: CIGR, 1994.p.6878.

SILVA, C.L.; OLIVEIRA, A.S. Runoff measurement and prediction for a watershed under natural vegetation in central Brazil. Revista Brasileira de Ciência do Solo, v.23, p.695-701,1999.

SILVA, T. M. Contribuição ao planejamento ambiental da bacia do Rio Faria Timbó: O uso das encostas. Caderno de Geociências, n.1, p.15-21, 1988.

SKAGGS, R.W.; KHALEEL, R. Infiltration, hydrologic modeling of small watershed. St. Joseph: American Society of Agricultural Engineers, 1982. 432p.

SOUTO, A. R.; CRESTANA, S. Identificação das áreas potenciais de produção de sedimentos com o modelo AGNPS e técnicas de SIG em uma microbacia hidrográfica. Revista Brasileira de Engenharia Agrícola e Ambiental, v.4, n.3, p.429-435, 2000.

SOUZA, J.L.; NETO, F.L.; TUBELIS, A. Estimativa e análise do escoamento superficial em solo descoberto e cultivado com a sucessão soja e trigo, sob diferentes sistemas de manejo. Revista Brasileira de Agronomia, v.3, p.77-84, 1995.

SPRUILL, C.A.; WORKMAN, S.R.; TARABA, J.L. Simulation of daily and monthly stream discharge from small watersheds using o SWAT model. Transactions of the ASAE, v.43, n.6, p.1431-1439, 2000. 
SRINIVASAN, R.; ARNOLD J. G. Integration of a basin-scale water quality model with GIS. Water Resources Bulletin, v.30, n.3, p.453-462, 1994.

SRINIVASAN, R.; ARNOLD J.G.; ROSENTHAL, W.; MUUTIAH, R.S. Hidrologic modeling of Texas Gulf Basin using GIS. In: INTERNATIONAL GIS AND ENVIRONMENTAL MODELING, 2., Breckinridge, Colorado, 1993. Proceedings. Breckinridge: International Association of Hydrological Sciences, 1993. p. 213-217.

SRINIVASAN, R.; RAMANARAYANAN, T.S.; ARNOLD, J.G.; BEDNARZ, S.T. Large area hydrologic modeling and assessment part II: model application. Journal of the American Water Resources Association, v.34, n.1, p. 91$101,1998$.

STALLINGS, C.; HUFFMAN, R. L.; KHORRAM, S.; GUO, Z. Linking GLEAMS and GIS. St. Joseph: ASAE, 1992. 124p. (ASAE Paper, 92-36/13)

STUART, N.; STOCKS, C. Hydrological modeling within GIS: An integration approach. In: Application of geographic information systems in hydrology and water resources management. Vienna: International Association of Hydrological Sciences, 1993. p.319-329. (Publication, 211)

TARBOTON, D. G.; BRAS, R. L.; RODRIGUEZ-ITURBE, I. On the extraction of channel networks from digital elevation data. Hydrological Processes, v.5, p.81-100, 1991.

TARDY, Y. Erosion. Encyclopedia Universalis, v.8, p.615-627, 1990. 
TERAMOTO, E.R. Relações solo, substrato geológico e superfícies geomórficas na microbacia do ribeirão Marins. Piracicaba, 1995. 93p. Dissertação (Mestrado) - Escola Superior de Agricultura "Luiz de Queiroz", Universidade de São Paulo.

TIM, U. S.; JOLLY R. Evaluating Agricultural Nonpoint-Source Pollution Using Integrad Geograpfhic Information Systems and Hidrology/Water Quality Model. Journal in Environmental Quality, v.23, p.25-35, 1994.

TIM, U. S. Emerging Technologies for Hydrologic and Water Quality Modeling Research. Transactions of the ASAE, v.39, n.20, p.465-476, 1996.

TIM, U. S.; MOSTAGHIMI, S.; SHANHOLTZ, V. O. Identification of critical nonpoint pollution source areas using geographic information systems and water quality modeling. Water Resources Bulletin, v.28, n.5, p.877-887, 1992.

TIMLIN, D. J.; PACHEPSKY, Y. A.; ACOCK, B.; WHISLER, F. Indirect estimation of soil hydraulic properties to predict soybean yield using GLYCIM. Agricultural Systems, v.52, n.2/3, p.331-353, 1996.

TIWARI, A. K.; RISSE, L.M.; NEARING, M.A. Evalution of WEPP and Its Comparion with USLE and RUSLE. Transactions of the ASAE, v.43, n.5, p.1129-1135, 2000.

TRIBE, A. Automated recognition of valley lines and drainage networks from digital elevation models: a review and a new method. Journal of Hydrology, v.139, p.263-293, 1992. 
TUCCI, C.E.M. Modelos hidrológicos. Porto Alegre: Ed. Universidade; UFRGS; Associação Brasileira de Recursos Hídricos, 1998. 669p.

TUCCI, C.E.M. Hidrologia: Ciência e aplicação. Porto Alegre: Editora da Universidade; UFRGS; Edups; ABRH, 1993. 943p.

U.S. DEPARTAMENT OF AGRICULTURE. Natural Resources Conservation Service. Hydrology In: ESTADOS UNIDOS. Natural Resources Conservation Service. National engineering handbooks. Washington: USDA, 1997. Part 630. (http://www.ftw.nrcs.usda.gov) (23 nov. 2001)

U.S. DEPARTAMENT OF AGRICULTURE. Riparian forest buffers: function and design for protection and enhancement of water resources. Pennsylvania: USDA, 1991. 24p.

U.S. DEPARTAMENT OF AGRICULTURE. Soil Conservation Service. Hydrology. National engineering handbooks. Washington: USDA, 1972. (Section 4).

U.S. DEPARTAMENT OF AGRICULTURE. Soil Conservation Service. Hydrology. National engineering handbooks. Washington: USDA, 1986. (Section 4).

VALÉRIO FILHO, M. V. Técnicas de geoprocessamento e sensoriamento remoto aplicadas ao estudo integrado de bacias hidrográficas. In: PEREIRA, V. P.; FERREIRA, M. E.; CRUZ, M. C. P. Solos altamente suscetíveis `a erosão. Jaboticabal: UNESP, FCAV; Sociedade Brasileira de Ciência do Solo, 1994. cap.5, p. 223-242. 
VAN DEN BERG, M.; BURROUGH, P.A.; DRIESSEN, P.M. Uncertainties in the appraisal of water availability and consequences for simulated surgarcane yield potentials in São Paulo State, Brazil. Agriculture, Ecosystems and Environmental, v. 81, p. 43-55, 2000.

VETTORAZZI, C. A. Sensoriamento remoto orbital. Piracicaba: ESALQ, Departamento de Engenharia Rural. 1992. 134p. (Série Didática, 2).

VIEIRA, L.S. Manual da ciência do solo: com ênfase nos solos tropicais. 2. ed. São Paulo: Editora Agronômica Ceres, 1988. 464p.

WARD, A. D.; ELLIOT, W.J. Environmental hydrology. Boca Raton: Lewis, 1995. 462p.

WARRICK, A.W.; NIELSEN, D.R. Spatial variability of soil physical properties in the field. In: HILLEL, D. (Ed.) Application of soil physics. New York: Academic Press, 1980, p. 319-344.

WEILL, M. A. M.; RANIERI, S. B. L.; SPAROVEK, G. Efeito da erosão na sustentabilidade do uso agrícola das terras na microbacia do ribeirão dos Marins, município de Piracicaba, SP. In: WORKSHOP DO PROJETO PIRACENA, 3., Nazaré Paulista, 1997. Banco de dados para bacias hidrográficas: discussão e formulação. Piracicaba: CENA, 1997. p.135140.

WILD, A. Soil and the environment: an introduction. Cambridge: University Press, 1993. 287p.

WILLIAMS, J. R. HYMO flood routing. Journal of Hydrology, v.26, p.17-27, 1975. 
WILLIAMS, J. R.; BERNDT, H. D. Sediment Yield Prediction Based on Watershed Hydrology. Transaction of the ASAE, v.20, p.1100-1104, 1977.

WILLIAMS, J. R.; JONES, C. A.; DYKE, P. T. A modeling approach to determining the relationship between erosion and soil productivity. Transaction of the ASAE, v.27, n.1, p.129-144, 1984.

WILLIAMS, J. R.; NICKS, A. D.; ARNOLD, J. G. Simulator for water resources in rural basins. Journal of Hydraulic Engineering, v.111, n.6, p.970-986, 1985.

WILLIAMS, J.R. Flood routing with variable travel time or variable storage coefficients. Transactions of the ASAE, v.12, n.1, p.100-103, 1969.

WILLIAMS, J.R. SPNM, a model for predicting sediment, phosphorus, and nitrogen yields from agricultural basins. Water Resources Bulletin, v.16, p.843-848, 1980.

WILSON, B.; WANG, B. Prediction of Surface Drainage Networks for GIS and water quality models, 3p. http://www.bae.umn.edu/annrpt/research/ water8.html. (13 mar. 1998).

WISCHMEIER, W. H.; JOHNSON, C. B.; CROSS, B. W. A soil erodibility nomograph for farmland and construction sites. Journal of Soil and Water Conservation, v.26, n.5, p.189-193, 1971.

WISCHMEIER, W. H.; SMITH, D.D. Predicting rainfall erosion losses - a guide to conservation planning. Washington: USDA, 1978. 58p. (USDA: Agricultural Handbook, 537). 
WISE, S. Assessing the quality for hydrological applications of digital elevation models derived from contours. Hydrological Processes, v.14, p.1909-1929, 2000.

WONG, S.L.; McCUEN, R.H. The design of vegetative buffer strips for runoff and sediment control: a technical paper developed as part of a study of stormwater management in coastal areas funded by Maryland Coastal Zone Management Program. Maryland: University of Maryland, Civil Engineering Department, 1982. 145p.

WOOLHISER, D. A.; BRAKENSIEK, D. L. Hydrologic system synthesis. In: HANN, C. T.; JOHNSON, H. P.; BRAKENSIEK, D. L. (Ed.) Hydrologic Modeling of Small Watershed, St. Joseph: ASAE, 1982. p.3-16. (ASAE Monograph)

YITAYEW, M; POKRZYWKA, S. J.; RENARD, K. G. Using GIS for facilitating erosion estimation. Applied Engineering in Agriculture, vol.15, n.4, p.295301, 1999.

YOUNG, R. A.; ONSTAD, C. A.; BOSCH, D. D. and ANDERSON, W. P. AGNPS: a nonpoint-source pollution model for evaluating agricultural watershed. Journal of Soil and Water Conservation, vol.44, n.2, p.168$173,1989$.

ZACHAR, D. Soil erosion: developments in soil science. New York: Elsevier Scientific, 1982. 547p.

ZHANG, H.; HAAN, C. T.; NOFZIGER, D. L. Hydrologic modeling with GIS: an overview. Applied Engineering in Agriculture, v.6, n.4, p.453-458, 1990. 